\title{
Promoting Climate Actions: A Cognitive-Constraints Approach
}

\author{
Junho Lee ${ }^{1,2, *}$, Emily. F. Wong ${ }^{1, *}$, Patricia W. Cheng ${ }^{1, \star *}$ \\ ${ }^{1}$ Department of Psychology, University of California, Los Angeles, Los Angeles, CA 90095 \\ ${ }^{2}$ Department of Psychology, Northeastern University, Boston, MA 02115
}

\section{UNDER REVIEW}

${ }^{*}$ J.L. and E.F.W. contributed equally and are listed in alphabetical order.

** corresponding author: Patricia W. Cheng, Department of Psychology, University of California, Los Angeles, Los Angeles, CA 90095

Corresponding author email: cheng@lifesci.ucla.edu

ORCIDs:

Junho Lee https://orcid.org/0000-0001-8246-3057,

Emily F. Wong https://orcid.org/0000-0003-1819-9129,

Patricia W. Cheng https://orcid.org/0000-0001-5047-5467

Short title: Coherence and causal invariance 


\begin{abstract}
The present paper reports an experiment with a two-year-delayed ( $M=695$ days) follow-up that tests an approach to raising willingness to take political and personal climate actions. Many Americans still do not view climate change as a threat requiring urgent action. Moreover, among American conservatives, higher science literacy is paradoxically associated with higher anthropogenic climate-change skepticism. Our experimental materials were designed to harness the power of two cognitive constraints coherence and causal invariance, which map onto two narrative proclivities that anthropologists have identified as universal - to promote climate action across the political spectrum. Towards that goal, the essential role of these constraints in belief formation predicts that climate-change information would be more persuasive when it is embedded in a personal climate-action narrative, the evocation of which can benefit from exposure to parsimonious scientific explanations of indisputable everyday observations, juxtaposed with reasoners' own, typically less coherent explanations, occurring in a context that engages their moral stance. Our brief one-time intervention, conducted in ten U.S. states with the highest level of climate skepticism, showed that across the political spectrum, our materials raised appreciation of science, openness to alternative views, and willingness to take climate actions in the immediate assessment. It also raised the likelihood of reports two years later of having taken or would have taken those actions had the opportunity existed, suggesting that the effect is long-lasting. Our approach adopts the framework that conceptions of reality are representations, and adaptive solutions in that infinite space of representations require cognitive constraints to narrow the search.
\end{abstract}

\title{
Keywords
}

belief revision; coherence; causal invariance; climate change; science communication 


\section{Introduction}

Before the advent of our currently divided world, it was often thought that a helpful step towards telling truth from falsehood was to check the trustworthiness of an information source. That step evidently no longer serves its function for both sides of the divide, now that the two sides trust divergent sources that do not share the same "facts" (Jurkowitz et al., 2020; Mitchell et al., 2014; Rosential, 2009). The divide has made clear that neither authority nor consensus within a group or a society is a measure of truth. In this polarized milieu, it may be helpful to consider basic cognitive constraints essential to belief formation to help guide the development of rational beliefs.

Climate change is one of the domains in which disinformation has impeded social progress (Lewandowsky, 2021; Pierre \& Neuman, 2021). The fossil fuel industry as well as conservative think tanks and media have organized disinformation campaigns on climate change (Farrell, 2016; Jacques et al., 2008; McKibben, 2019; Supran \& Oreskes, 2017), and studies show that disinformation has lowered the public's acceptance of anthropogenic climate change (ACC; Lewandowsky et al., 2019; Ranney \& Clark, 2016).

Perhaps in part due to the pervasive disinformation, conveying to the public the scientific evidence for ACC and the impending catastrophe have not resulted in sufficient understanding of the urgency for climate action. "Clearly, I haven't gotten this message across," lamented NASA astrophysicist James Hansen in his 2012 TED talk, "Why I must speak out about climate change" (Hansen, 2012). Hansen eloquently explained in his talk what had compelled him, the first scientist to testify to the U.S. Senate on the science of climate change (Shabecoff, 1988), to be an ardent climate activist for decades. Recognizing the world's failure to act despite urgent calls by climate scientists and activists, he pleaded for help.

The present paper suggests an answer to his plea based on work in cognitive science. To illustrate the effectiveness of our cognitive-constraint approach, we apply it to raise people's willingness to take climatemitigating and pro-environment actions.

Despite Earth's climate emergency (Intergovernmental Panel on Climate Change (IPCC), 2018), few countries are on track to meet the goal set in the Paris Climate Agreement (Kennedy, 2020; Rivera et al., 2023; UN News, October 26, 2022) to limit global warming to well below 2, preferably 1.5, degrees Celsius above pre-industrial levels (United Nations Framework Convention on Climate Change, 2022). According to a report issued jointly by the world's leading climate science organizations (World Meteorological Organization, 2020), limiting global warming to just 2 degrees Celsius by the end of the century would require that global carbon dioxide emission be reduced roughly three times more rapidly than the speed in 2020. However, even among the great majority who believe in ACC in the U.S. and U.K., relatively few prioritize governmental climate policies when casting their votes in elections (Leiserowitz et al., 2020; Crawley et al., 2020). Global warming was not among the top 10 issues that American registered voters in 2020 said would be "very important" to their vote in the 2020 presidential election (Goldberg et al., 2020). An NPR/Marist poll in 2022 shows that only 9\% of Americans view climate change as a top priority for the 
incoming 2023 Congress. More generally, most Americans do not take actions to promote governmental climate policies (Leiserowitz et al., 2018).

Without strong public demand, governments are unlikely to implement the concerted drastic changes necessary in energy infrastructure and laws, and inaction will result in a climate process that is beyond humanity's control. As a former U.S. Energy Secretary noted, "There will be no vaccine for climate change" (Inskeep, 2020).

Communicating climate science in a way that raises individuals' willingness to take political and personal climate actions would contribute to increasing public demand for climate policies, which may in turn pressure governments to prioritize climate actions (Leiserowitz, 2019; Ockwell et al., 2009). The recent movements for transformative laws and public policies - on the rights of lesbian, gay, bisexual, transgender, and queer (LGBTQ) people in the U.S. (Zurcher, 2020; Pew Research Center, 2019), the legalization of abortion in Argentina (Phillips et al., 2020), the passing of the Marine Mammal Protection Act (World Wildlife Fund, 2017), and the expansion of Title IX offices in U.S. universities to safeguard against sexual harassment (New, 2015) — are testimony to the sway of public will.

A challenge for such communication is that those unwilling to take climate action may not respond to scientific evidence supporting ACC. A survey by the Pew Research Center (Funk \& Kennedy, 2020) observed that "Partisanship is a stronger factor in people's beliefs about climate change than is their level of knowledge and understanding about science." The survey found that Democrats were likely to believe in ACC, and the higher their level of science knowledge measured in terms of science facts and methodologies, the more likely was that belief. In contrast, Republicans were unlikely to believe in ACC, and their position did not vary reliably as a function of science knowledge (for an analogous finding on people's trust in environmental researchers, see Funk et al., 2019). Other studies (Drummond \& Fischhoff, 2017; Kahan et al., 2012) have found an even more extreme form of the interaction between science literacy and political/cultural identity: those with the highest science literacy and technical reasoning capacity in fact showed the greatest polarization on climate-risk perception.

In response to such political polarization, some studies on how to promote ACC beliefs and intention to take climate actions have skirted conveying scientific evidence on human activities as the cause of climate change. Instead, they have turned to showing effective promotion by other means, such as emphasizing broad consensus among climate scientists on ACC (Lewandowsky, Gignac, \& Vaughan, 2013) or highlighting positive actions that individuals can take to promote a better society (Bain et al., 2012). Meanwhile, other studies have shown that direct presentation of scientific evidence can indeed be beneficial in promoting awareness of ACC across the political spectrum. For example, Ranney and Clark (2016) reported that explaining to Americans the mechanism of the greenhouse effect increased their acceptance of ACC, regardless of their political identity. Overall, the conditions under which laypeople's science knowledge interacts with their political identity to shape ACC beliefs remain unclear.

Promoting climate actions need not be a hopeless task. It is estimated that as many as $70 \%$ of Americans (Leiserowitz, 2019) — the middle four segments of "global warming's six Americas" (Leiserowitz 
et al., 2018), with views toward ACC ranging from "concerned" and "cautious" to "disengaged" and "doubtful" - are open to shifting their beliefs and actions toward governmental policies to slow climate change. For the middle four Americas, here we ask: In our polarized milieu, can principles basic to cognition be recruited to promote not only willingness to take climate actions, but also the odds of taking those actions? Can the approach more generally promote appreciation of science? To show that cognitive constraints operate pervasively, including on conservatives, we conducted an experiment testing our approach in the ten U.S. states that scored lowest in the belief that climate change is human-caused (Howe et al., 2015).

\subsection{The Mind's Representation-dependent Reality and Cognitive Constraints}

Cognitive science shows that human understandings of reality are representations of it (e.g., Atlas, 2005; Fodor \& Pylyshyn, 1981; Hawking \& Mlodinow, 2010; Hoffman, 2019; Hume, 1739/1987; Kant, 1781/1965). Percepts and beliefs are therefore the result of a search in an infinite space of possible representations (e.g., Kant, 1781/1965; Pizlo, 2001). This pervasive problem of under-determination is no longer an abstract insight confined to philosophy but an integral part of current vision science (Li \& Pizlo, 2011), engineering (Jayadevan et al., 2017), and clinical treatment (Ramachandran \& Hirstein, 1998; Botvinick \& Cohen, 1998).

Take perceiving a cube as an example. Cognitive scientists realize that our perception of a cube is a solution to the under-determination problem that makes use of a priori assumptions. The 2-dimensional image cast by a cube on our retina is ambiguous, in that it can map onto an infinite number of 3-dimensional objects - objects that need not be symmetric, and the edges of which do not have to be straight lines (e.g., Pizlo, 2001). But despite the inherent under-determination of the distal object, we are not paralyzed by indecision: we perceive a cube. Narrowing down to this adaptive percept within the infinite space of possible distal objects illustrates the application of potent constraints in the form of a priori assumptions - in this case, the default assumption that the distal object has the simplest form that is consistent with the image; in other words, a cube as the object provides a "parsimonious explanation" of the image. To analogously avoid paralysis, an adaptive solution for constructing causal beliefs in a vast search space of possible representations requires cognitive constraints (Marr, 1982).

Two central constraints that operate hand-in-hand address the challenge of forming generalizable causal knowledge in that immense space of possibilities. One is the coherence of causal explanations (Thagard, 1989). Diverse fields have converged in showing that scientists and untutored reasoners alike seek coherent explanations, and prefer more parsimonious ones: logically consistent explanations with fewer assumptions. Mathematical derivations show that parsimonious explanations yield the most efficient path to truth (Kelly, 2007). Brain-imaging studies show that parsimonious explanations, much like food and sex, bring pleasure (Biederman \& Vessel, 2006). Evidence for the constraint abounds in the history and philosophy of science (Kuhn, 1962/2012; Newton, 1687/1727; Thagard, 2000). A case in point is Rule I of Isaac Newton's three 'Rules of Reasoning in Philosophy' (1687/1934) states: "We are to admit no more causes of natural things than such as are both true and sufficient to explain their appearances." A paragon 
of parsimony in explanation is Charles Darwin's (1859) theory of evolution by natural selection. The final sentence in his On the origin of species illustrates the concept well: "There is grandeur in this view of life, ... from so simple a beginning endless forms most beautiful and most wonderful have been, and are being evolved" (p. 507). The alternative - less parsimonious - explanation is that an omnipotent being created the multitudinous existing lifeforms in their current states and extinct lifeforms in their states in fossil records. Omnipotence carries limitless post-hoc assumptions. Evidence for the constraint also comes from psychological experiments (e.g., see Lombrozo, 2016) and anthropological studies (Ochs \& Capps, 2001).

Two principles from Thagard's (1989) theory of explanatory coherence - Explanation and Contradiction - make explicit how we characterize coherence. ${ }^{1}$ His Explanation principle concerning a set of propositions $\left\{P_{1}, \ldots P_{m}\right\}$ states, "If $P_{1}, \ldots P_{m}$ explain $Q$, then: (a) For each $P_{i}$ in $P_{1} \ldots P_{m}, P_{i}$, and $Q$ cohere. (b) For each $P_{i}$ and $P_{j}$ in $P_{l} \ldots P_{m}, P_{i}$ and $P_{j}$ cohere. (c) In (a) and (b), the degree of coherence is inversely proportional to the number of propositions $\mathrm{P}_{\mathrm{I}} \ldots \mathrm{P}_{\mathrm{m}}$." (pp. 436-437). Thagard regards this principle to be "by far the most important for assessing explanatory coherence" (p. 437). His Contradiction principle states: "If $\mathrm{P}$ contradicts $Q$, then $P$ and $Q$ incohere." (p. 437). Following Thagard, our use of "logical inconsistency" covers not only syntactic contradictions like $P$ AND not-P, but also semantic contradictions. We treat observations as propositions. Thus, the belief that "there is one high tide a day at the Santa Monica Pier" is logically inconsistent with the observation that "there are two high tides a day at the Santa Monica Pier". ${ }^{2}$

A second cognitive constraint is causal invariance: Deviation from causal invariance provides a critical signal for a need for belief revision (e.g., Bye et al., 2023; Cheng, 1997; Cheng et al., 2007; Cheng \& Lu, 2017; Cheng et al., 2022; Liljeholm \& Cheng, 2007; Rescorla \& Wagner, 1972; Woodward, 2000, 2005; for explications of the constraint, see Ichien \& Cheng, 2022; Park et al., 2022). This constraint arises from a (tacit) goal to acquire useable/generalizable causal knowledge, "useable" in the sense that the knowledge is causally invariant across the learning and application contexts. It implies that when reasoners experience a deviation of the observed outcome from that predicted by the application of their causal explanation of a phenomenon to a new situation, that deviation signals a need to revise the explanation. The goal is to formulate an explanation that consistently holds across both the old and new contexts, so that the previously deviating observation can fall under the same (updated) set of assumptions. (See Section 2.2 for examples of experimental materials that were intended to engage these constraints.)

The coherence and causal-invariance constraints are intimately linked: if there is deviation from causal invariance, there would be lower parsimony, and hence lower coherence. A deviation from invariance

\footnotetext{
${ }^{1}$ For our purpose of evoking resonance with the coherence of scientific explanations to promote climate action, we see no need to adopt the connectionist implementation of Thagard's (1989) theory.

${ }^{2}$ Another conception of coherence concerns how well information from multiple sources "fit together". Harris and Hahn (2009) found that Bovens and Hartmann's (2003) Bayesian model of probabilistic coherence gives an excellent fit to intuitive judgments of how probable a conclusion was based on multiple witness testimonies. We return to discuss this conception in Section 3.
} 
results in lower parsimony because the unexplained observation (the deviation) would require the assumption of an exception condition or an extra cause. Viewed in another way, it results in lower coherence because the outcome according to the explanation contradicts the actual outcome. The preference for parsimony predicts a drive to revise the prior causal explanation to restore causal invariance.

Strikingly, these two constraints - identified under a cognitive-science analysis of the problem of underdetermination - map onto two universal proclivities that anthropologists Ochs and Capps (2001) have identified across everyday narratives in diverse cultures around the globe: a deep-rooted yearning to construct 1) a coherent account of life events and 2) an accurate, authentic account, noting deviations from what would fit the attempted coherent explanation. A "coherent narrative", to Ochs and Capps, is a logically consistent set of token causal relations that explains an event or a situation. The anthropologists note a dialectic tension between the two proclivities to resolve discrepancies: "how interlocutors move back and forth across time to make sense out of events, how causes and effects are stitched together, only to fall apart when narrators are reminded or informed of inconsistencies" (p. 23).

Like scientific theories, narratives are explanations. Bruner (1991) proposed that scientific theories are to narratives as explanations of phenomena are to explanations of the unfolding of human-related events or situations. Ocean tides occurring every day is a phenomenon, explained by Newton's law of universal gravitation. Narratives are the other type of explanation, notably issuing from a point of view that carries specific values and aims. Actions, the target outcome of our study, are explained by one's values and aims. Climate scientist James Hansen (2012), for example, explains why he protested in front of the White House, an act that led to his arrest by the police (Hansen asks plaintively, "What do I know that would cause me ... to get arrested ...?"). The root cause, left unspoken, was his aim to avert the catastrophes informed by his knowledge. Narratives are never "point-of-viewless," notes Bruner (p. 3). For the same reason, voluntary action is never point-of-viewless.

Similarly, Ochs and Capps (2001) observe that accounts of life events all adopt a perspective, and central to the perspective is its moral stance, "a disposition towards what is good or valuable and how one ought to live in the world" (p. 45). To illustrate, in a conversation between two men in a Western Samoan village, Tavo recounted to Fonati the events surrounding the mysterious disappearance of his watch while he slept (Ochs \& Capps, pp. 117-118). Implicit in Tavo's narrative is his stance that the theft of his watch is wrong. Similarly, by calling someone who publicly demonstrates opposition to a policy a "protester" or a "rioter", a narrator reveals different moral stances. In line with the anthropologists' observations, psychologists have argued that values are critical for effective science communication (Kahan, 2010; Medin \& Bang, 2014).

On the consequential role of narratives, the biologist Wilson (2001, p. xv) writes, "Narrative is the human way of working through a chaotic and unforgiving world... The stories we tell ourselves and others are our survival manuals." In the case of humanity's collective narratives about climate change, it is crucial whether our survival manuals take a perspective that values life as we know it on our precious planet or a perspective that lets profits in our current heavily fossil-fuel-based economy override all other values (McKibben, 2019). 
Why do people around the globe have the same two narrative proclivities? In our view, the underdetermination framework provides an explanation: These deep-rooted yearnings are implementations of the corresponding constraints that enable cognition itself. The need to avoid cognitive paralysis explains the need for coherent narratives. In return, findings on the universality of the yearnings provide evidence for the breadth of scope of the cognitive constraints, manifesting as they do in personal explanations of life events and of one's place in the world.

\subsection{Applying Cognitive Constraints to Climate Persuasion}

To persuade the middle four Americas to take climate actions, our study sought to foster the construction of a coherent climate-action narrative. The critical role of coherence and causal invariance in cognition suggests that to effectively change beliefs, an intervention should take these steps: 1) elicit reasoners' causal explanation of a phenomenon based on their prior beliefs, 2) provide information that enables them to notice inconsistencies between the prediction of their explanation and actual observations (steps 1 and 2 together evoking the causal-invariance constraint), and 3) provide a more coherent explanation as a replacement (evoking the coherence constraint). At the level of individual exercises in the science components of our intervention, we implemented these three steps, to be illustrated presently. At the more abstract level of the choice of topics to include in our materials, we aimed at providing essential building blocks for constructing a coherent climate-action narrative. Informed by anthropologists' findings on the human need for coherent and authentic narratives to account for life events (Ochs \& Capps, 2001), we propose that three such components are:

1) an understanding that climate change is anthropogenic,

2) an appreciation of science in general, and resonance with the parsimony of scientific explanations in particular, and

3) a conception of the self as someone morally responsible for the consequences of climate change.

The purpose of these components was to enable participants to "connect the dots" across them and create or revise their personal climate-action narrative. We cannot tell participants in our study what narrative to carry - everyone would have their own narrative, one that, importantly, comes from them. We can only provide potential narrative-building components. If one or more of the components are previously missing in some participants' belief system, our intervention would raise willingness to take climate actions.

The first component concerns scientific evidence for ACC. We believe that conveying such evidence is essential to building enduring support for climate action, despite reports of a positive correlation among conservatives between climate skepticism and science literacy (Drummond \& Fischhoff, 2017; Kahan et al., 2012). Fundamentally, ACC as explained and predicted by climate-science models (e.g., IPCC, 2018) is the raison d'être for climate action. Without some knowledge of scientific evidence for ACC, a climateaction narrative would be missing a crucial cause-and-effect link.

For the third component, to evoke moral values that would explain and motivate caring action, our materials included a question asking participants how they would like a psychotherapist (who spoke in the interview excerpted in the question) to counsel farmers who have become suicidal from losing their 
livelihood after historic floods in the Midwest (Rosmann \& Atkin, 2019). We selected farmers experiencing an extreme weather event as candidate targets of moral concern to most Americans. Many other candidates may serve that role and produce similar effects (e.g., animals in danger of extinction due to climate change), while others may not. Victims of mass shooting, for example, would evoke empathy but would not enable a coherent climate-action narrative.

If participants do connect the dots across the components, the climate-action narrative they implicitly construct might be something like this:

I saw that an extreme drought in the Midwest devastated farmers and their families. These folks didn't cause the drought any more than I did. Climate scientists explain the more frequent occurrence of oncein-a-lifetime droughts, floods, and wild fires by humans' burning of fossil fuel since industrialization. If I hadn't come across the scientists' explanation, I would never have thought that my plane trips or the cheeses I enjoy had anything to do with crops failing disastrously or houses being washed away in distant lands. My actions affecting greenhouse-gas emissions, especially actions contributing to largescale public policies, can mitigate the suffering brought by climate change.

\subsubsection{Resolving an apparent discrepancy}

In addition to guiding the construction of our materials, our framework offers a theoretical resolution of the seemingly conflicting findings on the relation between scientific expertise and ACC attitudes. Recall that some studies have found that teaching the mechanism of global warming leads to increased acceptance of ACC among both liberals and conservatives (Ranney \& Clark, 2016). However, other studies using correlational methods have found that conservatives with the highest science literacy actually have the highest level of climate skepticism (Drummond \& Fischhoff, 2017; Kahan et al., 2012). In our view, there are two potential factors that may contribute to the discrepancy: the aspect of science knowledge involved and whether or not one's moral stance is evoked when they are exposed to the potentially belief-changing ACC information.

First, the essential role that the coherence constraint plays in enabling cognition suggests that intuitive resonance with parsimony in scientific explanations will be conducive to belief revision. Acquired science literacy measured in terms of science facts and methodology has not played that role in human evolution. Second, for new information to be integrated into a newly coherent narrative, the reasoner's existing narrative with its moral stance may need to be evoked. Interestingly, in Ranney and Clark's studies, the following opening instruction was found to be crucial for obtaining a strong effect of their global-warmingmechanism explanation: "The information ... we are about to show you is true, and contains no deception. You can share this sincerely true information with your family and friends tonight, and you can of course check the information on-line" (personal communication with author via email, received permission to quote, June 2020). This opening instruction — which connotes that the information at hand concerns an important issue that participants' community would care about - may tap into participants' moral stance. When the opening instruction was omitted in a study that presented the short version of Ranney and Clark's mechanism explanations, the materials did not affect participants' beliefs about climate outcomes, despite 
increasing their mechanistic knowledge (Schotsch \& Powell, 2022). The studies that found an inverse relation between science literacy and ACC attitude among conservatives (Drummond \& Fischhoff, 2017; Kahan et al., 2012) likewise did not involve evoking participants' moral stance.

Our experiment addresses these two possible resolutions of the opposite influences of science knowledge observed in previous studies.

\subsubsection{Overview of materials}

To successfully convey the abstract concept of parsimony in scientific explanations to a broad audience, taking precaution to circumvent interference from disinformation, our intervention materials embedded climate-science information in the context of a diverse set of incontrovertible everyday phenomena explained by science (see our general-science prediction exercises). Whereas climate-change models can be denied, everyday phenomena would be more difficult to deny. Resonance with the parsimony in scientific explanations of such phenomena may help to narrow the political divide by countering the tendency by some to dismiss science and view scientists as alien elites.

To invoke the causal-invariance constraint, our climate- and general-science prediction exercises asked participants to first make a prediction about a phenomenon and formulate their best explanation of it (Chi et al., 1994). To effectively implement this constraint, we aimed for our prediction exercises to be surprising (Munnich \& Ranney, 2019), so that participants may better notice deviations of their own prediction from the observed phenomenon in the feedback. Their prediction is presumably based on applying the causal model in their mind to the novel situation. Deviation from the projected invariance is a signal for belief revision. Because this constraint was incorporated in every science-prediction exercise, causal invariance served as an enabling condition for the influence of coherence in those exercises.

The question mentioned earlier on farmers experiencing historic floods was intended to lead participants to interpret the general-science- and climate-science prediction exercises through the lens of a moral stance (Ochs \& Capps, 2001): Are the lives of climate-change victims valuable, and am I in a broad sense responsible for their well-being? Thus, without the moral-identity/farmers question, the science exercises on their own would be less effective at inducing participants to take climate actions.

Conversely, unless participants understand that severe storms are likely consequences of human activities, they would not relate the farmers' plight - their livelihood threatened by historic floods - to participants' own climate-related actions. Thus, the moral-identity/farmers question on its own would be less effective at promoting such actions.

To summarize, the condition with all three components - ACC information, relatable parsimonious scientific explanations, and moral concern - should facilitate the construction of a personal climate-action narrative, and hence raise willingness to take climate actions. Because the components collectively enable the "connecting" between them to form the relevant narrative, they should have non-additive effects. In other words, each component should acquire its effect only in the context of the other two, compared to a control condition with none of the components. (Some participants may come to our study already equipped with one or more of the components; we assume such participants are randomly distributed across 
conditions.) If these basic cognitive constraints are indeed universal (as theory and evidence both indicate), the predicted pattern of effects should occur across the political spectrum.

Two corollary predictions follow from the central role of the two constraints in belief revision. Because scientific explanations that are recognized to be more parsimonious than one's own should encourage belief revision, conditions including the general-science-prediction exercises should yield greater openness to alternative points of view compared to those omitting that component. Parsimonious scientific explanations should also encourage belief revision more so than do science facts that are not part of a parsimonious explanation. To test this latter prediction, our study measured both science-fact knowledge and appreciation of scientific explanations along with willingness to take climate actions. See Table 3 for a list of our climate related and other dependent measures.

\section{Experiment: Two Tests of the Cognitive-Constraints Hypothesis}

\subsection{Overview of experimental design}

Table 1 summarizes the six conditions in our experiment testing the cognitive-constraint hypothesis. The Full-coherence condition consisted of three components: 1) the moral-identity/suicidal-farmers question,

2) a set of seven general-science-prediction exercises, and 3) a climate-science-prediction exercise. Five other between-subject conditions omitted one or more of the three components of the intervention materials to form two $2 \times 2$ designs (see Table $2 a$ and $2 b$ ).

First, to test whether moral-identity is essential to constructing a coherent pro-climate-action narrative, we independently varied the moral-identity/farmers component and the rest of the components combined, namely, the complementary components consisting of the general- and climate-science-prediction exercises. Four of the conditions - Full coherence, All but moral identity, Moral identity only, and Control (rows a, b, c, and f in Table 1; Table 2a) - formed this 2 (moral-identity) x 2 (complementary coherence) design.

Second, to test whether the climate-science prediction component is essential to constructing a coherent pro-climate-action narrative, we independently varied the climate-science component and its complementary components, namely, the combination of the moral-identity question and general-scienceprediction exercises. Four conditions - Full coherence, All but climate, Climate only, and Control (rows a, $\mathrm{d}$, e and $\mathrm{f}$ in Table 1; Table 2b) - formed this 2 (climate-science) $\times 2$ (complementary coherence) design. The Full-coherence and Control conditions (bolded in Tables 2a and $2 b$ ) are in both designs. Note that the label "complementary coherence" refers to the components complementary to the single varied component and thus differed between the two designs.

In parallel with the six conditions just explained, we conducted a seventh condition (supplementary condition g), the Moral-identity-last condition. This condition was identical to our Full-coherence condition except that the moral-identity question was moved from the first to the last position (i.e., from preceding the science exercises to following them). The goal of manipulating the ordering was to rule out an explanation alternative to the cognitive-constraint hypothesis, namely, that the moral-identity question enhanced attention to the science-prediction exercises. 
All conditions ended with a survey assessing willingness to take various pro-environment moral actions, opinions on our science exercises, general science attitudes (Fraser, 1981), science-fact knowledge (Kennedy \& Hefferon, 2019), and demographic information (see Table 3).

Table 1. Component materials in each of six experimental conditions.

\begin{tabular}{lcccc}
\hline Condition & $\begin{array}{c}\text { Moral- identity/ General-science } \\
\text { farmers }\end{array}$ & $\begin{array}{c}\text { Climate- } \\
\text { science } \\
\text { prediction }\end{array}$ & $\begin{array}{c}\text { Assessment } \\
\text { survey }\end{array}$ \\
\hline $\begin{array}{l}\text { a) Full coherence } \\
\text { b) All but moral- }\end{array}$ & $\sqrt{ }$ & $\sqrt{ }$ & $\sqrt{ }$ & $\sqrt{ }$ \\
identity & $\sqrt{ }$ & $\sqrt{ }$ & $\sqrt{ }$ \\
$\begin{array}{l}\text { c) Moral-identity only } \\
\text { d) All but climate- }\end{array}$ & $\sqrt{ }$ & $\sqrt{ }$ & $\sqrt{ }$ \\
$\begin{array}{l}\text { science } \\
\text { e) Climate-science } \\
\quad \text { only }\end{array}$ & & & $\sqrt{ }$ \\
f) Control & & & $\sqrt{ }$ \\
\hline
\end{tabular}

Table 2a. Component materials in Experimental Conditions a (Full coherence), b (All but moral-identity), $c$ (moral-identity only), and $f$ (Control) for testing the effects of the moral-identity question, its complementary exercises, and the interaction between them.

\begin{tabular}{clll}
\hline & & \multicolumn{2}{c}{ General- and climate-science prediction exercises } \\
& \multicolumn{1}{c}{ Yes } & No \\
\hline Moral-identity & Yes & a) Full coherence condition & c) Moral-identity only \\
question & No & b) All but moral-identity & f) Control condition \\
\hline
\end{tabular}

Table 2b. Component materials in Experimental Conditions a (Full coherence), d (All-but-climate-science), e (Climate-science only), and $f$ (Control) for testing the effects of the climate-science prediction exercise, its complementary exercises, and the interaction between them.

\begin{tabular}{cccc}
\hline & & \multicolumn{2}{c}{$\begin{array}{c}\text { Moral-identity- and general-science prediction exercises } \\
\text { Yes }\end{array}$} \\
\hline $\begin{array}{c}\text { Climate-science- } \\
\text { prediction } \\
\text { exercise }\end{array}$ & Yes & a) Full coherence condition & e) Climate-science only \\
& No & d) All but climate-science & f) Control condition \\
\hline
\end{tabular}

\subsection{Features of Science Materials: Implementing the Cognitive Constraints}

Below we illustrate how our science materials were designed to engage the two cognitive constraints. The general-science-prediction exercises presented questions about events that laypeople could observe 
or verify in their own lives, such as water shooting out of a garden hose, or ocean tides that they could experience or look up in a tide chart.

In the garden hose exercise, the first of the science-prediction exercises, participants were shown a diagram of a coiled hose placed flat on the ground. They were asked to predict the path of the water as it leaves the hose by selecting from six diagrams depicting possible paths. The correct diagram showed a straight path tangential to the circle formed by the coil; other diagrams showed curved paths or straight paths non-tangential to the coil (McCloskey \& Kohl, 1983).

For feedback, a video showed water shooting out in a straight line from a horizontally coiled garden hose. Participants whose prediction - based on applying their prior causal model of forces to the situation - deviates from the observed phenomenon would be motivated to revise their causal model. Along with the video was a short paragraph explaining the phenomenon by Newton's First Law of Motion, which states that an object continues its motion with its velocity unchanged unless an external force acts on it (predicting that once the water is not confined within the hose, it would continue moving in the same direction in a straight line). This law is a more coherent explanation of the water's trajectory in two ways: 1) its prediction is consistent with the observed outcome (following part a of Thagard's, 1989, Explanation principle), and 2) it explains both celestial and terrestrial motion (following part $\mathrm{c}$ of the principle and a preference for higher coherence). Explication of the latter straddles the garden hose exercise and the ocean tides exercise.

In the ocean tides exercise, we aimed to illustrate the universality of Newton's explanations of motion. The exercise stated, "Gravitational force from the moon causes tides in coastal areas. How many high tides and low tides do you think a coastal area experiences a day? (Tides are regular rises and falls of sea levels.)" A video showed high and low tides at the Bay of Fundy, and a reminder stated that Earth makes one complete rotation on its axis every 24 hours.

The feedback stated that there are two 2 high tides and 2 low tides a day, noting, "Whether you be a fisherman or a surfer, the time for each of the 4 tides on a day is what you will find on any tide table." Alongside a diagram (see Supplementary Method), the feedback then proceeded with an explanation in terms of Newton's law of universal gravitation:

"As Earth rotates a full circle once a day (counter-clockwise in the diagram), the moon's gravity pulls on different parts of our planet. By Newton's law, for any two bodies, the closer they are to each other, the stronger the gravitational pull between them. Accordingly, the part of the ocean nearest to the moon is pulled the most, resulting in a bulge (see diagram).

By the same law, the part of the ocean farthest away from the moon is pulled the least, resulting in another bulge (think about it as being left behind the most). The solid Earth in the middle - which is not stationary but floating in space — is subjected to an average pull.

So, as your part of the coast on Earth rotates into these two bulges of water, once each day, you experience a high tide. And as your part rotates into each area in between the two bulges, because water is drained away from you (towards the bulges), you experience a low tide." 
The explanation brought attention to this law's prediction that the moon's pull operates everywhere on Earth, rather than only on the ocean facing the moon. (The following link was provided as a source of our explanation: https://scijinks.gov/tides/.)

The exercise continued, "By the way, what if the same natural force that causes the tides were to stop? What path do you think our moon would take? (Recall how water shoots straight out once its path isn't forced to curve inside the garden hose.) Earth's massive pull on the moon is what keeps it from flying off, causes it to curve its path, keeping it in orbit, close to Earth as we see crossing our night sky every night."

By drawing an analogy between water shooting out of a garden hose and the hypothetical path of the moon without Earth's gravitational pull (an external force), the feedback aimed to convey the parsimony of Newton's first law. Analogical mapping between the explanations of two phenomena is one of the seven principles in Thagard's (1989) theory of explanatory coherence. Likewise, showing that Newton's law of universal gravitation explains ocean tides as well as the moon's orbit, a terrestrial and a celestial phenomenon, brings further attention to the universality of these laws and adds to their appeal. Apples fall down but the moon does not; one would not intuitively think the same laws explain them.

In answer to the question on the number of tides, intuition typically predicts 1 high tide and 1 low tide a day. The thinking apparently is that while the moon pulls ocean water towards it, its pull on the core of the Earth is somehow omitted (i.e., the core stays still), resulting in a high tide on the side facing the moon and a low tide on the side away from the moon. The erroneous prediction is likely acquired in an Earth-centric everyday context where massive solids are immoveable but liquids are fluid. In contrast, Newton's broader and more realistic context assumes that the entire Earth - the lithosphere etc. as well as the oceans - is floating in space, and the moon's gravitational pull acts on all masses. After seeing that there are 2 high tides and 2 low tides, participants often could not explain the surprising high tide on the side of Earth away from the moon. To predict that other high tide, their intuitive explanation would require assuming an exception condition or the presence of an extra celestial body orbiting in sync with the moon but on the opposite side of the Earth.

By comparing their own explanation with Newton's, participants may come to realize that their prior explanation accounts for part of an indisputable real-world phenomenon but not all of it (i.e., there is an unequivocal deviation from causal invariance) and that science offers a far more invariant and parsimonious explanation.

\subsection{Method}

All of our study's materials, data, and code for analyses can be found at https://osf.io/4j738/.

\subsubsection{Participants}

The participants were 348 adults aged 18 years or older (198 females, 3 non-binary gender, $M_{\text {age }}=38.3$, $S D_{\text {age }}=12.6$ ) who were recruited through Amazon Mechanical Turk from December $12^{\text {th }}, 2019$ to January $27^{\text {th }}, 2020$. The UCLA Institutional Review Board approved the procedures of the experiment, which 
complied with all relevant ethical regulations involving human participants. All participants provided informed consent.

To have maximal access to conservative participants on MTurk, we recruited from only the ten U.S. states that scored lowest in the belief that climate change is human-caused (Howe et al., 2015): Wyoming, West Virginia, Alabama, Oklahoma, Idaho, Arkansas, Kentucky, North Dakota, Louisiana, and Utah.

An additional 130 MTurk workers recruited from these states were excluded, 112 of them because they self-identified as independents $(n=94)$ or libertarians $(n=18)$. We did not ask for political identity until the very end of our materials; we did not want awareness of political identity to influence our results. We excluded these groups because one of our goals is to evaluate whether there is any interaction between the effect of our intervention and political identity, analogous to previous reports of the different association between science knowledge and ACC attitudes in political conservatives and liberals (Drummond \& Fischhoff, 2017; Funk \& Kennedy, 2020; Kahan et al., 2012). Including independents would not be informative for our purpose because they are highly diverse in their political opinions. Confirming that understanding, political identity was the strongest predictor for the dependent variables in our regression analyses, and the adjusted R-squared was higher when political identity as a continuous covariate consisted of four levels (extreme conservative, moderate conservative, moderate liberal, and extreme liberal) than when independent was included as a middle point. Lewandowsky, Gignac, and Oberauer (2013) showed that libertarians are close to conservatives in their views on ACC. However, our sample had too few libertarians to include in our analyses ( 1 or 2 in all but the Control condition, which had 7).

In our total recruited sample, $33.8 \%$ self-identified as politically moderate or extreme conservative, $42.4 \%$ as politically moderate or extreme liberal, $20.4 \%$ as independent, and $3.9 \%$ as libertarian. Confirming expectation from the narrow scope of our recruitment, the proportion of political conservatives in our MTurk sample was substantially larger than observed in previous research on MTurk recruitments (Levay et al., 2016, 14.6\%) and closer to a more nationally representative dataset from 2020 (Saad, 2021, 36\%).

The remaining eighteen excluded MTurk workers were removed due to responses that were inattentive (e.g., wrote nonsensical responses such as "good" when asked to explain their answers) as judged by two independent scorers. The scorers readily resolved the few differences.

The surveys for the various conditions all carried the title "Survey on everyday reasoning," appended with different numerals randomly assigned to the seven conditions to identify them. Participants selected to participate in one and only one survey from the seven titles. The number of participants in the conditions were, respectively from a to g: $84,31,34,42,34,86$, and 37 . We aimed to recruit twice as many participants for the Full-coherence and Control conditions (conditions a and $f$ ) as for the rest because they were part of both our 1) moral-identity/farmers $x$ complementary-coherence design and 2) climate-science-prediction $x$ complementary-coherence design. Depending on the condition, the medians of the time spent on the entire survey, including the dependent measures, ranged from 5.1 to $37.9 \mathrm{~min}$. All participants were paid at the rate of around $\$ 8$ per hour. 
Between November 11 $11^{\text {th }}, 2021$ and December $7^{\text {th }}, 2021$ (Phase 2), among participants included in our analyses of the $2 \times 2$ designs in Tables $2 \mathrm{a}$ and $2 \mathrm{~b}$ (Phase 1), all those who indicated interest in a " 3 - to 5minute follow-up study" ( $N=224)$ were invited to return. Eighty-eight returned ( $39 \%$ of those invited). They were paid at the rate of $\$ 16$ per hour. All return participants were included in our analyses.

\subsubsection{Task, materials, and procedure}

In keeping with our view that the two cognitive constraints are universal, operating across scientists and nonscientists alike, our opening instruction to participants stated, "Your opinions and thoughts are important to us, because a major goal of our study is to understand how we as people think about issues." The wording connotes that we the research scientists are in the same inclusive group as they the participants. To avoid proselytizing, consistent with our respect for participants' independent thinking, we constructed the components to not appear related, leaving to participants the task of "connecting the dots". Towards that same goal, we avoided direct clashes with participants' preconceptions; our intervention materials made no mention of "climate change" or other politicized terms.

To fill in more details, we use the Full-coherence condition (see Supplementary Materials for the full set of materials). First, participants read excerpts from a short interview (Rosmann \& Atkin, 2019) with a clinical psychologist in lowa. The psychologist advised traumatized farmers whose loved ones threatened or committed suicide upon facing insolvency after the extreme flooding in the Midwestern U.S. in March 2019. Participants were asked to put themselves in the shoes of the farmers who called the therapist for help. They then chose what kind of help they would like to receive from the therapist among the provided options (e.g., "Help me apply for crop insurance", "Give me information on how to contact FEMA for emergency financial assistance"). They were also asked to suggest other important means of addressing the issue and to explain their answers briefly. The suicidal farmers intervention was intended to set an empathic moral stance (Ochs \& Capps, 2001) relevant to climate change.

Next, participants were shown a set of seven general-science-prediction exercises and one climatescience-prediction exercise in a fixed order. All eight science-prediction exercises, as illustrated earlier, shared a common structure: A problem regarding what the outcome would be in a real-world phenomenon (e.g., water poured out from drinking glasses) or a familiar scientific invention (GPS, antibiotics), with a question asking participants to predict the outcome and to give their best explanation for their prediction. The subsequent feedback showed the actual outcome (accompanied by a video when appropriate), a science-based explanation for the correct answer, and relevant references (e.g., URLs for NASA, NOAA, and other relevant educational websites).

Below we describe two more science-prediction exercises: the climate-science-prediction exercise and the water pouring exercise. (See Supplementary Method for the rest of our science exercises.)

\subsubsection{Climate-science-prediction exercise}

Like other science exercises, the climate-science-prediction exercise implemented the two cognitive constraints. This exercise appeared as the fifth of the eight science-prediction exercises in the Fullcoherence condition. Unlike other science exercises, the climate-science exercise presented more in- 
depth explanations and two questions instead of one. First, in an exercise simply labeled "Graph prediction", participants were asked to project a trend of an unknown quantity " $x$ " shown on a globaltemperature graph from the year 1880 to 1965 in which the label for the ordinate (i.e., global temperature) was notably omitted. The projection therefore could be based on only the visual past trend. See Fig. 1 for the graph shown to participants.

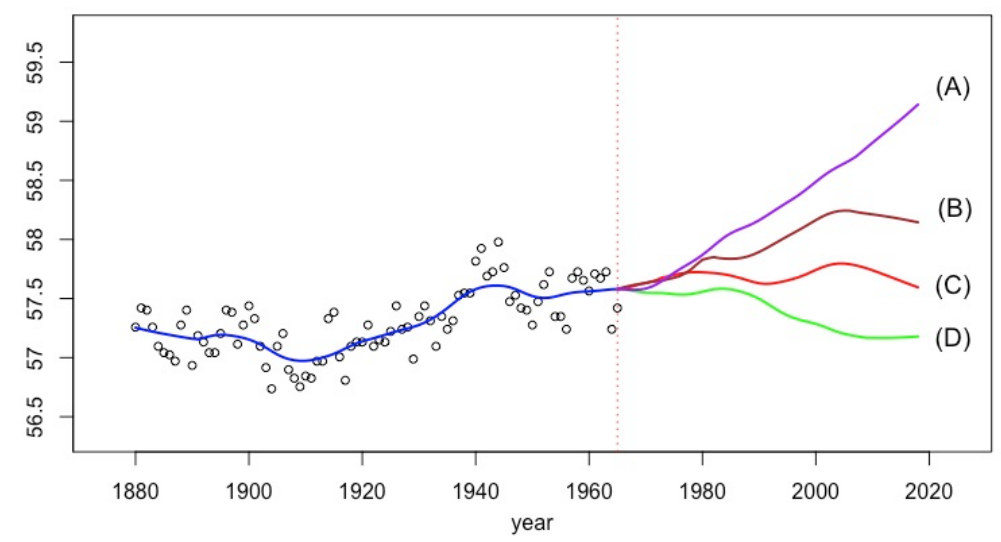

Fig. 1. Graph without a label for the ordinate in the graph-prediction climate-science exercise.

Participants were asked to choose the most plausible projection on the right side of the graph based on past measurements of $x$ from 1880 to 1965 as indicated by the blue line on the left. They chose from four response options, which ranged from various continuations of the previous trend with little or no change (curves labeled from "B", "C" and " $\mathrm{D}$ " in the figure) to one showing a salient upward rise (curve labeled "A"). Up to this point, the question did not involve climate.

The goal of the "unknown $x$ " projection exercise was to let participates commit to what they considered a natural projection, one that deviates from the actual observed trend. The projection is presumably based on the intuitive assumption that forces remain the same, an assumption free of one's political orientation. On the next page, ' $x$ ' was revealed to be the observed average global surface temperature from 1880 to 2018 (reported by NASA, https://climate.nasa.gov/vital-signs/global-temperature/). The line that shows the salient rise was the "correct" answer, chosen by few participants (11\%). The deviation of participants' own judgment from the actual observed trend enabled the causal-invariance constraint to apply.

A second question asked what participants thought caused the substantial recent deviation from the trend preceding 1965. Note the metaphoric application here of Newton's First Law (events continuing with no change unless an external cause is introduced), which participants saw in the garden hose exercise. ${ }^{3}$

The feedback page provided data graphs in support of ACC: the graphs showed the rapid rise in global surface temperature co-occurring with the sharp rise in human emission of greenhouse gases, but not with levels of other causes such as volcanic activity or solar activity (Masson-Delmotte et al., 2013).

\footnotetext{
${ }^{3}$ The law may be viewed as Newton's application of the causal-invariance constraint to the specific concept of "velocity", his choice of which enables the invariance of the law.
} 
The next page sketched the climate-science explanation of a broad range of climate phenomena previously unconnected to fossil-fuel burning, illustrating the parsimony of the explanation. It highlighted specific unexpected outcomes such as the extremeness of weather patterns predicted long ago by climate scientists' models: "in $1981, \ldots$ atmospheric physicist James Hansen $\ldots$ predicted that the $21^{\text {st }}$ century would see more extreme droughts and floods as climate zones shift, the erosion of ice sheets resulting in worldwide rise in sea level, and the opening of the fabled Northwest Passage.... these impacts predicted decades ago ... have since eerily become facts." Note that this feedback provided a potential explanation for the flooding inflicting farmers in the moral-identity/farmers question.

The page then showed graphs of simulated global temperature on land and ocean based on models using only natural forcings and models using both natural and anthropogenic forcings, with the observed temperature clearly aligning with the latter models (IPCC, 2007; see figure accompanying the task in Supplementary Method).

Lastly, the materials included a figure showing $97 \%$-consensus on ACC among climate scientists (Cook \& Lewandowsky, 2016). Studies have shown that emphasizing the broad consensus among scientists on purportedly contested scientific issues (e.g., climate change, genetically modified food, HIV and AIDS) generally increases people's acceptance of the science while attenuating the influence of their political ideology or worldview (e.g., free market endorsement, Lewandowsky, Gignac, \& Vaughan, 2013; van Stekelenburg et al., 2022). However, whether the consensus information can raise willingness to take related actions in daily lives remains to be tested. Including the information on the consensus among scientists in our climate-science-prediction exercise allows a sufficiency test: if our Climate-only condition fails to raise willingness to take climate actions compared to our Control condition, one can infer that consensus information does not suffice to raise that willingness.

\subsubsection{Water-pouring exercise}

Our eighth science-prediction exercise was the water-pouring exercise, where we showed a photo of two glasses of different widths and heights (one glass was narrower and taller than the other) filled with water. The question stated, "The distances between the top of the glass and surface of the water [as shown in the photo] are identical for two glasses. If someone gradually tilts both glasses at the same rate, from which glass would water start to pour out first?"

The feedback gave a geometric proof of why the water would pour out from the wider glass first (see Supplementary Method). The proof, which was followed by a video demonstrating the pouring from the two glasses, is a parsimonious explanation of the outcome: it requires no empirical assumption other than the conservation of water's volume.

\subsubsection{Dependent measures: General-science attitude and science-fact knowledge evaluations, willingness to take moral actions, and demographic information}

All conditions ended with seven surveys consisting of our dependent measures:

1) agreement with four general-science-attitude statements selected from a handbook on tests of science-related attitudes (Fraser, 1981) 
2) opinions on our science exercises, indicated by agreement with three science-appreciation statements

3) willingness to take political climate actions

4) willingness to take personal climate actions

5) willingness to take personal pro-environment actions that are not necessarily related to climate change

6) science-fact knowledge questions, selected from a survey by the Pew Research Center (Kennedy \& Hefferon, 2019), and

7) demographic information (age, gender, educational level, political identity) and general comments.

Participants were randomly assigned to rate agreement with general-science-attitude statements in one of two analogous sets. Everyone answered the same questions for the rest of the measures.

Table 3 lists the exact items from each of the seven dependent measures.

Table 3. Items from surveys on 1) general-science attitude, 2) opinion on our science prediction exercises, 3 ) willingness to take political climate actions, 4) willingness to take personal climate actions, 5) willingness to take personal pro-environment actions, 6) science-fact knowledge, and 7) demographic information.

\begin{tabular}{|c|c|}
\hline \multirow{4}{*}{$\begin{array}{l}\text { 1. General } \\
\text { Science } \\
\text { Attitude: Likert- } \\
\text { scale from } 1 \\
\text { (strongly } \\
\text { disagree) to } 5 \\
\text { (strongly agree) }\end{array}$} & $\begin{array}{l}\text { - I like to listen to people whose opinions are different from mine / I dislike } \\
\text { listening to other people's opinions (reverse coded). }\end{array}$ \\
\hline & $\begin{array}{l}\text { - Science helps to make life better / Scientific discoveries are doing more harm } \\
\text { than good (reverse coded). }\end{array}$ \\
\hline & $\begin{array}{l}\text { - I am curious about the world in which we live / I find it boring to hear about new } \\
\text { ideas (reverse coded). }\end{array}$ \\
\hline & $\begin{array}{l}\text { - Money spent on science is well worth spending / Money used on scientific } \\
\text { projects is wasted (reverse coded). }\end{array}$ \\
\hline \multirow{3}{*}{$\begin{array}{l}\text { 2. Opinion on } \\
\text { Science } \\
\text { Prediction } \\
\text { Exercises: } \\
\text { Same 5-point } \\
\text { scale as above }\end{array}$} & $\begin{array}{l}\text { - These exercises made me more aware of the significance of science in our } \\
\text { everyday life. }\end{array}$ \\
\hline & $\begin{array}{l}\text { - These exercises made me more aware of how science can explain everyday } \\
\text { events. }\end{array}$ \\
\hline & $\begin{array}{l}\text { These exercises impacted my view on how science enables us to make } \\
\text { useful predictions. }\end{array}$ \\
\hline \multirow{2}{*}{$\begin{array}{l}\text { 3. Willingness } \\
\text { to Take } \\
\text { Political } \\
\text { Climate } \\
\text { Actions: Binary } \\
\text { scale (yes/no) }\end{array}$} & - Participate in a climate-action demonstration. \\
\hline & $\begin{array}{l}\text { - Vote for political candidates and legislations that promote policies that help } \\
\text { create a more sustainable planet. }\end{array}$ \\
\hline \multirow{6}{*}{$\begin{array}{l}\text { 4. Willingness } \\
\text { to Take } \\
\text { Personal } \\
\text { Climate } \\
\text { Actions: Binary } \\
\text { scale (yes/no) }\end{array}$} & $\begin{array}{l}\text { - Reduce carbon dioxide emission by planting trees, cacti, or other vegetation } \\
\text { appropriate for my local climate. }\end{array}$ \\
\hline & $\begin{array}{l}\text { - Buy products from companies that are environmentally responsible (when } \\
\text { affordable). }\end{array}$ \\
\hline & - Eat less beef and dairy to reduce methane emission. \\
\hline & - Use public transportation. \\
\hline & $\begin{array}{l}\text { - Buy only what I need: avoid buying excess groceries and buy fewer clothes, } \\
\text { because the production and delivery of goods typically require fossil fuel. }\end{array}$ \\
\hline & $\begin{array}{l}\text { - Support the use of renewable energy (e.g., wind, water and solar power) } \\
\text { through personal action (e.g., installing solar panels, using a hybrid/electric car) } \\
\text { when affordable. }\end{array}$ \\
\hline
\end{tabular}




\begin{tabular}{|c|c|}
\hline \multirow{5}{*}{$\begin{array}{l}\text { 5. Willingness } \\
\text { to Take } \\
\text { Personal Pro- } \\
\text { Environment } \\
\text { Actions: Binary } \\
\text { scale (yes/no) }\end{array}$} & - Buy clothes from thrift stores / donate or sell clothes for re-use. \\
\hline & $\begin{array}{l}\text { - Use appropriate layers of warm or cool clothing as your personalized heater/air } \\
\text { conditioner. }\end{array}$ \\
\hline & $\begin{array}{l}\text { - Avoid single-use plastic items (e.g., plastic straws, grocery bags, foam to-go } \\
\text { boxes, plastic shampoo bottles) when affordable. }\end{array}$ \\
\hline & - Shop online only if an item is not available in your local store(s). \\
\hline & - Turn appliances off / unplug appliances when not in use. \\
\hline \multirow{3}{*}{$\begin{array}{l}\text { 6. Science-Fact } \\
\text { Knowledge } \\
\text { Questions } \\
\text { (Kennedy \& } \\
\text { Hefferon, 2019): } \\
\text { Multiple choice }\end{array}$} & $\begin{array}{l}\text { - What is the main cause of seasons on Earth? (Correct answer: The tilt of the } \\
\text { Earth's axis in relation to the plane of its orbit around the Sun). }\end{array}$ \\
\hline & $\begin{array}{l}\text { When large areas of forest are removed so land can be converted for other } \\
\text { uses, such as farming, which of the following occurs? (Correct answer: } \\
\text { Increased soil erosion). }\end{array}$ \\
\hline & $\begin{array}{l}\text { - An antacid relives an overly acidic stomach because the main components of } \\
\text { antacids are? (Correct answer: Bases). }\end{array}$ \\
\hline $\begin{array}{l}\text { 7. Demographic } \\
\text { Information: } \\
\text { Multiple-choice }\end{array}$ & $\begin{array}{l}\text { - } \text { Age: drop-down options between } 17 \text { and } 86 \\
\text { - Gender: Male, Female, Other (Specify) } \\
\text { - Educational level (highest attained): Less than high school degree, High school } \\
\text { degree or equivalent, Bachelor's degree, Master's degree, Doctoral degree (PhD, } \\
\text { JD, MD, etc.) } \\
\text { - Political identity: Extremely Conservative, Moderately Conservative, Moderately } \\
\text { Liberal, Extremely Liberal, Libertarian, Independent }\end{array}$ \\
\hline
\end{tabular}

\subsubsection{Dependent measures in Phase 2}

Participants who returned to the follow-up session were asked about the same set of moral actions listed in items 3, 4, and 5 in Table 3, except for the modification of "willingness to take an action" as explained below. The actions were presented in the same mixed order across conditions. The opening instruction asked, using the positive wording as before, "In the past two years, which actions have you taken to protect and support the flourishing of our planet?" The actions were shown one by one, each on a separate screen. The first 4 actions - eating less beef, buying only what is needed, turning appliances off when not in use, and using appropriate layers of warm or cool clothing - were those that we judged everyone would have had opportunities to take. For these, participants were directly asked a "yes/no" question: for example, "Have you been buying only what you need: have you avoided buying excess groceries and bought fewer clothes, because the production and delivery of goods typically require fossil fuel?"

The survey then went on to introduce the remaining set of moral items, for which taking the action may not have been an option. The instructions explained, "Depending on your neighborhood or your living conditions, taking these actions may not have been an option (e.g., public transit is not available in your area, certain goods are not affordable or accessible)". For these items, participants were first asked whether they have had opportunities to take the action in the intervening time; for example, "In the past two years, have you had an opportunity to vote for political candidates who advocate policies that help create a more sustainable planet, such as drastically phasing out fossil fuel?" If they answered "yes", they were further asked whether they have taken the action. Otherwise, they were further asked whether they would have 
taken the action if they could. The first branch of the conditional question measures having taken the action in the interim two years. The second branch is a measure of sustained willingness to take the action.

\subsubsection{Statistical analysis specifics}

All regression analyses were conducted in R Studio (v. 1.2.5). Ordinal regressions were conducted using the 'ordinal' package. Multiple linear regressions were conducted using the base $\operatorname{Im}()$ function in R. Simple effects were estimated using the "emmeans" package - explanatory variables were fixed at values of interest (e.g., levels of political identity, levels of science knowledge); when no particular value was of special interest, variables were fixed at the mean of that variable.

All ANCOVAs and MANCOVAs were conducted in SPSS (v. 26). Estimated marginal means were estimated by selecting to output "EMMEANS". To perform the Holm-Bonferroni correction for multiple comparisons, we chose the "LSD" correction (i.e., no correction) and adjusted the $p$-values by hand afterwards. To output the estimated marginal means, the default in SPSS is to fix all explanatory variables at the mean for that variable. In order to fix certain explanatory variables at different values, we adjusted the syntax for the EMMEANS command by changing 'MEAN' to our value of interest.

\subsection{Results}

\subsubsection{Overview of analyses}

We report our findings on how willingness to take political climate actions was associated with, or affected by, the following predictor (1) and independent $(2,3)$ variables:

1) participants' political identity and level of science literacy measured in terms of science-fact knowledge,

2) the moral-identity/farmers question depending on whether it was embedded in its complementary components in the Full-coherence condition (i.e., both the general- and climate-science-prediction exercises), and

3) the climate-science-prediction exercise depending on whether it was embedded in its complementary components in the Full-coherence condition (i.e., the moral-identity question and general-science-prediction exercises).

The independent variables test our cognitive-constraints hypothesis. More specifically, they test whether the components we proposed as essential for forming a coherent personal pro-climate-action narrative identifying as someone morally responsible for the consequences of climate change, ACC information, and resonance with the parsimony of scientific explanations of everyday events - are indeed essential. Last but not least, we report the effects of our science materials on appreciation of scientific explanations and openness to alternative opinions. All statistical tests are two-tailed except those with directional differences predicted by our cognitive-constraints hypothesis.

\subsubsection{Political identity and science literacy}

We first assessed whether the population from which we sampled shows a polarization of climate attitudes similar to that previously observed (Drummond \& Fischhoff, 2017; Funk \& Kennedy, 2020; Kahan et al., 2012). 
Fig. 2 shows that our sample displays the familiar pattern of polarized climate attitudes as a function of political identity and science literacy. Averaging across educational levels, liberals' odds of selecting an additional political climate action increased with science-fact knowledge, $O R=2.55, p<.001$, whereas conservatives' odds of doing so decreased with it, $O R=0.55, p=.021$. The interaction between political identity and science literacy was highly significant, $O R=1.53, p<.001$. (Education level was not significant, $O R=1.19, p=.19$, hence the averaging over those levels for the estimated probabilities in the figure.)

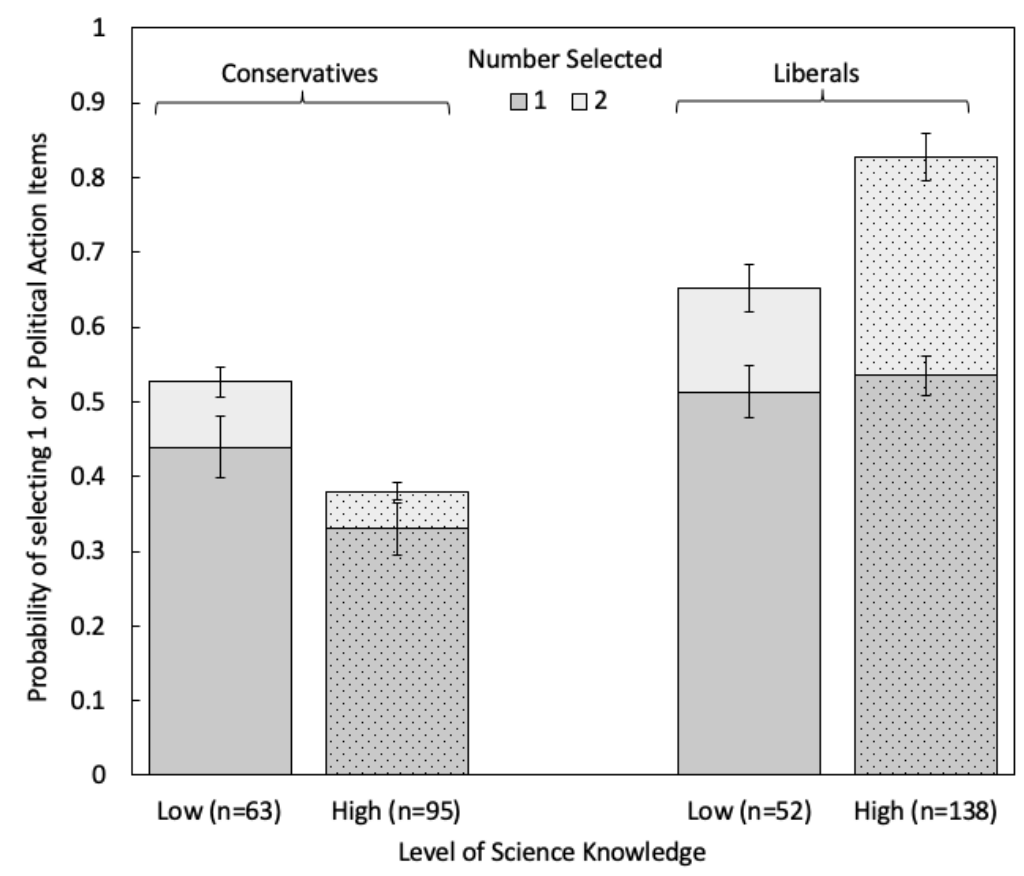

Fig. 2. Estimated probabilities of selecting 0,1 , or 2 political climate actions across different political identity and science-fact knowledge levels. To obtain these values, an ordinal regression analysis was conducted with political identity (self-reported conservatives vs. liberals), level of science-fact knowledge (high vs low), and the interaction between the two as predictors, controlling for education level (high school diploma or below, college degree, and postgraduate) by incorporating it as a covariate. In this and all other figures, error bars indicate 1 S.E. In all figures except Fig. 7, the unmarked height above each bar indicates the estimated probability of selecting zero action.

\subsubsection{Two tests of effect of coherence on willingness to take political climate actions}

To test our cognitive-constraints hypothesis, we separately analyzed the two $2 \times 2$ designs in Tables $2 a$ and $2 \mathrm{~b}$. As explained earlier, each design independently varied one component (e.g., the moralidentity/farmers question) and the combined two components complementary to it (the general-scienceand climate-science-prediction exercises) that all together constitute the "Full coherence" materials.

\subsubsection{Moral identity and complementary coherence}

Fig. 3 displays the estimated probabilities of selecting neither, one, or both of the political climate actions in the 2 × 2 design in Table 2a (see bars labelled "Moral identity Present" and "Moral identity Absent" respectively within the figure and bars labelled "Present" and "Absent" respectively on the abscissa 
representing the "complementary coherence questions" (i.e., the combination of the general- and climatescience-prediction exercises). The bars in the figure are labeled with letters referring to the rows in the list of conditions in Table 1. Recall that our cognitive-constraints hypothesis predicts that groups with all three requisite components for constructing a coherent personal climate-action narrative are more likely to take climate actions than those missing a component. Accordingly, all pairwise comparisons between the Fullcoherence condition and every other condition will report one-tailed $p$-values. But because the cognitiveconstraints hypothesis does not predict any difference (in any particular direction) between the partial and control conditions, those pairwise comparisons will report two-tailed $p$-values.

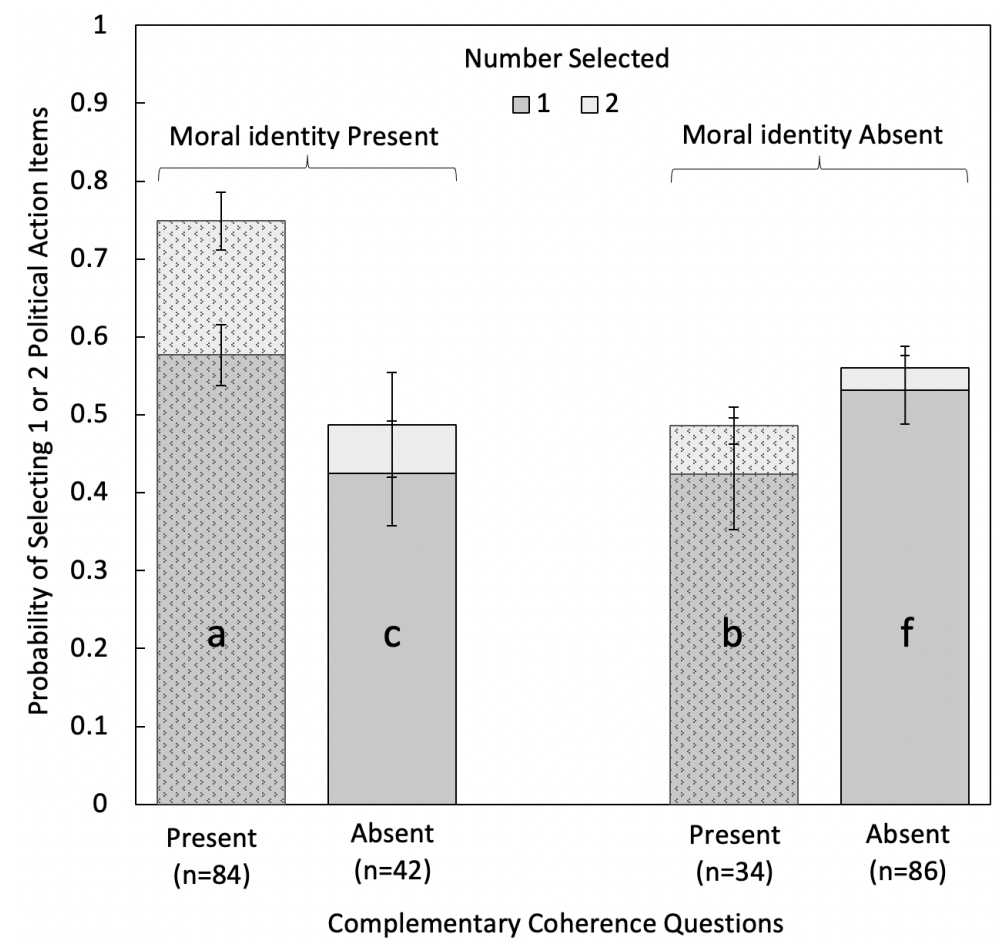

Fig. 3. Estimated probabilities of selecting 0, 1, or 2 political climate actions across experimental conditions. To obtain these values, an ordinal logistic regression was conducted with the moral-identity/farmers question, its complementary-coherence questions (i.e., the general- and climate-science-prediction exercises), and the interaction between the two as fixed factors, controlling for political identity (selfidentified extreme conservatives, moderate conservatives, moderate liberals, and extreme liberals), science-fact knowledge $(0,1,2,3)$, and educational level (high school diploma or below, college degree, and postgraduate) by incorporating them as covariates. The bars are labeled with letters referring to the rows in Table 1.

As Fig. 3 shows, the complementary coherence questions and the moral-identity/farmers question enhanced each other's effect on participants' willingness to take political climate actions. Neither the moralidentity question alone (bar $c$, corresponding to row $c$ of Table 1 ), $O R=0.53, p=.098$, nor the scienceprediction exercises alone (bar $b$, corresponding to row $b$ of Table 1 ), $O R=0.53, p=.12$, significantly changed the odds of selecting an additional political climate action, relative to the Control condition (bar $\mathrm{f}$, 
corresponding to row $\mathrm{f}$ of Table 1 ) in which neither was present. With the moral-identity question present, however, the science exercises (bar a, corresponding to row a of Table 1) more than tripled the odds of selecting an additional action, $O R=3.14, p=.002$, relative to the absence of the science exercises (bar $c$ ). Conversely, with the science exercises present, the moral-identity question (bar a) more than tripled the odds of selecting an additional action, $O R=3.15, p=.003$, relative to the absence of the moral-identity question (bar b). The interaction between the moral-identity and science exercises was highly significant, $O R=5.98, p<.001$. The mutual enhancement of the effects by the moral-identity and science questions strongly supports the cognitive-constraints hypothesis.

Liberals and conservatives did not significantly differ on the interaction between moral identity and complementary coherence, $O R=0.41, p=.44$. This result was obtained by a three-way factorial ordinallogistic regression on the frequencies of selecting 0,1 , or 2 political climate actions with the moral-identity question, the complementary-coherence questions, and political identity (conservative vs. liberal) as fixed factors, controlling for science-fact knowledge and educational level by incorporating them as covariates. Compared to the Moral-identity-only condition, adding the complementary-coherence questions raised the probability of selecting political climate actions for both conservatives and liberals, significantly so for conservatives, $O R=3.89, p=.03$, and marginally so for liberals, $O R=2.49, p=.07$.

We considered an alternative explanation of our pattern of findings: the moral-identity question might simply prime empathy toward the suicidal farmers, and trigger a broad generalization of that empathy. On this "empathy" hypothesis, the Moral-identity-only condition should raise willingness to take climate actions compared to the Control condition. In fact, as just reported, it did not (compare bar $\mathrm{c}$ to bar $\mathrm{f}$ in Fig. 3). Thus, empathy alone cannot explain why the moral-identity question enhanced the intervention effect of the science exercises.

A second alternative explanation is that the moral-identity question might have simply engaged and sustained attention throughout the subsequent science-prediction exercises, thus raising their efficacy. On this "attention" hypothesis, whether the moral-identity question is asked after rather than before the set of science exercises should make a difference. To test this hypothesis, we compared the conditions in which the moral-identity question was asked first (condition a) versus last, after the set of science exercises (supplementary condition g). Results show that presenting the moral-identity question before $(M=0.86, S E$ $=0.079)$ versus after all the science exercises $(M=0.80, S E=0.109)$ did not change the odds of selecting an additional political climate action, $O R=0.98, p=.955$. The Moral-identity-last condition more than tripled that odds, $O R=3.23, p=.009$, compared to the All-but-moral-identity condition (condition $\mathrm{b}$ ), in which the question was omitted. Thus, increased attention to the science exercises cannot explain why the moralidentity question boosted their effect.

The Control participants' probability of selecting a climate action is surprisingly high. One probable cause is the positive wording of our moral-action instructions, which stated (uniformly across conditions), "As individuals, we each can take impactful actions to protect and support the flourishing of our planet. To that end, what actions are you willing to take?" Highlighting positive actions that individuals can take to promote 
a better society has been found to increase intention to take pro-environment actions (Bain et al., 2012). We used the positive wording because our goal is to promote sustainability actions. However, the positive wording might have produced an experimenter-demand effect to which some Control participants might have been especially susceptible.

An interacting probable cause is that all but the Control condition had exercises that required participants to explain their answers. In those exercises, a small but nonnegligible percentage of participants gave nonsensical explanations such as "good" repeatedly across exercises. Those participants were excluded. Lacking those exercises, the Control condition would almost certainly have a disproportionately high proportion who would otherwise have given nonsensical responses. These inadvertently included participants may have been more likely than others to be affected by the experimenter demand due to the positive wording: they may have indicated willingness to take climate actions greater than their true assessments. If so, the mean willingness probabilities in the Control condition would have been artifactually inflated.

The ambiguity of the interpretation of the willingness responses in the Control condition is unsatisfactory. We return to the issue after examining the results in the next section.

\subsubsection{Climate and complementary coherence}

Fig. 4 displays the estimated probabilities of selecting neither, one, or both of the political climate actions in the four conditions in which the climate-science-prediction exercise and its complement in the Fullcoherence condition were independently varied (see bars denoted "Climate Present" and "Climate Absent" respectively in the figure and bars labelled "Present" and "Absent" respectively on the abscissa). "Complementary coherence questions" here denotes the combination of the moral-identity/farmers question and general-science-prediction exercises. The bars are labeled with letters referring to the rows in Table 1. As in section 2.3.3.1, all pairwise comparisons between the Full-coherence condition and every other condition will report one-tailed $p$-values. Because the cognitive-constraints hypothesis does not predict any difference (in any particular direction) between the partial and control conditions, those pairwise comparisons will report two-tailed $p$-values. 


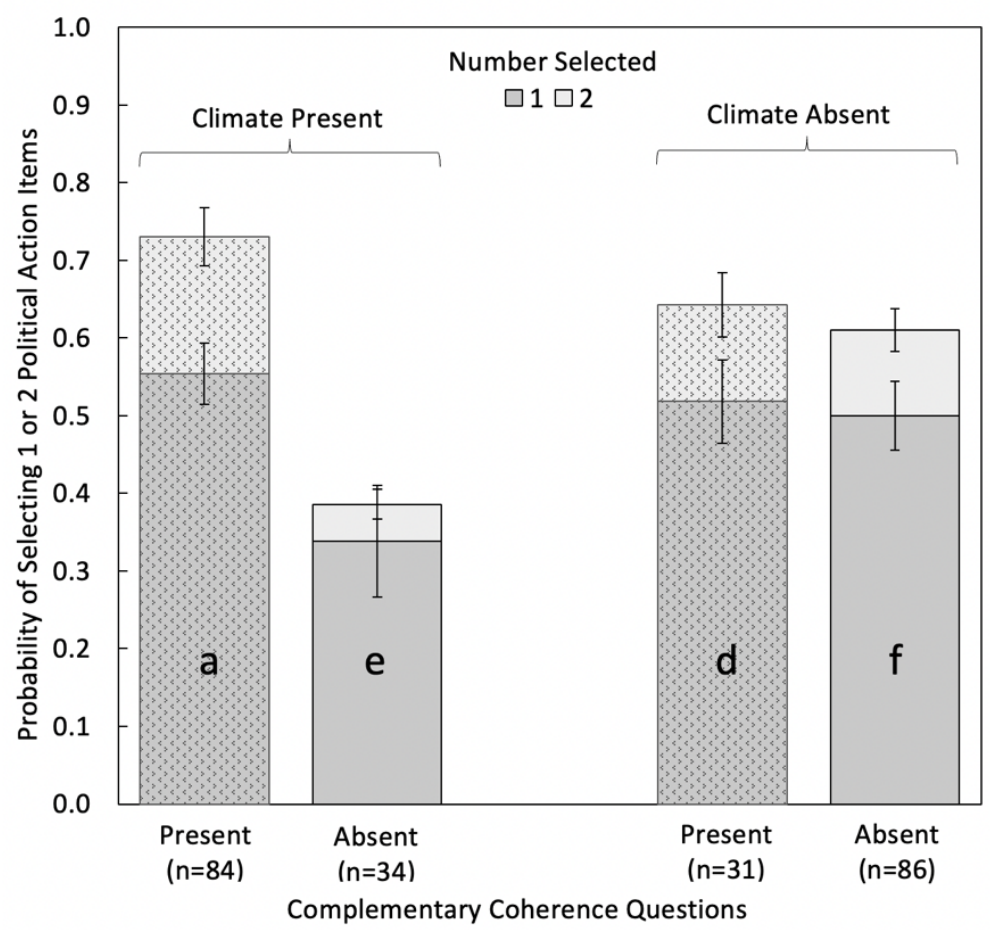

Fig. 4. Estimated probabilities of selecting 0,1 , or 2 political climate actions across experimental conditions. The model for this analysis was identical to that for Fig. 3 except that the fixed factors were the climatescience-prediction exercise, its complementary-coherence questions, and the interaction between them. "Complementary coherence questions" here denotes the combination of the moral-identity/farmers question and general-science-prediction exercises. The bars are labeled with letters referring to the rows in Table 1.

The complementary-coherence questions alone (bar $d$, corresponding to row $d$ of Table 1) did not significantly change the odds of selecting an additional political climate action relative to the Control condition (bar f), $O R=1.15, p=.73$. With the climate-science-prediction exercise present, however, the complementary-coherence questions (bar a) more than quadrupled the odds of selecting one more political action, $O R=4.31, p<.001$, relative to the absence of the complementary-coherence questions (bar e). The climate-science-prediction exercise alone (bar e, corresponding to row e of Table 1) apparently had a negative effect, $O R=0.40, p=.032$, in that the presence of the climate question decreased the odds of selecting an additional political climate action relative to the Control (bar $\mathrm{f}$ ). This difference need not reflect a backfire effect given the just-mentioned ambiguity in the interpretation of the responses in the Control condition. The effect of the climate exercise turned positive in the presence of its complementary-coherence questions (bar a), but the exercise did not significantly raise that odds, $O R=1.50, p=.15$, relative to the 
complementary-coherence questions without the climate exercise (bar d). The interaction between the two factors was significant, $O R=3.74, p=.012$, adding support to the cognitive-constraints hypothesis.

Liberals and conservatives did not significantly differ in the interaction between climate and complementary coherence, $O R=1.37, p=.79$. This result was obtained by a three-way factorial ordinallogistic regression analogous to that for the interaction between moral-identity and complementary coherence. Compared to the climate-only condition, adding the complementary-coherence questions raised the probability of selecting political climate actions for both conservatives and liberals, significantly so for liberals, $O R=6.52, p<.001$, although not for conservatives, $O R=1.69, p=.42$ [for this analysis, the sample size happens to be very small for conservatives who had low-science-fact knowledge $(n=3)$, the subgroup for whom the benefit of the complementary-coherence questions was the greatest].

Corroborating the cognitive-constraints interpretation of our findings on political climate actions (Figs. 1 \& 2), our interventions had a similar although weaker effect on personal climate actions, but no effect on personal pro-environment actions. The specific effect of our interventions on climate actions rules out a general "positive mindset" as an explanation of our findings. (See Supplementary Results for analyses of these two types of moral actions.)

The effectiveness of the various conditions cannot be explained by the number of questions in the condition or the amount of time spent. For example, although the moral-identity/farmers question by itself, which took a median of $7.2 \mathrm{~min}$, had no effect on willingness to take climate actions, omitting it from the full-coherence condition reduced such willingness by as much as omitting all eight science-prediction exercises, which took a median of $24.8 \mathrm{~min}$.

\subsubsection{A two-year follow-up assessment}

We turn now to address the unexpectedly high mean willingness probabilities in the Control condition. Recall that the Control condition, compared to other conditions, likely included more participants who would be susceptible to the experimenter-demand effect in light of the positive wording of our questions. To bring more closure to the interpretation of this condition, we conducted a follow-up (Phase 2) assessment after an approximately two-year delay to see whether participants in the various conditions actually took the moral actions they were asked about. Comparing the validities of a willingness response and a report of behavior, our conjecture is that people would be more resistant toward responding that they have taken a moral action when they in fact have not than responding that they are willing to take such an action when they in fact are unwilling. Thus, asking returning participants about whether they took the moral actions should reduce the experimenter-demand effect that might have affected the Control condition more than other conditions.

Importantly, this longitudinal assessment also allows us to assess whether participants' willingness responses predict their subsequent behavior. In other words, did the differences across conditions in 
willingness to take an action in Phase 1 manifest as analogous differences in reports of taking the action in Phase 2?

Participants who returned $(N=88)$ were presented again with the set of moral actions in Phase 1 . As mentioned, this time they were asked whether they have taken the action or would have taken it had the opportunity existed. As in our preceding analyses, the actions were grouped into three categories: political climate ( 2 actions), personal climate (6 actions), and personal pro-environment (5 actions) (see Table 3 ). The composite score for each group is the number of actions a participant reported to have taken or would have taken.

Table 4 summarizes the distribution of return participants across conditions who identified as liberals and conservatives in Phase 1. Recall that the Full-coherence and Control conditions were in both of the 2 $x 2$ designs in Tables $2 a$ and $2 b$ respectively; their sample sizes therefore approximately doubled those of the other conditions. The Partial-coherence conditions in Table 4 consist of all conditions aside from the Full and Control conditions (i.e., All-but-moral-identity, Moral-identity only, All-but-climate-prediction, Climate-prediction only); return participants in these conditions are pooled because the sample sizes in each are too small for meaningful $2 \times 2$ analyses as conducted for our Phase 1 data.

The average between-phase interval was close to 700 days for return participants in the Full condition $\left(M_{F}=693.5\right.$ days, $\left.S D_{F}=18.7\right)$, Partial conditions $\left(M_{P}=695.6\right.$ days, $\left.S D_{P}=13.3\right)$, and Control Condition $\left(M_{C}\right.$ $=696.9$ days, $S D_{C}=16.2$ ).

In the following four subsections, we report a series of ordinal regressions applying the three covariates in our preceding analyses: political identity, education level, and science knowledge. The first two subsections examine return participants' moral action responses in Phase 1 and Phase 2, respectively, comparing across conditions for each phase. Our cognitive constraints hypothesis predicts that, compared to participants in the Partial and Control conditions, those in the Full-coherence condition would be more willing to take climate actions, and hence more likely to report having taken those actions. The third subsection assesses the relation between the moral-action responses in Phases 1 and 2, specifically, the predictiveness of a participant's willingness responses for each of the three categories of moral actions in Phase 1 for reports of having (or would have) taken those actions in Phase 2. A fourth subsection examines whether return participants show a self-selection bias that could explain why the Full-coherence group reported a greater number of political climate actions. It compares the Phase 1 moral-action willingness responses of return participants to those in their group who did not return.

Table 4. Distribution of conservatives and liberals who returned for the two-year follow-up across conditions.

\begin{tabular}{lccc}
\hline Condition & Conservative & Liberal & Total \\
\hline Full-coherence & 12 & 13 & 25 \\
Partial-coherence & 22 & 17 & 39 \\
Control & 12 & 12 & 24 \\
Total & 46 & 42 & 88 \\
\hline
\end{tabular}




\subsection{Return participants' willingness responses in Phase 1}

To examine whether the subset of participants who returned was representative of the whole sample, we first compare the three groups of participants on their willingness responses in Phase 1. The results presented in Fig. 5 were obtained by running an ordinal logistic regression for willingness to take political climate actions in Phase 1 comparing return participants across conditions, controlling for the three covariates just mentioned. Political identity was specified at 2 rather than 4 levels here because even with only 2 levels, the number of participants in each cell of the analysis is quite small (see Table 4).

Consistent with the pattern of results in Figures 3, 4, and 8, return participants in the Full-coherence condition indicated willingness to take a greater number of political climate actions compared to those in the Partial conditions, $O R_{F, P}=3.25, p=.015$, and the Control condition, $O R_{F, C}=3.02, p=.027$. Participants in the Partial conditions did not indicate greater willingness to act relative to those in the Control condition, $O R_{P, C}=0.93, p=.45$. Notably, for the return participants as for the whole sample, there was no indication that our Full-coherence condition was any less effective for conservatives than for liberals (see Fig. 5). If anything, the effect was larger for conservatives than liberals. In a separate likelihood ratio test of cumulative link models (Christensen, 2019), we compared the above logistic model with one that included an interaction between condition and political identity; that non-directional analysis does not show evidence for an interaction between condition and political identity, $\chi^{2}(2)=3.22, p=.20$. This pattern of results suggests that the subset of participants who returned was indeed representative.

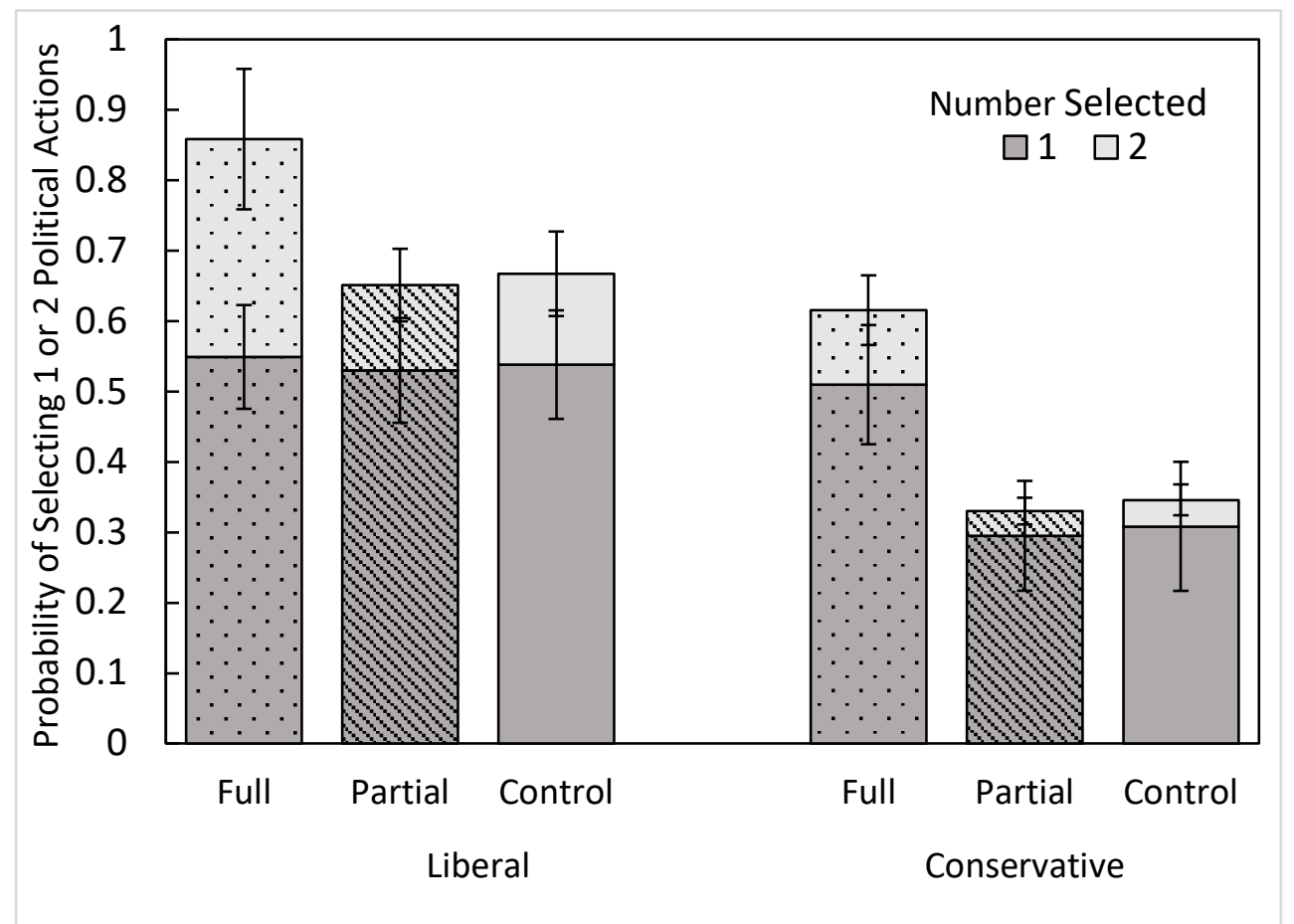

Fig. 5. Probability of responding willing to take 1 or 2 political climate actions at the end of Phase 1 among participants who returned. 
Analogous analyses were conducted for the other two categories of moral actions. For personal climate actions, the same pattern of results as above was obtained. For personal non-climate-specific pro-environment actions, the pattern of results was similar, but the difference between the Full-coherence and Control conditions did not reach statistical significance. Neither of these types of actions showed evidence for an interaction between condition and political identity. This pattern of results reflects that for the whole sample. (See Supplementary Results for details.)

\subsection{Return participants' reports of taking moral actions in Phase 2}

To assess whether our brief online intervention affected (reported) behavior during the close-to-twoyears between phases, the following ordinal logistic regression compares return participants on their responses in Phase 2. The outcome of interest throughout this section is whether participants reported having taken/would have taken the action had the opportunity existed. Most return participants $(81 \%)$ reported they had the opportunity to vote for legislations that promote sustainability, but few $(8 \%)$ reported they had the opportunity to participate in a pro-climate demonstration, likely due to the Covid-19 pandemic. The analyses and predictions are analogous to those in the preceding section.

Strongly corroborating the validity of the willingness measure in Phase 1, and in further support of the cognitive-constraints hypothesis, return participants in the Full-coherence condition were more likely to report having taken/would have taken additional political climate actions compared to those in the Control condition, $O R_{F, C}=2.95, p=.035$, but those in the Partial conditions did not, $O R_{P, C}=1.74, p=.167$. However, the Full-coherence return participants were not more likely to report taking more of these actions compared to those in the Partial conditions, $O R_{F, P}=1.70, p=.15$. As before, the differences between conditions show a similar pattern across conservatives and liberals, with conservatives showing a clearer effect (see Fig. 6). A separate likelihood ratio test of cumulative link models does not show a significant interaction between condition and political identity, $\chi^{2}(2)=3.11, p=.21$.

Analogous analyses were conducted for the other two categories of moral actions. For personal climate actions, a similar pattern of results obtained, except the Full-coherence condition was significantly more likely to report taking additional such actions compared to the Partial conditions, $O R_{F, P}=3.00, p$ $=.01$. Note that four of the six actions in this category concern everyday choices that most participants would have had the opportunity to take (see Supplementary Results for details). Remarkably, the greater number of personal climate actions reported by Full-coherence participants than by other participants suggests that our intervention affected people's everyday choices over the interim two years.

For personal pro-environment actions, there were no significant differences between groups. As for our other dependent measures, the climate-specific effect of our intervention rules out a general "positive mindset" as an explanation of our findings. Neither of these types of actions showed evidence for an interaction between condition and political identity. (See Supplementary Results for details.) 


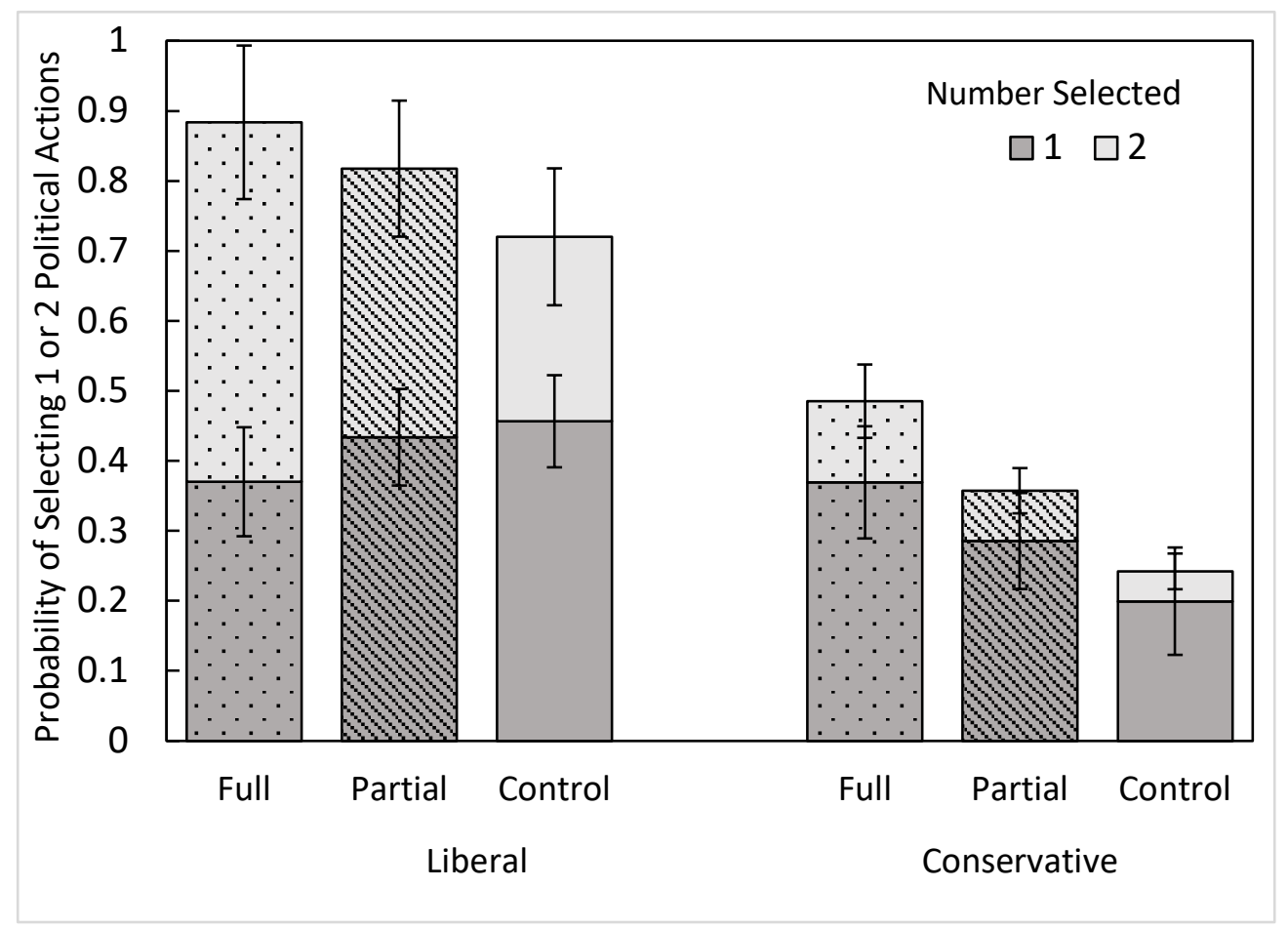

Fig. 6. Probability of selecting having taken (or would have taken had the opportunity existed) 1 or 2 political climate actions in Phase 2 for participants who returned.

It is difficult to interpret why the Partial conditions' political climate-action responses are descriptively closer to the Full-coherence condition's in Phase 2 (Fig. 6) relative to Phase 1 (Fig. 5). Note that, for any number of reasons, liberal Partial participants' Phase 2 responses have substantially higher variability compared to their Phase 1 responses, adding to the uncertainty of any answer. If we are to offer an interpretation of the descriptively closer responses, however, one possibility is that once Partial participants who previously lacked an essential component of a political climate-action narrative were provided with that component in Phase 1, they had fewer missing components to fill in on their own during the two-year interim.

Recall that it was unclear whether the Climate-only condition had a backfire effect. Among the return participants, there was no difference between the estimated mean probability of reporting taking a political climate action for the Climate-only condition (0.64) and Control condition (0.63), suggesting that there was no backfire effect. This finding supports our conjecture that, compared to willingness-to-act responses, reports on actual actions are less likely to be subject to experimenter-demand effects, and that the Control condition's surprisingly high mean willingness response in Phase 1 was likely artifactually inflated.

In summary, the Full-coherence return participants' consistently higher probabilities of reports of taking additional political and personal climate actions in Phase 2 compared to their Control counterparts' reinforce and clarify the effect of our intervention in Phase 1. 


\subsection{Predictiveness of willingness to act in Phase 1 for reporting actually having acted or would have acted in Phase 2}

The following analysis examines how well participants' Phase 2 reports of taking a political climate action are predicted using their willingness responses from Phase 1 as the primary predictor. The result below was obtained by running an ordinal logistic regression for political climate actions, controlling for political identity (4 levels: moderately/extremely conservative, moderate/extremely liberal), education, and science knowledge. The to-be-predicted outcome is whether a participant reported having taken an action/would have taken the action if they had the opportunity. We report two-tailed $p$-values here, because we do not have an a priori hypothesis on the predictiveness. Political identity as a covariate is set at 4 levels here to better rule out this variable as a confounding factor that predicts Phase 2 responses. (Setting this covariate at 2 levels gives a similar pattern of results.)

The more political climate actions participants responded they were willing to take in Phase 1, the more likely they were to report a greater number of these actions they have actually (or would have) followed through two years later, $O R=4.46, p<.001$.

Analogous analyses were conducted for the other two categories of moral actions. For personal climate actions, similarly high predictiveness was found. For personal pro-environment actions, slightly lower but nonetheless significant predictiveness was found. (See Supplementary Results for details.) It is unlikely that participants would remember their willingness responses to the 13 moral items in the brief online survey taken two years ago.

The high predictiveness of the willingness responses in Phase 1 for the moral-action responses in Phase 2 for all three categories of moral actions validates both our willingness-to-act and report-of-action measures. More specifically, it corroborates our just reported findings on the effectiveness of our intervention in promoting climate action.

\subsection{Ruling out self-selection bias}

To ensure that the results above are not due to return participants having a self-selection bias, we compare the Phase 1 willingness responses of the return participants to those of participants who did not return. It is possible that our interventions caused participants who were more concerned with ACC to return, rather than influenced them in the ways suggested by their responses at face value. It is especially critical to verify that the Full-coherence return participants did not show this "positive" self-selection bias. To examine this possible bias, we conducted an ordinal logistic regression for each of the three groups of participants, controlling for political identity (4 levels: moderately/extremely conservative, moderate/extremely liberal), education level, and science knowledge. We report analyses of all three moral-action categories in order to detect the bias in any category. Because our hypothesis does not make a prediction about any characteristics of participants who chose to return or not, all reported $p$-values here are two-tailed. Political identity as a covariate is again set at 4 levels here to better control for this confounding variable. (Setting this covariate at 2 levels gives a similar pattern of results.) 
2.4.3.3.4.1 Full-coherence condition. Within the Full-coherence condition, there was no difference for any of the moral-action categories in the number of actions that return participants indicated they were willing to take compared to those who did not return. For political climate actions, return participants indicated being willing to take a similar number $\left(M_{R}=1.00\right)$ as those who did not return $\left(M_{N R}=0.97\right), O R_{R, N R}$ $=1.26, p=.62$. There was also no difference between the two subsets in the number of indicated personal climate actions $\left(M_{R}=4.04, M_{N R}=3.53\right), O R_{R, N R}=1.70, p=.23$, or the number of indicated personal proenvironment actions $\left(M_{R}=2.80, M_{N R}=2.73\right), O R_{R, N R}=1.11, p=.82$.

2.4.3.3. 2 Partial-coherence conditions. Within the Partial conditions, there was likewise no indication of a difference in the number of political climate actions that return participants indicated they were willing to take $\left(M_{R}=0.33\right)$ compared to those who did not return $\left(M_{N R}=0.63\right), O R_{R, N R}=0.68, p=.33$.

However, for personal climate actions, participants who did not return indicated being willing to take a greater number $\left(M_{N R}=3.42\right)$ than those who returned $\left(M_{R}=2.13\right), O R_{N R, R}=2.07, p=.029$; the same holds for personal pro-environment actions $\left(M_{N R}=2.85, M_{R}=2.00\right), O R_{N R, R}=2.37, p=.013$. It is unclear what explains a "negative" selection bias. It seems implausible that our study caused those who were more willing to take those actions to choose not to return. A more plausible possibility is that participants who took our initial survey more seriously may have been more likely to return, and they gave more authentic, less experimenter-demand-driven responses than those who took our survey less seriously.

2.4.3.3.4.3 Control condition. Within the Control condition, as for the Full-coherence condition, there was no difference for any of the moral-action categories in the number of actions that return participants indicated they were willing to take compared to those who did not return. For political climate actions, return participants indicated they were willing to take a similar number $\left(M_{R}=0.50\right)$ as those who did not return $\left(M_{N R}=0.56\right), O R_{R, N R}=0.71, p=.48$. There was also no difference in the number of indicated personal climate actions $\left(M_{R}=2.67, M_{N R}=2.94\right), O R_{R, N R}=0.86, p=.73$, or in the number of indicated personal proenvironment actions $\left(M_{R}=2.83, M_{N R}=2.82\right), O R_{R, N R}=.86, p=.74$.

2.4.3.3.4.4 Summary. To summarize, for all three conditions, there was no indication of a difference in the number of political climate actions that return participants indicated they were willing to take compared to those who did not return. A self-selection bias therefore cannot explain our just reported Phase 1 and Phase 2 patterns of results on political climate actions (see Figures 5 and 6).

For personal climate actions, the two subsets of participants in neither the Full-coherence nor the Control condition differed from each other on the number of such actions they indicated being willing to take. Thus, a self-selection bias is not a potential explanation of our Phase 2 results showing that, compared to the Control condition, our Full-coherence intervention led to a higher probability of reporting more personal climate actions. For personal pro-environment actions, these two conditions did not differ on either their indicated willingness to act or reports of having acted; neither was there a selection bias for either condition for this category of actions.

In view of the "negative" self-selection bias for personal climate actions among Partial-coherence return participants, it is possible that our Partial-coherence interventions raised willingness to take such actions 
during the interim two years. However, our results do not allow a clear interpretation. But if that turns out to be the case, then the high predictiveness of participants' Phase 1 willingness response for their Phase 2 response would suggest that the number of climate actions reported by Partial participants in Phase 2 shifted higher relative to the shifts by participants in other conditions, but the ordering of those numbers remains stable across phases and conditions.

\subsubsection{Conclusion on promoting climate actions}

In conclusion, our analyses indicate that our brief one-time online Full-coherence intervention, compared to the Control condition, not only raised participants' willingness to take more political and personal climate actions in the immediate assessment, but likely also led them to take such actions during the interim two years. The effect of the Partial-coherence intervention is intriguing but ambiguous, and awaits future research.

It is rare for belief-revision interventions to have an effect that lasts for more than several weeks or months. For example, popular interventions such as inoculation against disinformation (Maertens et al., 2021) and endorsement of growth-mindsets for academic achievement (Sisk et al., 2018) apparently completely dissipate their effects after two and four months, respectively; Horne et al.'s (2015) intervention on vaccine skeptics that emphasized the risks of not vaccinating showed a significant immediate effect, but in a successful replication study, the effect was unclear after one week (personal communication with Derek Powell via email, received permission to quote, September 2022); and Maertens et al. (2020), in their successful replication of the effect of messaging scientists' consensus on ACC (Lewandowsky, Gignac, \& Vaughan, 2013), found that the effect shows partial decay after one week. All of these interventions involved confronting entrenched countervailing societal or personal narratives. It seems that none involved harnessing cognitive constraints to foster a competing pro-science personal-action narrative.

The exceptional longevity of our intervention's effect on promoting climate actions speaks to the fundamental role in belief formation played by the coherence and causal invariance constraints, a role that follows from the view that belief formation occurs as a search in an infinite space of possible representations of reality, and cognitive constraints are essential for enabling the possibility of solutions. Our approach is but one among other ways of making use of cognitive science to effectively promote climate actions.

\subsubsection{Effect of general-science exercises on science appreciation in Phase 1}

Our experimental design allows an assessment of our general-science-prediction exercises on raising science awareness and appreciation. We analyzed Phase 1 data in the four conditions in Table 1 that included any science exercise (conditions $a, b, d$ and e) to compare the conditions with and without the general-science-prediction exercises. Fig. 7 displays the estimated marginal means of three questions on raised science appreciation and awareness in these conditions.

The mean agreement ratings on all three science-appreciation questions for those conditions with general-science-prediction exercises were consistently higher than those for the Climate-only condition. Participants' ratings of their agreement with the statement, "These exercises made me more aware of how science can explain everyday events," differed across conditions, $F(3,176)=5.66, p=.001, \eta_{P}^{2}=0.09$. 
Holm-Bonferroni-corrected pairwise comparisons indicate that participants in the Climate-only condition gave lower ratings than those in the Full-coherence $[t(176)=4.10, p<.001, d=1.57]$, All-but-climate $[t(176)$ $=2.50, p=.026, d=0.86]$, and All-but-moral-identity conditions $[t(176)=2.30, p=.022, d=0.79]$. Our results confirm that our general-science exercises were successful in raising appreciation of scientific explanations. The other two science appreciation statements showed a similar pattern of results (see Supplementary Results for details).

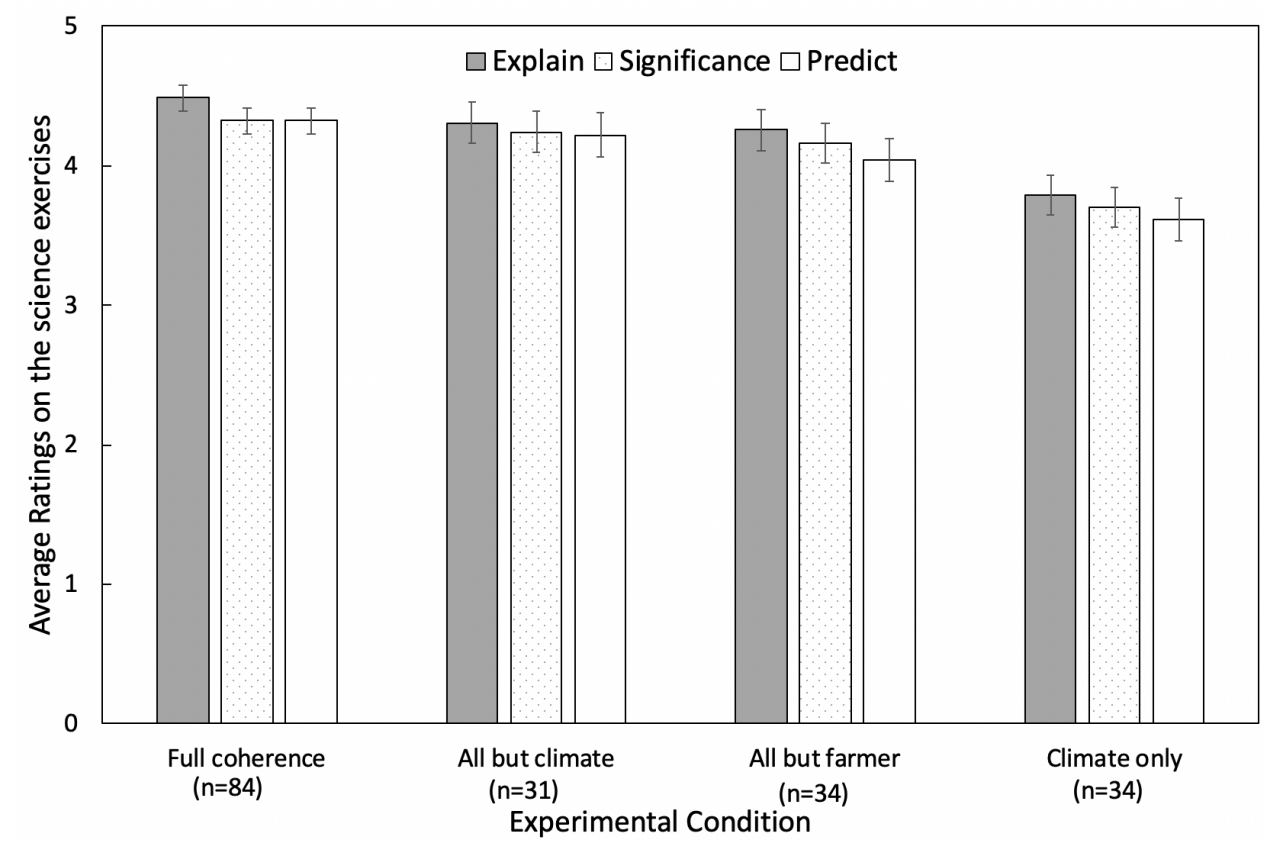

Fig. 7. Estimated marginal means of science-appreciation scores after exercises. Scores ranging from 1 (strongly disagree) to 5 (strongly agree) were analyzed in a one-way MANCOVA with experimental condition as a fixed factor, and the same covariates as the analysis for Fig. 3. Experimental condition predicted the composite variable (Wilk's Lambda $=.887, F(9,423.6)=2.37, p=.013, \eta_{P}^{2}=.039$ ), but the covariates did not (Wilk's Lambdas $>.98, p s>.40, \eta_{P}^{2}<.018$ ).

In further support of the intuitive appeal of coherent explanations, some participants spontaneously thanked us for a "thought-provoking" experience, a "highly educational" survey, or stated that they "enjoyed" the study because "it made me think". Such comments are suggestive of the educational efficacy of our materials. Notably, such positive comments came from both conservatives and liberals.

\subsubsection{General-science attitudes and openness to alternative views}

To provide additional support for the effectiveness of our general-science-prediction exercises, we conducted a MANCOVA on our general science-attitude questions (Fraser, 1981), comparing the three conditions in Table 1 that contained the general-science exercises (conditions $a, b$, and d) with the three that omitted them (conditions $\mathrm{c}$, e, and f), controlling for the same variables as the preceding analysis on 
appreciation of science. The analysis shows that participants in the general-science conditions exhibited more favorable attitudes toward science, $F(4,303)=3.09, p=.016, \eta_{P}^{2}=.039$.

Notably, consistent with the role played by the causal-invariance constraint on belief-revision, the participants who were shown general-science exercises were more open to alternative points of view than those who were not, as indicated by the former group's greater agreement with the statement, "I like to listen to people whose opinions are different from mine / I dislike listening to other people's opinions (reverse coded)", $t(306)=2.69, p=.007, d=0.43$. (Given that the parsimony of scientific explanations and their greater invariance are by no means arbitrary judgments, increased openness to alternative views does not imply reasoners would become more susceptible to believing in conspiracy theories and other disinformation.)

Both effects obtained across all four levels of political identity. (See Supplementary Figs. S1 and S2 and associated analyses.)

\subsubsection{Science facts versus explanations}

The intriguing divergence in the pattern of effects of 1) science-fact knowledge and 2) parsimony in scientific explanations warrants a closer look. Fig. 8 displays the estimated probabilities of selecting 0,1 , or 2 political climate actions for conservatives and liberals with high and low levels of science-fact knowledge in our sample for the same four conditions as in Fig. 3.

Recall that Fig. 2 shows that as science-fact knowledge increased for participants in our sample, willingness to take climate actions decreased for conservatives, but increased for liberals. However, as Fig. 8 shows, regardless of political identity, as knowledge of parsimonious scientific explanations increased, willingness to take climate actions increased: participants in the Full-coherence condition (bar a in each subgraph) were more willing to take such actions than those in the Moral-identity-only condition (bar $\mathrm{c}$ in each subgraph). These two conditions differed only in whether our parsimony-based science exercises were presented. The boost resulting from working through those exercises was greater for those with low science-fact knowledge, for both conservatives and liberals. For those with high science-fact knowledge, the boost seems greater for conservatives than for liberals, possibly due to a large proportion of such liberals coming to our study already possessing all or most essential components.

It is evidently not the case that providing science information to conservatives would itself discourage them from climate actions: what matters is whether the information involved parsimonious explanations. The divergence of the effects of the two kinds of science information highlights the crucial role played by the two cognitive constraints on belief revision. 

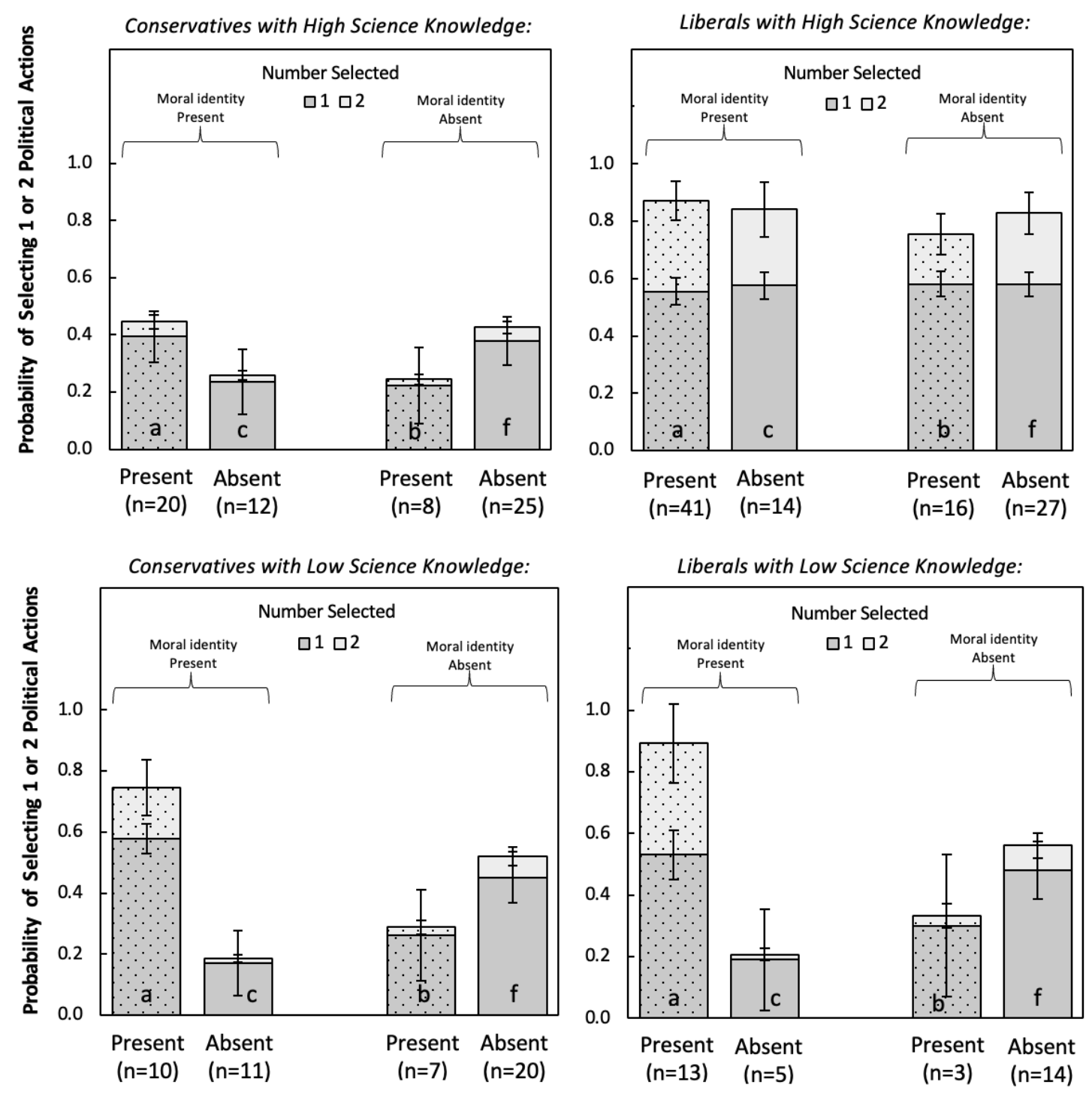

Complementary Coherence Questions

Complementary Coherence Questions

Fig. 8. Estimated probabilities of selecting 0 , 1, or 2 political climate actions across conditions, political identity, and levels of science-fact knowledge. To obtain these values, a 3-way factorial ordinal logisticregression analysis was conducted with political identity (conservative vs liberal), science knowledge (high vs low), experimental condition (treated as a nominal variable), and their interactions as fixed factors, with the full-coherence condition serving as the baseline and education as a covariate. "Complementary Coherence Questions" here denotes the combination of the general-science and climate-science exercises.

\section{Discussion}

In the polarized milieu in the U.S., where divergent information sources do not share the same "facts", efforts to promote climate actions by conveying climate science across broad sectors of "global warming's six Americas" (Leiserowitz et al., 2018) may seem futile. The results of our study offer reasons for hope. 
Our findings show that climate-change persuasion can be effective when the educational materials used leverage two basic cognitive constraints: causal invariance and coherence. Participants in the Fullcoherence condition, compared to those in other conditions, not only indicated greater willingness to take political climate actions, but also were more likely to report having taken/would have taken those actions when assessed two years later. The effect held across the political spectrum, even though conservatives with higher levels of science knowledge in our sample, compared to those with lower levels, were on average less willing to take climate actions (cf. Drummond \& Fischhoff, 2017; Funk \& Kennedy, 2020; Kahan et al., 2012).

Specifically, for both conservatives and liberals, embedding ACC information in materials on 1) incontrovertible everyday observations for which science gives explanations that are recognized as more coherent than a reasoner's own, and 2) victims suffering from a weather catastrophe that can be coherently explained by ACC, raised both willingness and likelihood to take climate actions, compared to presenting ACC information alone. Whereas resonance with the coherence of scientific explanations have these effects, knowledge of science- and climate-facts would not (cf. Drummond \& Fischhoff, 2017; Kahan et al., 2012). Science facts and skills are tools for serving specific goals, rather than general constraints essential to cognition itself, constraints that are the human mind's natural immune defense against maladaptive beliefs. Our results cannot be explained by either increased attention to the science materials or increased empathy resulting from exposure to information about extreme-weather-victims.

In further support of the paralysis-prevention role of the two cognitive constraints in belief formation, our general-science-prediction exercises increased both appreciation of scientific explanations and openness to alternative opinions. The fact that our science exercises (taking less than 25 min on average) had these more general effects suggests that current science education in the U.S. states where we conducted our study (those with the highest level of climate skepticism), but possibly in places beyond, does not often convey the parsimony of explanations in a relatable form. There is room for our approach to guide more effective science education. Materials such as ours may provide a previously unfamiliar benchmark of coherence, for science education as well as more generally.

An appeal of the cognitive-science framework is that it offers an explanation of why the two narrative proclivities identified by anthropologists, which map onto the two cognitive constraints, are universal (Ochs \& Capps, 2001): Central to the functioning of human cognition is the need to carry a coherent narrative of our lives - an adaptive solution to the problem of under-determination. Our results suggest that recognizing this need may enable us to harness its power to change minds towards more rational actions in our currently divided world.

Our findings represent a step beyond studies showing enhancement of ACC beliefs (e.g., Cook \& Lewandowsky, 2016; Lewandowsky, Gignac, \& Vaughan, 2013; Bain et al., 2012; Ranney \& Clark, 2016). We acknowledge that participants' willingness-to-act responses or their reports of having taken or would have taken a climate action do not imply actual actions. However, consistent and orderly differences in these measures across conditions should nonetheless reflect degrees of likelihood to take such actions. 
The high predictiveness of the stated willingness in Phase 1 for reports of action two years later in Phase 2 reinforces the validity of both measures.

The universal need for a coherent narrative paradoxically governs even conspiracy theories denying ACC, despite their incoherence from a scientific perspective (Lewandowsky et al., 2018). Kahan et al. (2012) found that when someone's worldview, identity, or livelihood are threatened by climate or environmental mitigation policies, they frequently engage in "identity-protective cognition". Lewandowsky et al. examined conspiracy theories and found that they characteristically involve logical contradictions at the level of specific propositions about climate. The authors note that coherence is achieved at an abstract level, "namely that 'something must be wrong' with the scientific evidence in order to justify a political position against climate change mitigation" (p. 175). The denial of scientific evidence and the mistrust of climate scientists may be viewed at a more abstract level to be a "simulation of coherence by conspiracies" (p. 175) to achieve a narrative of a moral self.

If conspiracy theories can withstand their internal logical contradictions, do they achieve their "simulation of coherence" via a process different from the one that prizes explanatory coherence? The alternative conception of coherence in terms of how testimonies from multiple sources are consistent with each other may play a role (Bovens \& Hartmann, 2003; Harris \& Hahn, 2009). Disinformation is reified as facts in echo chambers (Mitchell et al., 2014; Rosential, 2009). Koriat et al., (2018) found that conformity pressure and the process of confidence evaluation both result in majority views being held with greater confidence, regardless of whether the views are accurate. This finding holds across a wide range of stimuli (e.g., which of two shapes has a larger area? is avocado a fruit?) (Koriat, 2012, 2018; Koriat \& Adiv, 2016). The apparent cognitive bias may be viewed as the result of a normal, even rational, cognitive process (cf. Bovens \& Hartmann, 2003) when it operates on distorted data: As Koriat (2018) notes, no matter how much we know about the world, "we have no knowledge about the world over and above what we know about it" (p. 620).

Coherence in terms of consistency of testimonies across multiple sources is a double-edged sword. On one hand, conspiracy theorists exploit the under-determination inherent to cognition to fabricate their lies, aided by echo chambers where falsehoods permeate information sources (Jurkowitz et al., 2020; Mitchell et al., 2014; Rosential, 2009). Their theories are "coherent" and "authentic" to adherents given the distorted data within those chambers. On the other hand, providing information on the broad consensus on ACC among climate scientists was found to increase acceptance of ACC (Lewandowsky, Gignac \& Vaughan, 2013).

Our findings suggest an entry into circumventing conspiracy theories. Ochs and Capps (2001) observed that there exists a dialectic tension between the two narrative proclivities to resolve the discrepancies. This tension is likely a window of vulnerability where belief change can occur. Conspiracy theories, given their logical contradictions (Lewandowsky et al., 2018), are inherently at the low end of explanatory coherence by any measure. In contrast, our materials were designed to showcase the exemplary - to some of us, astounding - parsimony of scientific explanations. The parsimony of scientific explanations, unlike consensus within an information source, is not matchable by either conspiracy theories or disinformation. 
For the most effective persuasion towards more rational beliefs and actions, however, openness to alternative points of view (recall our results) and to alternative information sources (e.g., those conveying consensus among scientists) would be beneficial, so that coherence in both its senses can augment each other's effect.

Numerous questions await future research. Would our cognitive-constraints approach aid communication about other scientific topics, such as biodiversity, pandemics, vaccination, and evolution? Tests of our approach in other domains is especially important in view of our study's relatively small sample size. Climate change may be viewed as a "public good game", a variant of the Prisoner's Dilemma (Heitzig et al., 2011). Can our approach promote understanding of rational decision making in this and other public good situations? What are the boundary conditions of the moral identity component? How are actual coherence and "simulated coherence" in conspiracy theories related? Would brief educational materials similar to ours enhance early education in the basic sciences and foster appreciation of science? 


\section{Acknowledgments}

We thank Keith Holyoak, James Woodward, Carla Chandler and the UCLA Reasoning Lab for thoughtful comments on our project. We thank Natalie Anggawidjaja and Zehua Xu for help with data screening. We thank Stephan Lewandowsky, Ulrike Hahn, and Lisa Travis for their exceptionally thoughtful and helpful comments on earlier versions of our manuscript. Preparation of this paper was supported by the National Science Foundation (BCS-1827374). 


\section{References}

Atlas, J. D. (2005). Logic, meaning, and conversation: Semantical Underdeterminacy, implicature, and their interface. Oxford: Oxford University Press.

Bain, P. G., Hornsey, M. J., Bongiorno, R., \& Jeffries, C. (2012). Promoting pro-environmental action in climate change deniers. Nature Climate Change, 2, 600-603. https://doi.org/10.1038/nclimate1532

Biederman, I. \& Vessel, E. A. (2006). Perceptual pleasure and the brain. American Scientist, 94(3), 249255.

Botvinick, M. \& Cohen, J. (1998). Rubber hands 'feel' touch that eyes see. Nature, 391, 756-756. https://doi.org/10.1038/35784

Bovens, L., \& Hartmann, S. (2003). Bayesian epistemology. Oxford, England: Oxford University Press.

Bruner, J. (1991). The narrative construction of reality. Critical inquiry, 18(1), 1-21. https://doi.org/10.1086/448619

Bye, J. K., Chuang, P. J., \& Cheng, P. W. (2023). How do humans want causes to combine their effects? The role of analytically-defined causal invariance for generalizable causal knowledge. Cognition, 230, 105303. https://doi.org/10.1016/j.cognition.2022.105303

Cheng, P.W. (1997). From covariation to causation: A causal power theory. Psychological Review, 104, 367-405.

Cheng, P. W. \& Lu, H. (2017). Causal invariance as an essential constraint for creating a causal representation of the world: Generalizing the invariance of causal power. In M. R. Waldmann (Ed.), The Oxford Handbook of Causal Reasoning. Oxford University Press, Oxford, England. https://doi.org/10.1093/oxfordhb/9780199399550.013.9

Cheng, P. W., \& Novick, L. R. (1991). Causes versus enabling conditions. Cognition, 40(1-2), 83-120. https://doi.org/10.1016/0010-0277(91)90047-8

Cheng, P.W., Novick, L.R., Liljeholm, M. \& Ford, C. (2007). In M. O'Rourke (Ed.), Topics in contemporary philosophy, Volume 4: Causation and explanation (pp. 1 - 32). Cambridge, MA: MIT Press.

Cheng, P. W., Sandhofer, C. M., \& Liljeholm, M. (2022). Analytic Causal Knowledge for Constructing Useable Empirical Causal Knowledge: Two Experiments on Pre-schoolers. Cognitive Science, 46(5), e13137. https://doi.org/10.1111/cogs.13137

Chi, M. T., De Leeuw, N., Chiu, M. H., \& LaVancher, C. (1994). Eliciting self-explanations improves understanding. Cognitive Science, 18(3), 439-477. https://doi.org/10.1016/0364-0213(94)90016-7

Christensen, R. H. B. (2019). Cumulative Link Models for Ordinal Regression with the R Package Ordinal. Available at https://cran.rproject.org/web/packages/ordinal/vignettes/clm article.pdf Accessed December 17, 2022.

Cook, J., \& Lewandowsky, S. (2016). Rational irrationality: Modeling climate change belief polarization using Bayesian networks. Topics in cognitive science, 8(1), 160-179.

https://doi.org/10.1111/tops.12186 
Crawley, S., Coffe, H., \& Chapman, R. (2020). Public opinion on climate change: Belief and concern, issue salience and support for government action. The British Journal of Politics and International Relations, 22(1), 102-121. https://doi.org/10.1177/1369148119888827

Drummond, C. \& Fischhoff, B. (2017). Individuals with greater science literacy and education have more polarized beliefs on controversial science topics. Proceedings of the National Academy of Sciences of the United States of America, 114(36), 9587-9592. https://doi.org/10.1073/pnas.1704882114

Farrell, J. (2016). Corporate funding and ideological polarization about climate change. Proceedings of the National Academy of Sciences, 113(1), 92-97. https://doi.org/10.1073/pnas.1509433112

Finkel, E. J., Bail, C. A., Cikara, M., Ditto, P. H., lyengar, S., Klar, S., Mason, L., McGrath, M. C., Nyhan, B., Rand, D. G., Skitka, L. J., Tucker, J. A., Van Bavel, J. J., Wang, C. S. \& Druckman, J. N. (2020). Political sectarianism in America. Science, 370(6516), 533-536.

https://doi.org/10.1126/science.abe1715

Fodor, J. A. \& Pylyshyn, Z.W. (1981). How direct is visual perception? Some reflections on Gibson's "ecological approach". Cognition, 9, 139-196. Doi: 10.1016/0010-0277(81)90009-3

Fraser, B. J. (1981). TOSRA: Test of Science-Related Attitudes: Handbook. Australian Council for Educational Research, Camberwell, Victoria, Australia.

Funk, C., \& Kennedy, B. (2020, April 21). How Americans see climate change and the environment in 7 charts. Pew Research Center Fact Tank. Retrieved from https://www.pewresearch.org/facttank/2020/04/21/how-americans-see-climate-change-and-the-environment-in-7-charts/. Accessed December 16, 2021.

Funk, C., Hefferon, M., Kennedy, B., \& Johnson, C. (2019, August 2). Trust and mistrust in Americans' views of scientific experts. Pew Research Center. Retrieved from https://www.pewresearch.org/science/2019/08/02/trust-and-mistrust-in-americans-views-of-scientificexperts/. Accessed September 24, 2020.

Goldberg, M. H., Gustafson, A., \& van der Linden, S. (2020). Leveraging social solutions to generate lasting engagement with climate change. One Earth, 3(3), 314-324.

https://doi.org/10.1016/j.oneear.2020.08.011

Hansen, J. (2012, February). Why I must speak out about climate change [video]. TED Conferences. Retrieved from https://www.ted.com/talks/james hansen why i must speak out about climate change?language =en/. Accessed September 24, 2020.

Harris, A. J., \& Hahn, U. (2009). Bayesian rationality in evaluating multiple testimonies: Incorporating the role of coherence. Journal of Experimental Psychology: Learning, Memory, and Cognition, 35(5), 1366-1373. https://doi.org/10.1037/a0016567

Hawking, S., \& Mlodinow, L. (2010). The grand design. New York: Bantam Books. 
Heitzig, J., Lessmann, K., \& Zou, Y. (2011). Self-enforcing strategies to deter free-riding in the climate change mitigation game and other repeated public good games. Proc. Natl. Acad. Sci. U.S.A. 108, 15739-15744.

Hoffman, D. (2019). The case against reality: Why evolution hid the truth from our eyes. New York: W.W. Norton \& Company.

Horne, Z., Powell, D., Hummel, J. E., \& Holyoak, K. J. (2015). Countering antivaccination attitudes. Proceedings of the National Academy of Sciences, 112(33), 10321-10324. https://doi.org/10.1073/pnas.150401911

Howe, P. D., Mildenberger, M., Marlon, J.R., \& Leiserowitz, A. (2015). Geographic variation in opinions on climate change at state and local scales in the USA. Nature Climate Change, 5, 596-603. https://doi.org/10.1038/nclimate2583

Hume, D. (1739/1987). A treatise of human nature ( $2^{\text {nd }}$ edition, Clarendon Press, Oxford).

Ichien, N. \& Cheng, P.W. (2022). Revisiting Hume in the 21st century: The possibility of generalizable causal beliefs given inherently unobservable causal relations. In A. Wiegmann \& P. Willemsen (Eds). Advances in Experimental Philosophy of Causation (pp. 7-34). London, UK: Bloomsbury Press. Inskeep, S. (2020). Ex-Energy Secretary Says Fixing Climate Change Is Tough, There's No Vaccine. National Public Radio. Retrieved from https://www.npr.org/2020/12/07/943768888/ex-energysecretary-says-fixing-climate-change-is-tough-theres-no-vaccine. Accessed December 7, 2020. IPCC (2007). Summary for Policymakers. In S. Solomon, D. Qin, M. Manning, Z. Chen, M. Marquis, K. B. Averyt, M. Tignor, \& H. L. Miller (eds.), Climate Change 2007: The Physical Science Basis. Contribution of Working Group I to the Fourth Assessment Report of the Intergovernmental Panel on Climate Change. Cambridge University Press, Cambridge, United Kingdom and New York, NY, USA. Retrieved from https://www.ipcc.ch/site/assets/uploads/2018/02/ar4-wg1-spm-1.pdf. Accessed September 24, 2020.

IPCC. (2018). In V. Masson-Delmotte, P. Zhai, H.-O. Pörtner, D. Roberts, J. Skea, P. R. Shukla, A. Pirani, W. Moufouma-Okia, C. Péan, R. Pidcock, S. Connors, J. B. R. Matthews, Y. Chen, X. Zhou, M. I. Gomis, E. Lonnoy, T. Maycock, M. Tignor, \& T. Waterfield (Eds.), Global Warming of $1.5^{\circ} \mathrm{C}$. An IPCC Special Report on the Impacts of Global Warming of $1.5^{\circ} \mathrm{C}$ Above Pre-industrial Levels and Related Global Greenhouse Gas Emission Pathways, in the Context of Strengthening the Global Response to the Threat of Climate Change, Sustainable Development, and Efforts to Eradicate Poverty. Retrieved from https://www.ipcc.ch/sr15/. Accessed September 24, 2020.

Jacques, P. J., Dunlap, R. E., \& Freeman, M. (2008). The organisations of denial: Conservative think tanks and environmental scepticism. Environmental politics, 17(3), 349-385.

\section{https://doi.org/10.1080/09644010802055576}

Jayadevan, V., Michaux, A., Delp, E., \& Pizlo, Z. (2017). 3D Shape Recovery from real images using a symmetry prior. Electronic Imaging, 17, 106-115. https://doi.org/10.2352/ISSN.2470-

1173.2017.17.COIMG-452 
Jurkowitz, M., Mitchell, A., Shearer, E., \& Walker, M. (2020, January 24). US media polarization and the 2020 election: A nation divided. Pew Research Center. Retrieved from https://www.pewresearch.org/journalism/2020/01/24/u-s-media-polarization-and-the-2020-election-anation-divided/. Accessed November 27, 2021.

Kahan, D. M. (2010). Fixing the communications failure. Nature, 263, 296-297.

Kahan, D. M., Peters, E., Wittlin, M., Slovic, P., Ouellette, L. L., Braman, D., \& Mandel, G. (2012). The polarizing impact of science literacy and numeracy on perceived climate change risks. Nature Climate Change, 2, 732-735. https://doi.org/10.1038/nclimate1547

Kant, I. (1781/1965). Critique of pure reason. Macmillan, London.

Kelly, K. T. (2007). Ockham's Razor, Truth, and Information, In J. van Benthem, P. Adriaans (Eds.), Philosophy of Information. Elsevier, Amsterdam, Netherlands.

Kennedy, S. (2020, January 2). Few countries on track to meeting climate goals. Yale Climate Connections. Retrieved from https://yaleclimateconnections.org/2020/01/few-countries-on-track-tomeet-paris-climate-goals/. Accessed September 24, 2020.

Kennedy, B., \& Hefferon, M. (2019, March 28). What Americans Know about Science: Science Knowledge Levels Remain Strongly Tied to Education; Republicans and Democrats Are about Equally Knowledgeable. Pew Research Center. Retrieved from https://www.pewresearch.org/science/2019/03/28/what-americans-know-about-science/. Accessed December 16, 2021.

Koriat, A. (2012). When are two heads better than one and why? Science, 336, 360-362. http://dx.doi.org/10.1126/science.1216549

Koriat, A. (2018). When reality is out of focus: Can people tell whether their beliefs and judgments are correct or wrong? Journal of Experimental Psychology: General, 147(5), 613-631.

Koriat, A. \& Adiv, S. (2016). The self-consistency theory of subjective confidence. In J. Dunlosky \& S. Tauber. (Eds.), The Oxford handbook of metamemory (pp. 127-147). New York: Oxford.

Koriat, A., Adiv-Mashinsky, S., Undorf, M. \& Schwarz, N. (2018). The prototypical majority effect under social influence. Personality and Social Psychology Bulletin, Vol. 44(5), 670-683. doi/10.1177/0146167217744527.

Kuhn, T. S. (1962/2012). The structure of scientific revolutions. University of Chicago Press.

Leiserowitz, A. (2019). Building public and political will for climate change action. In D. Esty (Ed.), A Better Planet: 40 Big Ideas for a Sustainable Future. Yale University Press.

Leiserowitz, A., Maibach, E., Rosenthal, S., Kotcher, J., Bergquist, P., Ballew, M., Goldberg, M., Gustafson, A., \& Wang, X. (2020, May 19). Climate Change in the American Mind: April 2020. Yale University and George Mason University. New Haven, CT: Yale Program on Climate Change Communication. Retrieved from https://climatecommunication.yale.edu/publications/climate-changein-the-american-mind-april-2020/. Accessed September 24, 2020. 
Leiserowitz, A., Maibach, E., Roser-Renouf, C., Rosenthal, S., Cutler, M., \& Kotcher, J. (2018, April 17). Climate change in the American mind: March 2018. Yale University and George Mason University. New Haven, CT: Yale Program on Climate Change Communication. Retrieved from https://climatecommunication.yale.edu/publications/climate-change-american-mind-march-2018/. Accessed September 24, 2020.

Levay, K. E., Freese, J., \& Druckman, J. N. (2016). The demographic and political composition of Mechanical Turk samples. SAGE Open, 6(1), 1-17. https://doi.org/10.1177/2158244016636433

Lewandowsky, S. (2021). Climate Change Disinformation and How to Combat It. Annual Review of Public Health, 42, 1-21. https://doi.org/10.1146/annurev-publhealth-090419-102409

Lewandowsky, S., Cook, J. \& Lloyd, E. (2018). The 'Alice in Wonderland' mechanics of the rejection of (climate) science: simulating coherence by conspiracism. Synthese, 195, 175-196. https://doi.org/10.1007/s11229-016-1198-6

Lewandowsky, S., Gignac, G. E., \& Oberauer, K. (2013). The role of conspiracist ideation and worldviews in predicting rejection of science. PloS one, 8(10), e75637.

https://doi.org/10.1371/journal.pone.0134773

Lewandowsky, S., Gignac, G. E., \& Vaughan, S. (2013). The pivotal role of perceived scientific consensus in acceptance of science. Nature Climate Change, 3, 399-404.

https://doi.org/10.1038/nclimate1720

Lewandowsky, S., Pilditch, T. D., Madsen, J. K., Oreskes, N., \& Risbey, J. S. (2019). Influence and seepage: An evidence-resistant minority can affect public opinion and scientific belief formation. Cognition, 188, 124-139. https://doi.org/10.1016/j.cognition.2019.01.011

Li, Y. \& Pizlo, Z. (2011). Depth cues vs. simplicity principle in 3D shape perception. Topics in Cognitive Science, 3(4), 667-685. https://doi.org/10.1111/j.1756-8765.2011.01155.x

Liljeholm, M., \& Cheng, P.W. (2007). When is a cause the "same"? Coherent generalization across contexts. Psychological Science,18, 1014-1021.

Lombrozo, T. (2016). Explanatory preferences shape learning and inference. Trends in Cognitive Science, 20(10), 748-759. https://doi.org/10.1016/j.tics.2016.08.001

Maertens, R., Anseel, F., \& van der Linden, S. (2020). Combatting climate change misinformation: Evidence for longevity of inoculation and consensus messaging effects. Journal of Environmental Psychology, 70, 101455. https://doi.org/10. 1016/j.jenvp.2020.101455

Maertens, R., Roozenbeek, J., Basol, M., \& van der Linden, S. (2021). Long-term effectiveness of inoculation against misinformation: Three longitudinal experiments. Journal of Experimental Psychology: Applied, 27(1), 1-16. https://doi.org/10.1037/xap0000315

Marr, D. (1982). Vision: a Computational Investigation into the Human Representation and Processing of Visual Information. W. H. Freeman and Co., San Francisco, CA.

Masson-Delmotte, V., Schulz, M., Abe-Ouchi, A., Beer, J., Ganopolski, A., González Rouco, J. F., Jansen, E., Lambeck, K., Luterbacher, J., Naish, T., Osborn, T., Otto-Bliesner, B., Quinn, T., 
Ramesh, R., Rojas, M., Shao, X., \& Timmermann, A. (2013). Information from paleoclimate archives. In T. F. Stocker, D. Qin, G.-K. Plattner, M. Tignor, S. K. Allen, J. Doschung, A. Nauels, Y. Xia, V. Bex, \& P. M. Midgley (Eds.), Climate Change 2013: The Physical Science Basis. Contribution of Working Group I to the Fifth Assessment Report of the Intergovernmental Panel on Climate Change (pp. 383464). Cambridge University Press. https://doi.org/10.1017/CBO9781107415324.013. Retrieved from https://www.ipcc.ch/site/assets/uploads/2018/02/WG1AR5 Chapter05 FINAL.pdf. Accessed September 24, 2020.

McKibben, B. (2019). Falter: Has the human game begun to play itself out? Henry Hold and Co., New York, NY.

McCloskey, M., \& Kohl, D. (1983). Naive physics: The curvilinear impetus principle and its role in interactions with moving objects. Journal of Experimental Psychology: Learning, Memory, and Cognition, 9(1), 146-156. https://psycnet.apa.org/record/1983-24852-001

Medin, D. L. \& Bang, M. (2014). The cultural side of science communication. Proceedings of the National Academy of Sciences of the United States of America, 111(Supplement 4), 13621-13626.

https://doi.org/10.1073/pnas.1317510111

Mitchell, A., Gottfried, J., Kiley, J., \& Matsa, K. E. (2014, October 21). Political Polarization \& Media Habits. Pew Research Center. Retrieved from https://www.pewresearch.org/journalism/2014/10/21/political-polarization-media-habits/. Accessed November 27, 2021.

Munnich, E. \& Ranney, M. A. (2019). Learning from surprise: Harnessing a metacognitive surprise signal to build and adapt belief networks. Topics in Cognitive Science, 11(1), 164-177. https://doi.org/10.1111/tops.12397

New, J. (2015, April 27). Title IX coordinators required. Inside Higher Ed. Retrieved from https://www.insidehighered.com/news/2015/04/27/education-department-reminds-colleges-hire-titleix-coordinators. Accessed December 29, 2021.

Newton, I (1687). Principia Mathematica, 1st ed. (Streater, London); modern English translation, A. Motte, Sir Isaac Newton's Mathematical Principles of Natural Philosophy (Univ of California Press, Berkeley and Los Angeles, 1934).

NPR/Marist poll (2022). https://maristpoll.marist.edu/polls/a-new-session-of-congress/. Accessed December 15, 2022.

Ochs, E. \& Capps, L. (2001). Living narrative: creating lives in everyday storytelling, Harvard University Press.

Ockwell, D., Whitmarsh, L. \& O'Neill, S. (2009). Reorienting climate change communication for effective mitigation: forcing people to be green or fostering grass-roots engagement? Scientific Communication, 30(3), 305-327. https://doi.org/10.1177/1075547008328969 
Park, J., McGillivray, S., Bye, J.K. \& Cheng, P.W. (2022). Causal invariance as a tacit aspiration: Analytic knowledge of invariance functions. Cognitive Psychology. https://authors.elsevier.com/sd/article/S0010-0285(21)00055-4

Pew Research Center. (2019, May 14). Majority of public favors same-sex marriage, but divisions persist. Retrieved from https://www.pewresearch.org/politics/2019/05/14/majority-of-public-favors-same-sexmarriage-but-divisions-persist/. Accessed November 27, 2021.

Phillips, T., Booth, A. \& Goñi, U. (2020, December 30). Argentina legalises abortion in landmark moment for women's rights: Country becomes only the third in South America to permit elective abortions. The Guardian. Retrieved from https://www.theguardian.com/world/2020/dec/30/argentina-legalisesabortion-in-landmark-moment-for-womens-rights. Accessed December 30, 2021.

Pierre, J. \& Neuman, S. (2021, October 27). How decades of disinformation about fossil fuels halted U.S. climate policy. National Public Radio. Retrieved from https://www.npr.org/2021/10/27/1047583610/once-again-the-u-s-has-failed-to-take-sweeping-climateaction-heres-why. Accessed December 17, 2021.

Pizlo, Z. (2001). Perception viewed as an inverse problem. Vision Research, 41(24), 3145-3161. https://doi.org/10.1016/S0042-6989(01)00173-0

Ramachandran, V. S. \& Hirstein, W. (1998). The perception of phantom limbs: The D.O. Hebb lecture. Brain, 121(9), 1603-1630. https://doi.org/10.1093/brain/121.9.1603

Ranney, M. A. \& Clark, D. (2016). Climate change conceptual change: Scientific information can transform attitudes. Topics in Cognitive Science, 8(1), 49-75. https://doi.org/10.1111/tops.12187

Rescorla, R. A. \& Wagner, A. R. (1972). A theory of Pavlovian conditioning: Variations in the effectiveness of reinforcement and nonreinforcement. In A.H. Black \&W.F. Prokasy (Eds.), Classical conditioning II: Current research and theory (pp. 64-99). New York: Appleton-Century-Crofts.

Rivera, A., King, B., Larsen, J. \& Larsen, K. (2023, Jan 10). Preliminary US Greenhouse Gas Emissions Estimates for 2022. The Rhodium Group. Retrieved from https://rhg.com/research/us-greenhouse-gasemissions-20221. Accessed January 10, 2023.

Rosential, T. (2009, Oct 30). Partisanship and cable news audiences. Pew Research Center. Retrieved from https://www.pewresearch.org/2009/10/30/partisanship-and-cable-news-audiences/. Accessed November 3, 2021.

Rosmann, M. \& Atkin, M. (2019, April 22). I Work with suicidal farmers. It's becoming too much to bear. The New Republic. Retrieved from https://newrepublic.com/article/153604/work-suicidal-farmers-itsbecoming-much-bearl. Accessed September 24, 2020.

Saad, L. (2021, January 11). Americans' Political Ideology Held Steady in 2020. Gallup. https://news.gallup.com/poll/328367/americans-political-ideology-held-steady-2020.aspx/. Accessed December 30, 2022. 
Shabecoff, P. (1988, June 24). Global Warming Has Begun, Expert Tells Senate. The New York Times. https://www.nytimes.com/1988/06/24/us/global-warming-has-begun-expert-tells-senate.html/. Accessed September 24, 2020.

Schotsch, B., \& Powell, D. (2022). Understanding intuitive theories of climate change. In J. Culbertson, A. Perfors, H. Rabagliati \& V. Ramenzoni (Eds.), Proceedings of the $44^{\text {th }}$ Annual Meeting of the Cognitive Science Society. Toronto, Canada: Cognitive Science Society.

Sisk, V. F., Burgoyne, A. P., Sun, J., Butler, J. L., \& Macnamara, B. N. (2018). To What Extent and Under Which Circumstances Are Growth Mind-Sets Important to Academic Achievement? Two MetaAnalyses. Psychological Science, 29(4), 549-571. https://doi.org/10.1177/0956797617739704

Supran, G., \& Oreskes, N. (2017). Assessing Exxon Mobil's climate change communications (19772014). Environmental Research Letters, 12(8), 084019. https://doi.org/10.1088/1748-9326/aa815f

Thagard, P. (1989). Explanatory coherence. Behavioral and Brain Sciences, 12, 435-502.

Thagard, P. (2000). How scientists explain disease. Princeton University Press.

UN News (2022, October 26). Countries' climate promises still not enough to avoid catastrophic global warming: UN Report. Retrieved from https://news.un.org/en/story/2022/10/1129892/. Accessed December 27, 2022.

United Nations Framework Convention on Climate Change (2022). The Paris Agreement. Retrieved from https://unfccc.int/process-and-meetings/the-paris-agreement/the-paris-agreement. Accessed January 10, 2022.

van Stekelenburg, A., Schaap, G., Veling, H., Van't Riet, J., \& Buijzen, M. (2022). Scientific-Consensus Communication About Contested Science: A Preregistered Meta-Analysis. Psychological Science, 33(12), 1989-2008. https://doi.org/10.1177/09567976221083219

Wilson, E. O. (2001). Life is a narrative. In E.O. Wilson \& B. Bilger (Eds.), The best American science and nature writing 2001. Boston: Houghton Mifflin Company.

Woodward, J. (2000). Explanation and invariance in the special sciences. The British Journal for the Philosophy of Science, 51(2), 197-254. https://doi.org/10.1093/bjps/51.2.197

Woodward, J. (2005). Making Things Happen: A Theory of Causal Explanation. Oxford University Press. World Meteorological Organization. (2020). United in Science 2020: A multi-organization high-level compilation of the latest climate science information. Retrieved from https://public.wmo.int/en/resources/united in science. Accessed November 1, 2020.

World Wildlife Fund. (2017, Spring). New US regulations offer better protection from bycatch. Retrieved from https://www.worldwildlife.org/magazine/issues/spring-2017/articles/new-us-regulations-offerbetter-protection-from-bycatch. Accessed December 28, 2020.

Zurcher, A. (2020, June 15). US Supreme Court backs protection for LGBT workers. BBC. Retrieved from https://www.bbc.com/news/world-us-canada-53055632/. Accessed September 24, 2020. 
Supplementary Materials for

\section{Promoting Climate Actions: A Cognitive-Constraints Approach}

Junho Lee, Emily F. Wong, Patricia W. Cheng

This PDF file includes:

Figure S1

Figure S2

Supplementary Results

Supplementary Discussion

Supplementary Methods 


\section{Supplementary Results}

Participants in our Full-coherence, All-but-climate, All-but-moral-identity, Moral-identity-only, Climate-only, Control, and Moral-identity-last conditions took a median of $37.9 \mathrm{~min}, 32.6 \mathrm{~min}, 28.7 \mathrm{~min}, 10.5 \mathrm{~min}, 11.7$ $\mathrm{min}, 5.1 \mathrm{~min}$, and $29.5 \mathrm{~min}$ to complete in entirety the respective seven conditions in our survey. All inferential statistical tests in this section are two-tailed unless otherwise stated.

\section{Additional science-appreciation ratings (see Fig. 7 in main manuscript)}

Respectively for the statements - "These exercises made me more aware of the significance of science in our everyday lives" and "These exercises impacted my view on how science enables us to make useful predictions" - the agreement ratings varied significantly across experimental conditions, $F(3,168)=3.82$, $p=.011, \eta_{P}^{2}=0.06$ and $F(3,168)=4.68, p=.004, \eta_{P}^{2}=0.08$. Participants' mean ratings for both of these two science-appreciation statements (see Fig. 7) show the same pattern as for the "explain" statement reported in the main Results, and their effect sizes were likewise large. Pairwise comparisons indicate that participants in the Climate-only condition gave lower ratings than those in the Full-coherence and All-butclimate conditions for the "significance" statement, $t(168)=3.26, p=.004, d=0.81$ and $t(168)=2.61, p$ $=.030, d=0.93$, respectively, and they gave marginally significant lower ratings than participants in the Allbut-moral-identity conditions, $t(168)=2.24, p=.080, d=0.77$. The same pattern of differences held for pairwise comparisons between the Climate-only condition and the other three conditions for the "predictions" statement, $t(168)=3.65, p=.001, d=0.85 ; t(168)=2.70, p=.020, d=0.95$, and $t(168)=2.23, p=.080$, $d=0.67$, respectively.

\section{Additional general science-attitude ratings}

As Fig. S1 shows, for both liberals and conservatives, our general-science-prediction exercises boosted participants' science-attitudes on all four general-science-attitude statements (see Table 3 in main manuscript for the statements).
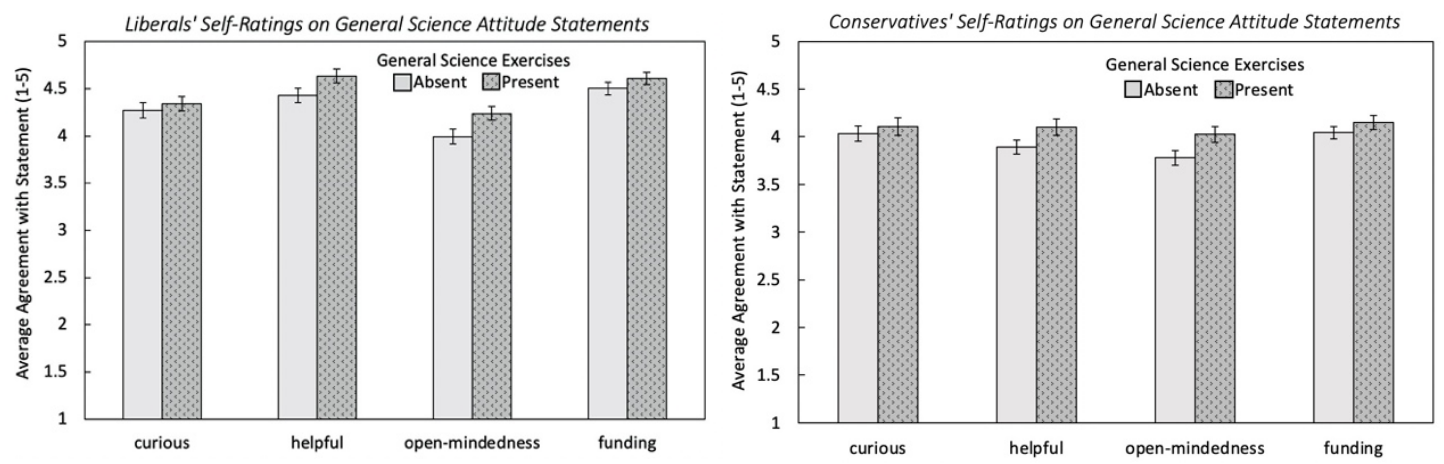

Fig. S1.

Estimated marginal means of liberals' and conservatives' science-attitude self-ratings in conditions with and without general-science-prediction exercises. Error bars indicate 1 S.E. A one-way MANCOVA was conducted on ratings of agreement with four general science-attitude statements on a scale from 1 (strongly disagree) to 5 (strongly agree), with general-science conditions (present vs absent) as a fixed factor, and political identity (liberal vs conservative), education (3 levels), and science-fact knowledge (4 levels) as covariates. General-science conditions significantly predicted the composite variable [Wilk's Lambda $\left.=.964, F(4,303)=2.86, p=.024, \eta_{P}^{2}=.04\right]$, as did science-fact knowledge and political identity ( $\left.p s<.001, \boldsymbol{\eta}_{\boldsymbol{P}}^{2}=.08\right)$, but not education $\left(p=.16, \boldsymbol{\eta}_{\boldsymbol{P}}^{2}=.02\right)$. Adjusted $\boldsymbol{R}^{2}$ for each individual item was .028 (curious), .161 (helpful), .053 (open-mindedness), and .188 (funding).

In particular, as Fig. S2 shows, our general-science-prediction exercises boosted participants' ratings on openness to alternative opinions, and the boost is consistent across the four levels of political identity.

Our general-science-prediction exercises also boosted agreement on one other statement, "Science helps to make life better / Scientific discoveries are doing more harm than good (reverse coded)", $t(306)=$ 2.49, $p=.039, d=0.40$. 


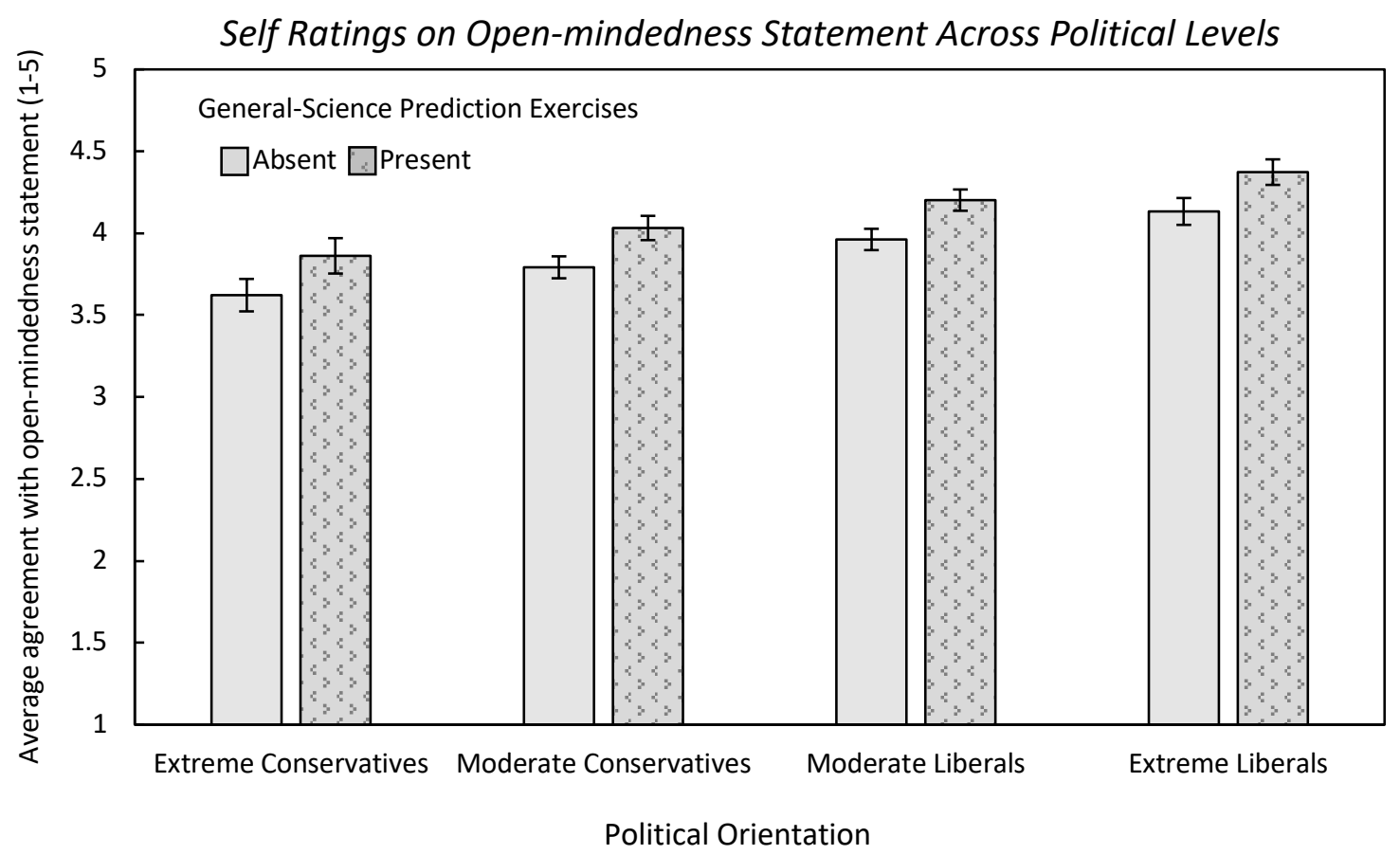

Fig. S2. Estimated marginal means (EMMEANS) of self-ratings on the open-mindedness statement in conditions with and without general-science-prediction exercises, across the 4 levels of political orientation. Error bars indicate $1 \mathrm{~S}$.E. The EMMEANS were obtained from a MANCOVA identical to that in Fig. S1 with the exception that political in the current model has 4 levels instead of 2 [Wilk's Lambda = $0.961]$. In this model, general-science conditions significantly predicted self-ratings on the openmindedness statement, $F(1,311)=7.26, p=.007$, adjusted $R^{2}=.070, \eta_{P}^{2}=.023$. An alternative model that includes an interaction between general science (present and absent) and political identity [Wilk's Lambda $=0.980$ ] likewise yielded a significant main effect of general-science conditions on self-ratings on the open-mindedness statement, $F(1,301)=6.82, p=.009$, adjusted $R^{2}=.067, \eta_{P}^{2}=.022$, and a nonsignificant interaction, $F(3,301)=0.24, p=.867$, adjusted $R^{2}=.067, \eta_{P}^{2}=.002$. Therefore, this model was not used to obtain the EMMEANS.

\section{Effect of coherence on the probability of selecting zero to six personal climate actions}

For our set of personal climate-mitigating actions (e.g., reduce carbon dioxide by planting trees), compared to the political climate actions reported in the main Results, our interventions had a similar although weaker effect.

Neither the Moral-identity question alone $(O R=0.82, p=.55)$, nor the science-prediction exercises alone $(O R=0.86, p=.67)$, significantly changed the odds of selecting an additional nonpolitical climate action relative to the Control condition in which neither was present. With the moral-identity question present, however, the science exercises doubled the odds of selecting an additional such action, $O R=2.00, p=.040$, relative to the absence of those exercises. Likewise, with the science exercises present, the moral-identity question nearly doubled the odds of selecting an additional such action, $O R=1.91, p=.036$ (one-tailed), relative the absence of the moral-identity question. The interaction between the two factors showed the same pattern as that for the political climate actions, $O R=2.32, p=.043$ (one-tailed).

Similarly, neither the climate-science question alone $(O R=0.82, p=.58)$, nor its complementarycoherence questions alone $(O R=1.17, p=.68)$, significantly changed the odds of selecting an additional nonpolitical climate action relative to the Control condition in which neither was present. With the climatescience question present, however, the complementary-coherence questions doubled the odds of selecting an additional such action, $O R=2.10, p=.042$. With the complementary-coherence questions present, the 
climate question had a small and insignificant positive effect on the odds of selecting an additional such action, $O R=1.47, p=.30$. The interaction between the two was not significant, $O R=1.80, p=.26$.

In summary, our interventions had a similar although weaker effect on personal climate actions, compared to the effect on political climate actions reported in Results in the main manuscript.

\begin{abstract}
Effect of coherence on the probability of selecting zero to five personal pro-environment actions that are ambiguously climate-mitigating

A potential alternative explanation for the effects of our intervention to create a pro-science climate-action personal narrative is that, rather than enabling the creation of that narrative, our materials somehow put participants in a positive mindset, leading them to be more willing to take responsible actions overall, climate-mitigating or otherwise, personal or societal. On this "positive-mindset" hypothesis, participants should be more willing to take responsible actions in general, ones that are not necessarily climate-related as well. Recall that a subset of the moral action items (e.g., unplugging appliances when not in use) may have non-climate motives such as thrift. These actions are ambiguously climate-mitigating. They therefore enable a test of the prediction according to the positive-mindset hypothesis.
\end{abstract}

First, neither the moral-identity question alone $(O R=0.66, p=.22)$, nor the science-prediction exercises alone $(O R=0.76, p=.44)$, significantly changed the odds of selecting an additional ambiguous-climatemitigating action relative to the Control condition. The interaction between the moral-identity question and science exercises was also not significant, $O R=2.14, p=.12$. A contrast comparing the effect of the science exercises in the presence of the moral-identity question indicates that the moral-identity question did not enhance the effectiveness of the science exercises, $O R=1.61, p=.15$. Neither did the science exercises enhance the effectiveness of the moral-identity question, $O R=1.42, p=.34$.

Likewise, neither the complementary-coherence questions alone, $O R=1.19, p=.64$, nor the climatescience question alone, $O R=0.68, p=.28$, significantly changed the odds of selecting an additional ambiguous-climate action relative to the control condition. The interaction between the two was also not significant, $O R=1.31, p=.61$. With the climate-science question present, the complementary-coherence questions slightly and nonsignificantly raised the odds of selecting an additional ambiguous-climatemitigating action, $O R=1.56, p=.22$. With the complementary-coherence questions present, the climatescience exercise did not raise that odds, $O R=0.89, p=.75$.

The observed lack of effect of our intervention on ambiguously climate-mitigating actions offers no support for the positive-mindset hypothesis.

\title{
Return Participants' Willingness Responses in Phase 1 for Personal Climate Actions and Personal Non-climate-specific Pro-environment actions
}

Personal Climate Actions. Participants in the Full condition indicated greater willingness to take personal climate actions compared to those in the Partial conditions, $O R_{F, P}=3.74, p=.004$, and the Control condition, $O R_{F, C}=3.12, p=.015$. Participants in the Partial conditions did not demonstrate greater willingness to act relative to those in the Control condition, $O R_{P, C}=0.83, p=.35$. In a separate likelihood ratio test of cumulative link models (Christensen, 2019), we compared the above model with one that included an interaction between condition and political identity; that analysis does not show evidence for an interaction between condition and political identity, $\chi^{2}(2)=1.57, p=.46$.

Personal Non-climate-specific Pro-Environment Actions. Participants in the Full condition indicated greater willingness to take personal pro-environment actions compared to those in the Partial conditions, $O R_{F, P}=2.32, p=.041$, but not those in the Control condition, $O R_{F, C}=1.34, p=.27$. Participants in the Partial conditions did not demonstrate greater willingness to act relative to those in the Control condition, $O R_{P, C}=0.59, p=.14$. A likelihood ratio test of cumulative link models does not show evidence for an interaction between condition and political orientation, $\chi^{2}(2)=4.34, p=.11$. 


\section{Return Participants' Reports in Phase 2 for Taking Personal Climate Actions and Personal Non- climate-specific Pro-environment actions}

Personal Climate Actions. Participants in the Full condition were more likely to report taking additional personal climate actions compared to those in the Partial conditions, $O R_{F, P}=3.00, p=.01$. Relative to those in the Control condition, the Full-coherence condition showed a marginally significant higher chance of reporting taking additional personal climate actions $\left(O R_{F, C}=2.21, p=.07\right)$, but those in the Partial condition did not $\left(O R_{P, C}=0.70, p=.23\right)$. The Full condition was more likely to report taking additional personal climate actions compared to all other conditions, $O R=2.61, p=.016$.

A separate non-directional likelihood ratio test of cumulative link models confirmed that there was no significant interaction between condition and political identity, $\chi^{2}(2)=2.41, p=.30$.

Personal Non-climate-specific Pro-Environment Actions. Participants in the Full-coherence condition were not more likely to report taking additional personal pro-environment actions in the interim compared to those in the Partial conditions, $O R_{F, P}=0.87, p=.38$, or the Control condition, $O R_{F, C}=1.70$, $p=.16$. Participants in the Partial conditions were marginally more likely to report taking more of these actions relative to the Control condition, $O R_{P, C}=1.96, p=.094$. The Full condition was not more likely to report taking a greater number of personal pro-environment actions compared to all other conditions, $O R=1.14, p=.76$.

A separate likelihood ratio test of cumulative link models confirmed that there was no significant interaction between condition and political orientation, $\chi^{2}(2)=2.23, p=.33$.

\section{Predictiveness of Willingness to Act in Phase 1 for Reporting Actually Having Acted or Would Have Acted in Phase 2}

Personal Climate Actions. Of the six personal climate actions, all return participants $(N=88)$ had the opportunity to reduce beef consumption and buying excess goods. Most return participants had the opportunity to support environmentally responsible companies $(N=66)$ and plant native vegetation $(N=$ $50)$. However, most did not have the opportunity to use public transit $(N=65)$, nor support the use of renewable energy $(N=68)$.

The more personal climate actions participants indicated they were willing to take in Phase 1 , the more likely they were to report they have actually (or would have) followed through two years later, $O R=2.47, p$ $<.001$.

Personal Pro-Environment Actions. Of the five personal pro-environment actions, all participants had the opportunity to use appropriate layers of clothing in lieu of using heater/air conditioning and to unplug appliances when not in use. Most return participants had the opportunity to avoid single-use plastics $(N=$ $70)$, avoid shopping online $(N=50)$, and buy from thrift stores $(N=74)$.

The more personal pro-environment actions participants indicated they were to take in Phase 1, the more likely they were to report a greater number of such actions they have actually (or would have) followed through two years later, $O R=1.74, p=.004$.

\section{Supplementary Discussion}

The two cognitive constraints that motivated our study and explain its success suggest that they can be applied to promote other science-based public policies. Consider how they may be applied to promote measles vaccination. While measles was declared eradicated from the U.S. in 2000 by the World Health Organization, it has re-emerged in part due to parents' refusal to vaccinate their children. The number of reported cases of measles in the U.S. was 1282 in 2019, an almost twenty-fold increase in a decade. To promote measles vaccination, educational materials analogously constructed as ours might consist of three components: 1) a question asking what might be going through a mother's mind as she is told true stories about children suffering from a measles infection, including one about a child who contracted encephalitis (the stories may be accompanied by information about major and minor consequences of a measles infection), 2) a question analogous to the climate "graph prediction" exercise: the question asks participants to explain frequency data from an actual randomized control study for which information on the nature of the intervention is withheld. The data show that one group of children had a much lower incidence of measles than another group. Participants are asked to conjecture an explanation for the data before 
receiving feedback, namely, that the group with the lower incidence was vaccinated and the other not, and 3) questions asking for explanations of everyday observations for which science gives parsimonious explanations, similar to those in our study.

Whether our approach generalizes to other domains remains an open question.

\section{Supplementary Methods}

Here we present all our experiment materials, including all exercises, survey on science-related beliefs and opinions, measurements of willingness to take pro-environment actions, comprehension-check questions, and demographic information. Materials are presented here in the order of their appearance in the fullcoherence condition. Depending on the condition (see Table 1), some or all of the three main components (moral-identity/farmers question, general-science exercises, climate-science exercise) were omitted in the other conditions. The materials in the "Moral-identity-last condition" were identical to those in the fullcoherence condition, except that the moral-identity question was presented after the science exercises instead of before them. This condition was included to rule out the "attention" hypothesis, see "Effect of coherence on the probability of selecting zero, one, or two political climate actions: Testing the coherence hypothesis" in the main Results.

Because the figures in this section are part of our intervention materials that we presented to the participants rather than created for illustration of our results, they will be embedded in the following text without independent captions.

1) Introduction (headings here were not shown to participants)

Welcome to our study!

To make this experience more enjoyable for you, our survey comes with relaxing nature sounds.

If you don't mind, please take a moment to put on your headphones, and keep them on.

Please adjust the volume until you are comfortable, either on your computer speaker or headphones.

\section{2) Moral-identity/Farmers question}

page break

You will first read a short excerpt from a magazine article and provide your response to a related question. There is no right or wrong answer, although you will be asked to briefly explain your answer.

Your opinions and thoughts are important to us, because a major goal of our study is to understand how we as people think about issues.

\section{Farmers in Need}

The excerpts below are from an interview with Dr. Mike Rosmann, who left seminary to serve as a counselor and therapist for ranchers and farmers. Dr. Rosmann works from his office in the Methodist Church in Harlan, lowa. In spring 2019, as historic flooding in major river systems ravages the Midwest, his work has become unbearable.

The story is in his own words, edited and arranged for clarity by Emily Atkin:

"I only take on the most difficult and unresolvable problems that you could ever see among farm people, where depression has not been successfully treated by any kind of medication or psychiatric help. I try to figure out what to do about them, because-well, I don't know how else to say this, except that I have a lot of experience doing this. 
But the two calls I got today - those just wore me out emotionally.

The first came from a lady whose lover-and I say lover, because both he and she are divorced -is a large farmer. And he's been told by creditors that he has to negotiate the sale or disposal of some of his farm assets, or they'll shut him down. He said, I will not go to mediation or court, l'll kill myself before I have to do that. I will lose. I can't do this. So she called me in desperation....

The second call came from another farmer. She told me she was desperate, because she didn't know how to deal with uncertainty in her farming operation. Her email said-l'll read it to you:

'Thank you Dr. Rosmann for getting back to me. I am desperate. The financial strains of the farm are hard to take. Everything is compounded by my emotions.... I experienced a trauma two and a half years ago and I can't get past it. My brother, with whom I worked on our family farm, committed suicide ... in front of me. My husband says I'm changing, and I know I am.'

So this woman is looking to me about how to continue, and maybe even gauging whether she needs to join her brother.

... farmers have been calling me more and more recently .... The number of calls has really increased since the beginning of March, when the flooding began."

Question: Put yourself in the shoes of one of the two farmers who called Dr. Rosmann. How would you like Dr. Rosmann or anyone else to help? You may check any number of the following:

A) Help me apply for crop insurance

B) Give me information on how to contact FEMA for emergency financial assistance

C) Direct me to another farmer who has been hit by a similar catastrophe so I don't feel so alone.

D) Connect me with other farmers in similar straits to organize a protest against government inaction to protect us from such devastating damage to our means of livelihood.

Give us your best explanation for your selection(s):

(Open-ended response collected)

Are there any other means of addressing the issue that comes to mind? Briefly explain why you think it is important:

(Open-ended response collected)

\section{Sources:}

https://en.wikipedia.org/wiki/2019 Midwestern U.S. floods

https://newrepublic.com/article/153604/work-suicidal-farmers-its-becoming-much-bear

In case you want to revisit our materials, you will have access to all the links, with annotations, when you finish the survey.

\section{3) General-science-prediction exercises including the climate-science-prediction exercise (5th exercise)}

Now, you will be asked some questions about everyday events. The following questions will have a correct answer.

As before, you will be asked to briefly explain your answers. 
We will provide feedback and explanation after each question. It is important that you understand our explanations. Pay attention to the content of the questions and feedback. For us to check your comprehension, you will be asked about the materials at the end of the survey.

(In case you find the nature sounds distracting rather than relaxing, feel free to lower the volume or turn them off.)

page break

3-1) Garden hose exercise, taken from McCloskey and Kohl (1983)

Q1: Water hose. If this were a hose coiled on the floor (viewed from above) with water shooting out, which drawing below (A through $F$ ) best depicts the path of the water as it leaves the hose?

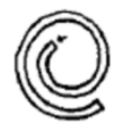

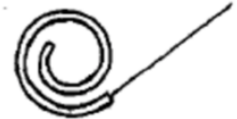

A

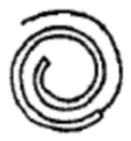

D

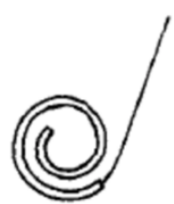

B

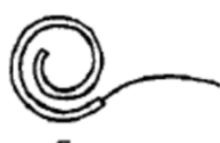

E

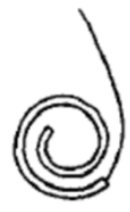

c

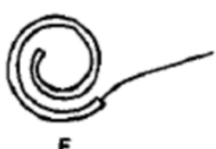

A)

B) C)

D)

E) F)

You may or may not have enough background knowledge to answer the question, but give us your best explanation in one or two sentences:

(Open-ended response collected)

-page break-

Answer: Option A is correct. Water will shoot straight out.

According to Newton's First Law of Motion, objects continue their motion (i.e., straight, in the same direction with the same speed) unless an external force acts on it. In accordance with that law, as can be seen in this video, water shoots out in a straight line once it's not confined within the coil.

(The following video was embedded in Qualtrics survey page: https://vimeo.com/428907981)

\section{3-2) Superforecaster exercise}

Q2: Superforecasters. In a series of prediction competitions held between 2011 and 2014, talented individuals were invited to participate in a competition to predict future events such as, "How many refugees will flee Syria next year?" and "How fast will China's economy grow next quarter?" The competing forecasters were asked to give an estimate of how likely ( $0 \%$ to $100 \%)$ a certain outcome would occur. In each competition, between 2,200 to 3,900 individuals participated. The study varied conditions such as whether forecasters would work collaboratively or individually. 
By the end of the first competition, the top 60 most accurate forecasters were selected as "super forecasters". However, some of these 60 forecasters could have performed well simply by luck. These super forecasters were therefore asked to return and compete with other forecasters. They maintained their superior performance in subsequent competitions, and continued to be more accurate than standard forecasters by a large margin.

Super forecasters are experts who are especially good at making accurate predictions. What makes super forecasters so super? Select any number of features below that you think are exceptional about these super forecasters:

A) Commitment to and depth of knowledge in one and only one area of expertise

B) Open-minded thinking and willingness to update one's beliefs in response to new evidence

C) Natural ability to reason intelligently about novel problems (high fluid intelligence)

D) Treating beliefs as sacred possessions to be defended, rather than as testable hypotheses

You may or may not have enough background knowledge to answer the question, but give us your best explanation in one or two sentences:

(Open-ended response collected)

Answer: Options B and C

page break-

Super forecasters are super not just due to raw talent, but also due to behavioral choice. Various factors were examined to predict forecast accuracy, some of which were participants' natural abilities (e.g. the fluid intelligence component of IQ) others were participants' deliberate choices (e.g. choosing to revise beliefs based on new information).

While fluid intelligence was the strongest natural-ability predictor of forecast accuracy, frequency of belief updating was the strongest deliberate-choice predictor of it.

Below is a graph of the prediction performances of the superforecasters (blue bars), high-performing individuals (red bars), and all others (green bars). The vertical axis indicates performance for all participants. Zero indicates the average score.

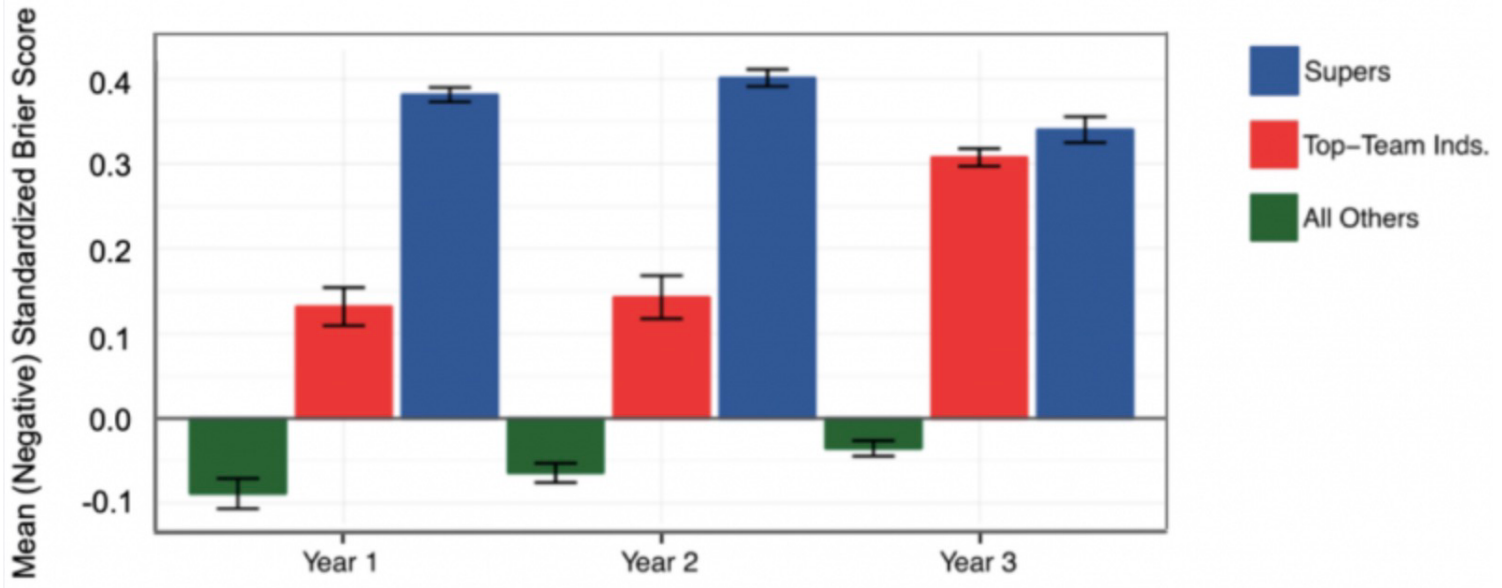

\section{Source:}


- Mellers, B., et al. (2015). Identifying and Cultivating Superforecasters as a Method of Improving Probabilistic Predictions, Perspectives on Psychological Science, 10(3) 267-281. https://doi.org/10.1177/1745691615577794.

\section{3-3) Life expectancy exercise}

-page break

Q3: Life expectancy. In 2018, the average life expectancy in the U.S. is roughly 79 years old. What would be your best estimate of the average life expectancy back in the year 1900 (in industrialized countries)?

Life expectancy for males (in years): (Open-ended answer collected)

Life expectancy for females (in years): (Open-ended answer collected)

You may or may not have enough background knowledge to answer the question, but give us your best explanation in one or two sentences:

(Open-ended response collected)

Answer: 46 years for males and 48 years for females.

With medical advancement, people began dying less from infectious diseases. Back in 1900, the top two causes of death were pneumonia/influenza and tuberculosis. Nowadays, most forms of these diseases are treatable with antibiotics. As a result, people began living longer: We now live more than $\mathbf{3 0}$ years longer on average than in 1900.

Source:

- Leading causes of death from 1900 to 1998

https://www.cdc.gov/nchs/data/dvs/lead1900_98.pdf

-page break

\section{3-4) Preventable diseases exercise}

Q4: Preventable diseases. In high-income countries, the rate of death from preventable diseases in children under five years is 1 in 200. In Sub-Saharan Africa, the rate of death from these same preventable diseases in children under five is 1 in _ ?

1 in (how many children?): (Open-ended response collected)

You may or may not have enough background knowledge to answer the question, but give us your best explanation in one or two sentences:

(Open-ended response collected)

Answer: 1 in 13

-page break

The leading cause of death for children under five worldwide is pneumonia. Other top causes of death for children this age are malaria, measles, diarrhea, cholera, and leukemia. All of these causes of death are nearly always preventable or curable -- due to modern medical science. 
As would be expected, these deaths occur vastly disproportionately in under-developed countries than in high-income countries. This contrast is due to the difference in the availability of modern medical care. Worldwide, in 2018 , there are $\mathbf{1 5 , 0 0 0}$ deaths of children under five per day in under-developed countries from preventable diseases.

Source:

- About 6.2 million children and adolescents under 15 died, mostly from preventable causes, in 2018: https://www.who.int/news-room/fact-sheets/detail/children-reducing-mortality

- Pneumonia currently kills about 1.4 million children under 5 worldwide:

https://www.who.int/maternal_child_adolescent/news_events/news/2011/pneumonia/en/

page break

3-5) Global temperature prediction ("Graph prediction" was shown as the name of the exercise to the participants). The terms "climate change" and "global warming" were never used in our materials.

Q5: Graph prediction. The blue line on the left side of the graph below shows the actual changing amount of some quantity, call it $\mathrm{x}$, from the year 1880 to 1965. The horizontal axis indicates the years spanning 1880 to 1965 and beyond to 2020 . The vertical axis indicates units of quantity $x$.

Without first knowing what $x$ is, how would you extrapolate this graph beyond the year 1965? The four colored lines on the right side are your response options. What do you think would be the most plausible projection based on the past measurements of $x$ as indicated by the blue line?

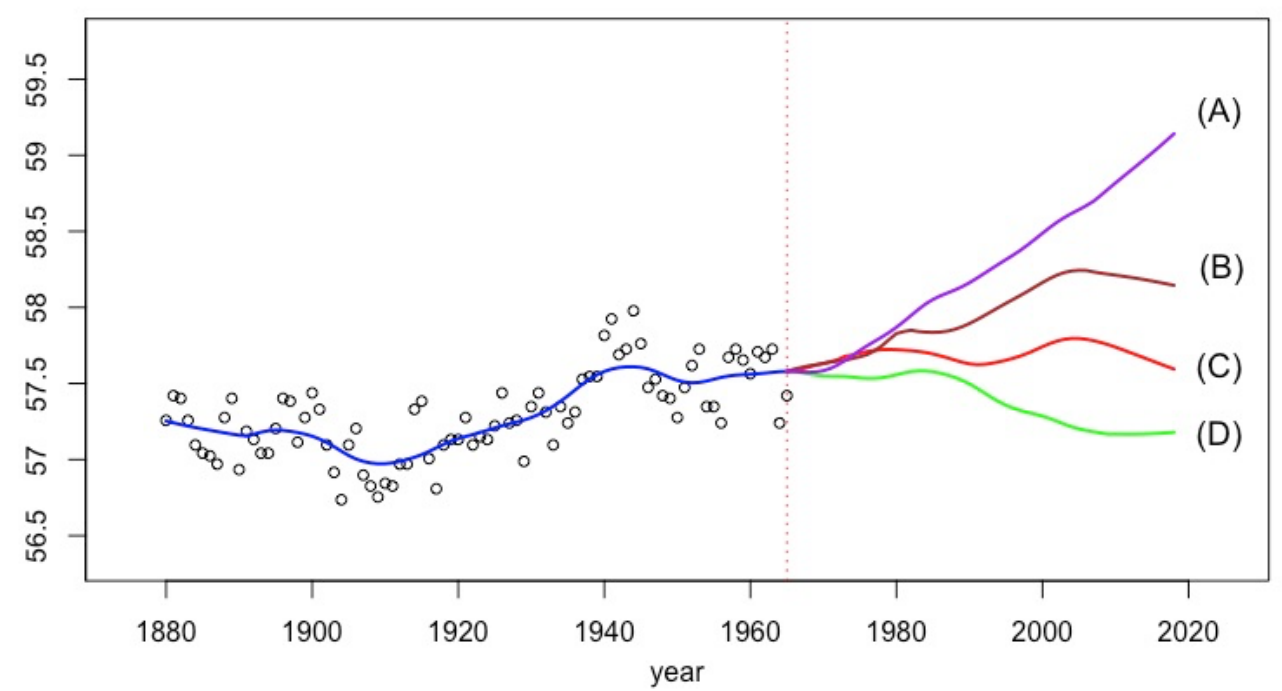

Choose the most plausible projection up to 2020 based on past measurements of $x$ from 1880 to 1965 .
A)
B)
C)
D)

You may or may not have enough background knowledge to answer the question, but give us your best explanation in one or two sentences:

(Open-ended response collected) 


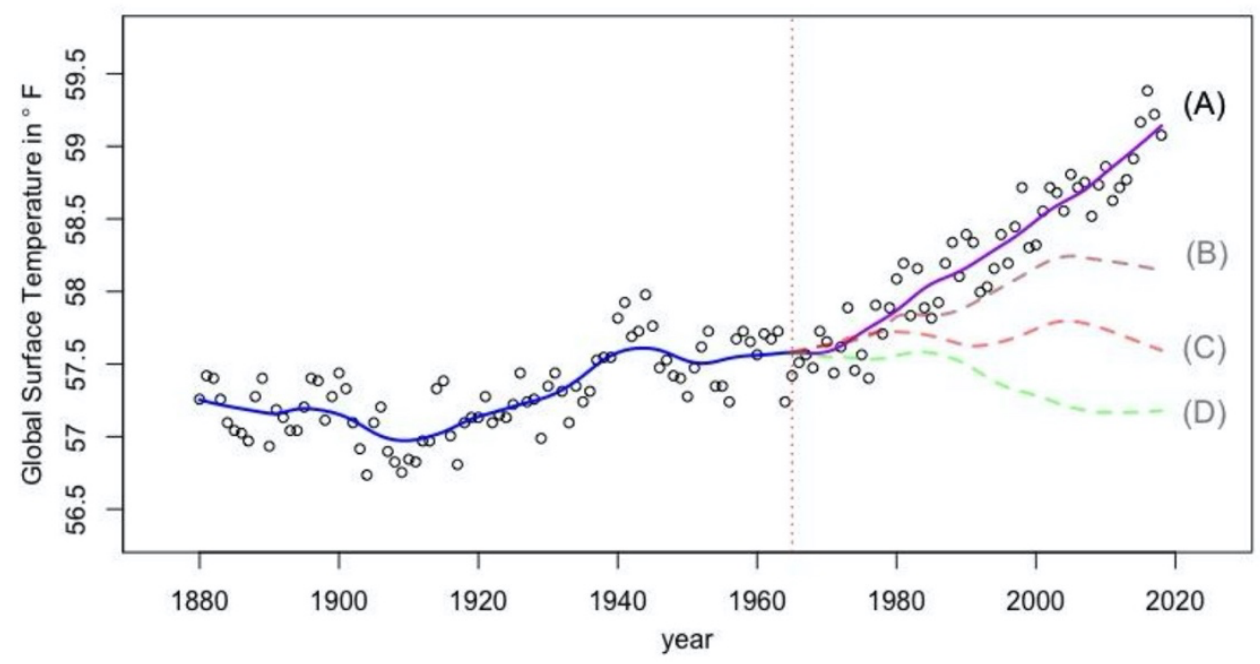

Answer: Option A

It may be reasonable to think that (without any change in circumstances) quantity $x$ should remain similar before and after 1965, as indicated by response options B or C. However, quantity $\mathrm{x}$ has actually risen sharply between 1965 and 2018 (option A), as shown in the graph above. Quantity $\mathbf{x}$ is actual global temperature in ${ }^{\circ} \mathrm{F}$ (Fahrenheit).

The unusually rapid rise since 1965 suggests that some external cause led global temperature to deviate from past trends.

What do you think caused the rapid rise in global temperature since 1965? (Open-ended response collected)

-page break-

Answer: Data suggest that increase in the amounts of greenhouse gases emitted by human activities is the cause of the rapid rise in global temperature during the last half century.

The graphs below show that changes in global temperature (graph a) vary along with changes in human-caused gas emissions (graph e on the bottom left) rather than with other natural causes such as solar (graph b) or volcanic activities (graph c). 
(a) Global Surface Temperature

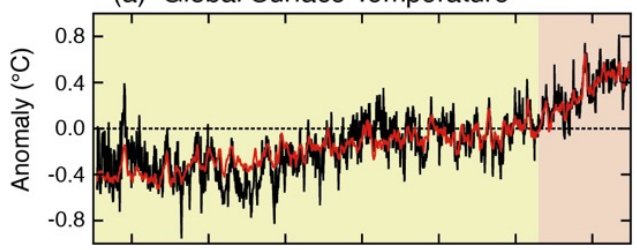

(c) Volcanic Component

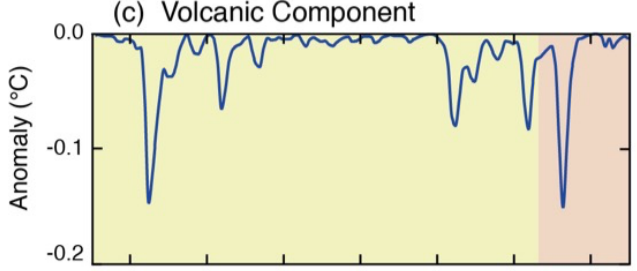

(e) Anthropogenic Component

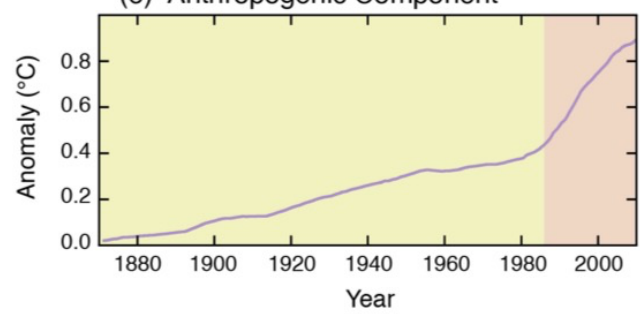

(b) Solar Component

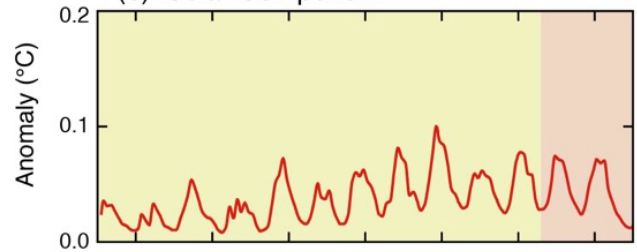

(d) Internal Variability

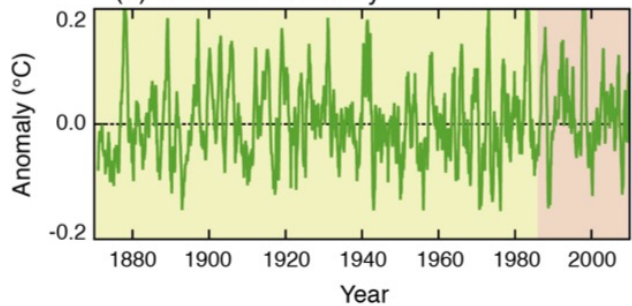

Two important greenhouse gases are carbon dioxide (generated by burning fossil fuels) and methane (emitted by cattle). In recent decades, the greater amounts of these gases has led to an evermore rapid rise in accumulated greenhouse gases, and in turn, a rise in global temperature.

Long before our current experience of extreme weather patterns and global temperature rise, climate scientists have predicted these outcomes. For example, in 1981, atmospheric physicist James Hansen, son of a tenant farmer in lowa, predicted that the 21st century would see more extreme droughts and floods as climate zones shift, the erosion of ice sheets resulting in worldwide rise in sea level, and the opening of the fabled Northwest Passage. All these impacts predicted decades ago last century have since eerily become facts.

Hansen et al. (1981) Climate impact of increasing atmospheric carbon dioxide. Science, 213, 957-966. (52)

James Hansen's TED talk gives an explanation of the causes and consequences of increased atmospheric carbon dioxide.

The following graphs show simulation results of global temperature from 1900 to 2000 . The red region depicts the range of simulated temperatures when both human and natural influences on temperature are taken into account. In contrast, the blue region depicts the range of simulation results when only natural forces are considered. As can be seen, actual observed temperatures--the black lines--align better with the red regions and deviate from the blue. 


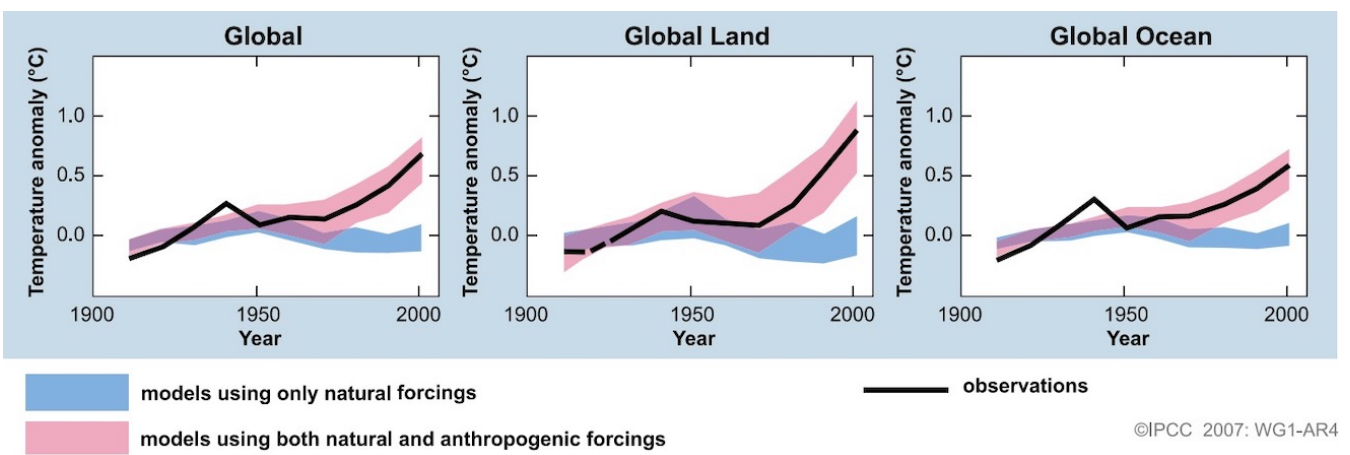

A recent survey of scientists found that out of 100 climate scientists, 1 disagrees, 2 are undecided, and 97 agree that the global warming we are witnessing is a direct consequence of the burning of fossil fuels by humans.

\section{7 out of 100 climate scientists agree humans are causing global warming}

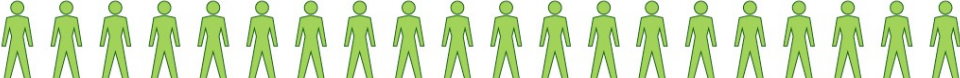

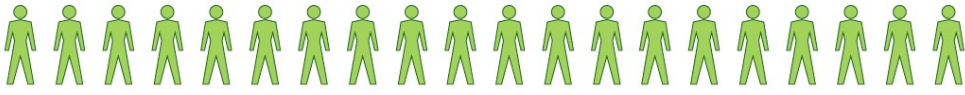

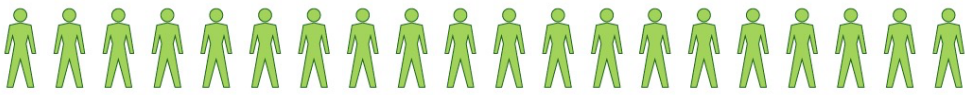

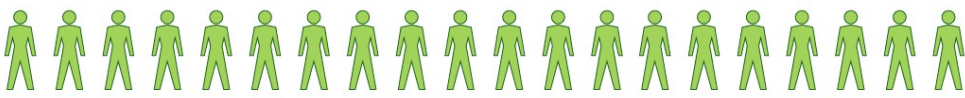

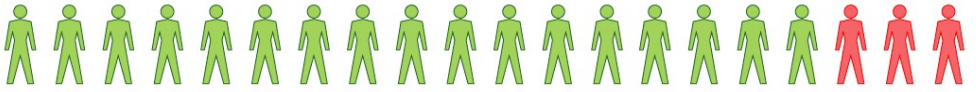

Unlike temperature from day-to-day or week-to-week, global temperature over decades and centuries is far less variable, and therefore more predictable. The difference between day-to-day temperature and decade-to-decade temperature is analogous to the difference between mood and personality.

\section{Sources:}

- Global surface temperature from 1880 to 2020:

https://climate.nasa.gov/vital-signs/global-temperature/

- James Hansen's TED talk on the causes and consequences of increased carbon dioxide: https://www.ted.com/talks/james_hansen_why_i_must_speak_out_about_climate_change?language=en

- James Hansen's research in 1981 predicted the impact of human-caused climate change https://pubs.giss.nasa.gov/abs/ha04600x.html

- Accuracy of the climate models that predicted global warming https://www.carbonbrief.org/analysis-how-well-have-climate-models-projected-global-warming

- Greenhouse gases absorb and contain heat from the sun and Earth https://en.wikipedia.org/wiki/Greenhouse_gas 
- Intergovernmental Panel on Climate Change - 4th Assessment Report https://www.ipcc.ch/report/ar4/wg1/

- Intergovernmental Panel on Climate Change - 5th Assessment Report

https://archive.ipcc.ch/report/ar5/syr/

- Cook, J., \& Lewandowsky, S. (2016). Rational irrationality: Modeling climate change belief polarization using Bayesian networks. Topics in cognitive science, 8(1), 160-179. (53)

- Do scientists agree on climate change?

https://climate.nasa.gov/faq/17/do-scientists-agree-on-climate-change/

\section{3-6) Tides exercise}

-page break

Q6: Tides. Gravitational force from the moon causes tides in coastal areas. How many high tides and low tides do you think a coastal area experiences a day?

(Tides are regular rises and falls of sea levels. See video for an example.)

(A Youtube video of Hall's Harbor, Bay of Fundy, showing the contrast of high tides and low tides, was embedded in the page: https://www.youtube.com/watch?v=l8r7lglbbSI)

Number of high tides a day: (Open-ended response collected)

Number of low tides a day: (Open-ended response collected)

You may or may not have enough background knowledge to answer the question, but give us your best explanation in one or two sentences:

(Open-ended response collected)

Answer: 2 high tides and 2 low tides a day. Whether you be a fisherman or a surfer, the time for each of the 4 tides on a day is what you will find on any tide table. 


\section{The schematic picture below shows the Earth and the moon.}

Imagine you are looking down at the rotating Earth from above the North

Pole, so that as Earth rotates around its axis once each day, it is daytime for

the side facing the Sun, and nighttime for the side away from the Sun.

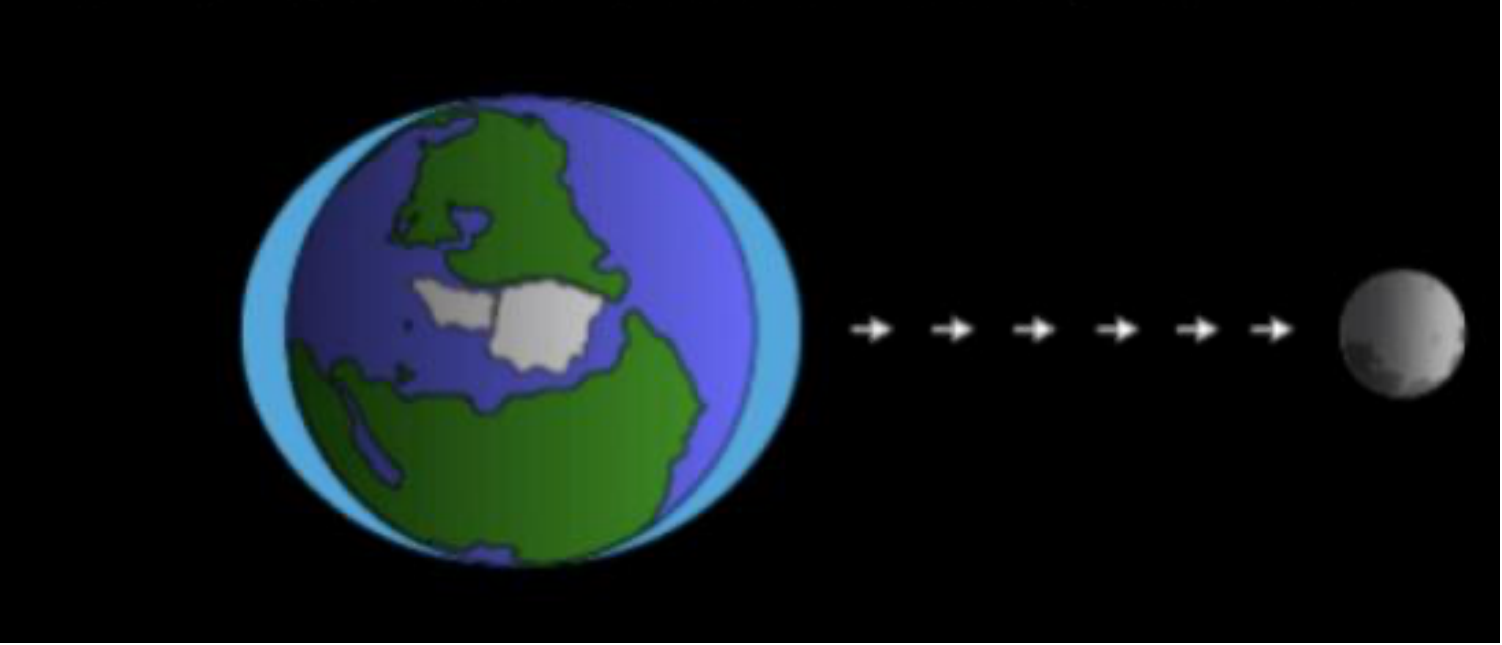

Newton's universal law of gravitation explains why. As Earth rotates a full circle once a day (counterclockwise in the diagram), the moon's gravity pulls on different parts of our planet. By Newton's law, for any two bodies, the closer they are to each other, the stronger the gravitational pull between them. Accordingly, the part of the ocean nearest to the moon is pulled the most, resulting in a bulge (see diagram).

By the same law, the part of the ocean farthest away from the moon is pulled the least, resulting in another bulge (think about it as being left behind the most). The solid Earth in the middle - which is not stationary but floating in space - is subjected to an average pull.

So, as your part of the coast on Earth rotates into these two bulges of water, once each day, you experience a high tide. And as your part rotates into each area in between the two bulges, because water is drained away from you (toward the bulges), you experience a low tide.

By the way, what if the same natural force that causes the tides were to stop? What path do you think our moon would take? (Recall how water shoots straight out once its path isn't forced to curve inside the garden hose.) Earth's massive pull on the moon is what keeps it from flying off, causes it to curve its path, keeping it in orbit, close to Earth as we see crossing our night sky every night.

Source:

- Explanation with animation:

https://scijinks.gov/tides/

\section{3-7) GPS exercise}

-page break-

Q7: GPS. Global positioning system (GPS) is very useful and commonplace when driving nowadays. However, few people know that for GPS to work well, it has to make a critical correction, which is based on our best current scientific theory of time and space. 
Imagine that we did not make this theory-based correction for one day. We would expect an accumulation of prediction error during that time. Suppose this uncorrected GPS directs you to turn at a certain intersection to reach your destination. By how many city blocks would you be off from the actual intersection?

A city block is typically 0.06 miles long.

\# of typical city blocks off: (Open-ended response collected)

You may or may not have enough background knowledge to answer the question, but give us your best explanation in one or two sentences:

(Open-ended response collected)

Answer: 100 typical city blocks (6.2 miles)

GPS locates a place on Earth by using satellite signals that arrive at a GPS receiver at that place. The signals are transmitted at regular intervals by multiple satellites about their positions at the current time. A wrinkle in the process is that -- according to Einstein's theory of general relativity -- time runs slower for objects nearer to something as massive as Earth. Therefore, atomic clocks installed in satellites run faster than those on Earth, and aligning the clocks on satellites with those on Earth is crucial for accurate GPS predictions.

After a day without correction by Einstein's theory, atomic clocks in satellites will be about 38 microseconds ( 0.000038 seconds) faster than the clocks on Earth. This subtle difference is enough to greatly mislead, resulting in a recommended turn 6.2 miles too early or too late. The system would become useless.

The fact that your GPS can announce that it's time to turn as you approach your desired intersection speaks to the profound orderliness of natural forces. The high and low tides twice each day tells the same story.

Source:

- How does a GPS work and what corrections does it make? http://www.pdana.com/PHDWWW files/gpsrole.pdf

- Using theory of general relativity to make corrections in GPS:

http://www.astronomy.ohio-state.edu/ pogge/Ast162/Unit5/gps.html

\section{3-8) Water pouring exercise}

page break-

Q8: Water pouring. The photo below has two glasses with different widths and heights. The distances between the top of the glass and surface of the water are identical for two glasses. If someone gradually tilts both glasses at the same rate, from which glass would water start to pour out first? 


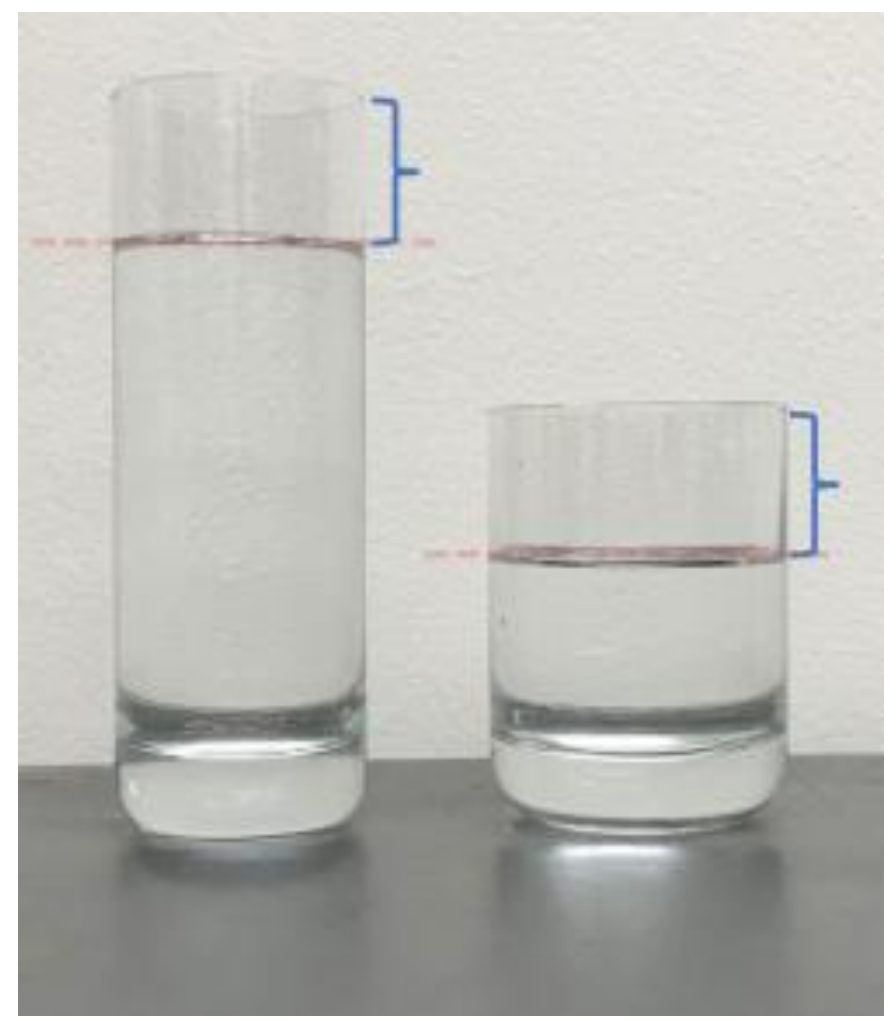
A) Narrower glass first
B) Wider glass first
C) Both at the same time
D) It is impossible to predict

You may or may not have enough background knowledge to answer the question, but give us your best explanation in one or two sentences:

(Open-ended response collected)

Answer: B) Wider glass first.

-page break-

Below we show a way to find the answer using logic and geometry. If the correct answer is not immediately clear, you may want to read the explanation below.

For each glass, let's draw a straight line through the center of the surface of water as shown in the diagram (see the dotted lines). These lines indicate the surface of water at the moment when water starts pouring out of the glasses (imagine tilting the diagram so that these lines are horizontal). The blue and vellow triangles are the respective amounts of water that move from tilting the glasses. 


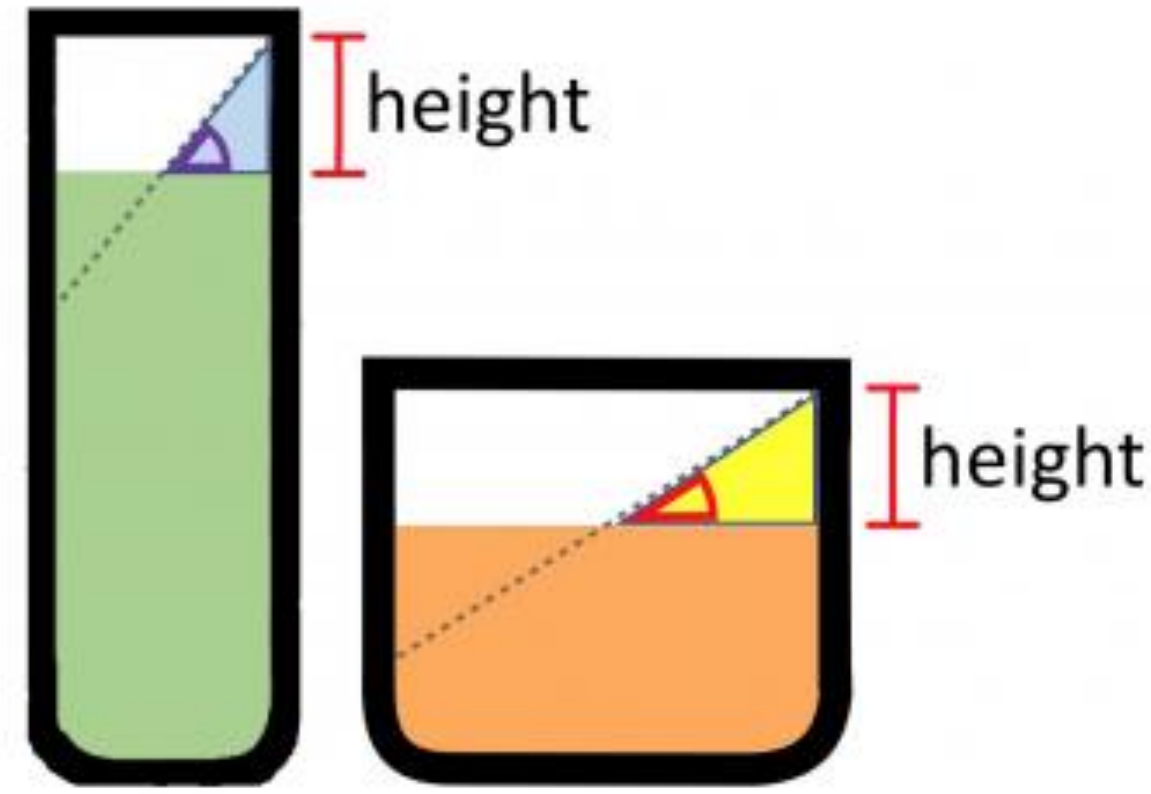

From the diagram, you may be able to see the solution already. Let's compare the blue and vellow triangles. The question stated that they have the same height. However, the vellow triangle (in the wider glass) has a longer base than the blue triangle. Therefore, the red angle in the wider glass (the angle between the base and hypotenuse of the vellow triangle) is smaller than the purple angle in the narrower glass. This angle is how much the glass needs to be tilted for water to pour out. Therefore, water will pour out of the wider glass first.

(The following video was embedded in Qualtrics survey page: https://vimeo.com/428908071)

In this video, you can see that water pours out of the wider glass first.

\section{4) Comprehension questions (correct answers are underlined)}

Please answer the following comprehension questions about the content you saw earlier. Select the best option.

What evidence supports the claim that the drastic change in climate was due to more than just natural forces?

A) Scientists conducted controlled experiments

B) Many simulations showed that if it were just natural forces, the climate would have changed much less drastically

C) Leaders in most countries came to the same conclusion as the climate scientists

D) Both the second and third option

Which of the following is most critical for GPS to operate with high accuracy?

A) Advancement in technology to allow for cell phone reception of satellite signals

B) The proper placement of satellites up in space

C) Newton's theory of universal gravitation which explains gravitational pull

D) Correcting for the difference in atomic clocks up in space and on Earth 
What enables us to live so much longer now than did our ancestors just 100 years ago?

A) We eat healthier foods and have more exercise/physical activity

B) Less environmental pollution now has led to better respiratory health

C) Advancements in medicine has increased survival rates for acute diseases that were deadly to our ancestors

D) All of the above

5) Survey on general attitudes toward science

(Most of the questions we used asked about the social implications of science or measured the adoption of scientific attitudes, taken from Fraser (1981). One question asking about the scientists' role on public-policy debates was created by the authors. The underlined questions below were the ones that asked about attitudes toward science. Attitudes toward nature were also asked to disguise our intention but were not analyzed.)

Please answer how much you agree with each of these statements in terms of the way you generally feel. There are no right or wrong answers. Using the following scale, indicate your thoughts as honestly and candidly as you can.

(5-point Likert scale used to collect responses, 1: Strongly disagree, 5: Strongly agree)

(Set 1 - presented to half of the participants for counterbalancing)

- $\quad$ When I think of my life, I imagine myself to be part of a larger cyclical process of living.

- $\quad$ I find it boring to hear about new ideas.

- $\quad$ Scientific discoveries are doing more harm than good.

- I recognize and appreciate the intelligence of other living organisms.

- $\quad$ l like to listen to people whose opinions are different from mine.

- $\quad$ Like a tree can be part of a forest, I feel embedded within the broader natural world.

- $\quad$ Scientists should take an active role in public policy debates about scientific issues, rather than simply focus on establishing sound scientific facts.

- $\quad$ Money spent on science is well worth spending.

(Set 2 - presented to half of the participants for counterbalancing)

- I often feel a kinship with animals and plants.

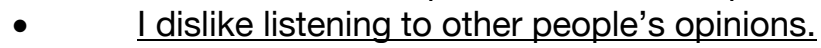

- $\quad$ Scientists should take an active role in public policy debates about scientific issues, rather than simply focus on establishing sound scientific facts.

- I think of the natural world as a community to which I belong.

- $\quad$ Money used on scientific projects is wasted.

- $\quad$ Science helps to make life better.

- $\quad$ I often feel part of the web of life.

- $\quad$ I am curious about the world in which we live.

6) Willingness to take pro-environment actions

\section{6) Willingness to take pro-environment actions}

(Political climate actions are highlighted in red, personal climate actions are in blue, and personal pro-environment actions not necessarily related to climate are in green. These colors were not shown to the participants)

Information collected in this survey will be used for research purposes only, without identifying individuals. All information will be kept private and confidential.

As individuals, we each can take impactful actions to protect and support the flourishing of our planet. To that end, what actions are you willing to take? 
Please select all such actions.

- $\quad$ Avoid single-use plastic items (e.g. plastic straws, grocery bags, foam to-go boxes, plastic shampoo bottles) when affordable.

- Use public transportation.

- $\quad$ Eat less beef and dairy in order to reduce methane emissions (cattle emit methane, a greenhouse gas).

- $\quad$ Use appropriate layers of warm or cool clothing as your personalized heater/air conditioner.

- $\quad$ Buy only what I need: avoid buying excess groceries and buy fewer clothes, because the production and delivery of goods typically require fossil fuel.

- $\quad$ Buy clothes from thrift stores / donate or sell clothes for re-use.

- $\quad$ Buy products from companies that are environmentally responsible (when affordable).

- $\quad$ Shop online only if an item is not available in your local store(s).

- $\quad$ Reduce carbon dioxide emission by planting trees, cacti, or other vegetation appropriate for my local climate.

- $\quad$ Turn appliances off / unplug appliances when not in use.

- $\quad$ Vote for legislations that promote policies that help create a more sustainable planet.

- $\quad$ Support the use of renewable energy (e.g., wind, water and solar power) through personal action (i.e. installing solar panels, using a hybrid/electric car).

- $\quad$ Participate in a climate-action demonstration.

- If there are any other important actions you would take, please list them below: (Open-ended response collected)

\title{
7) Purpose of the study
}

-page break

What do you think is the purpose of this study?

(Open-ended response collected)

At what point did you notice the purpose of this study?

(Open-ended response collected)

\section{8) Measurement of increase in science awareness and appreciation after interventions}

Earlier in this survey, you went through prediction exercises involving:

\author{
Trajectory of water \\ Superforecasters \\ Life expectancy \\ Preventable diseases \\ Graph prediction \\ Tides \\ GPS and \\ Water pouring
}

Please indicate how much you agree or disagree with the following statements about these exercises:

(5-point Likert scale used to collect responses, 1: Strongly disagree, 5: Strongly agree)

- $\quad$ These exercises made me more aware of the significance of science in our everyday lives.

- $\quad$ These exercises made me more aware of how science can explain everyday events.

- $\quad$ These exercises impacted my view on how science enables us to make useful predictions.

- $\quad$ These exercises helped me learn interesting facts about science. 
- $\quad$ These exercises provided interesting information that I would like to share with friends and family.

9) Knowledge of scientific facts (correct answers are underlined), taken from Funk, Hefferon, Kennedy, and Johnson (2019). Aiming for a sensitive measure, we selected our test items (see below) to cover a wide range of difficulty. We did so based on the percentage of correct answers for individual items reported in Funk et al.

Please answer the following questions. If you don't know the answer, select "Not sure".

What is the main cause of seasons on the Earth?

A) The speed that the Earth rotates around the Sun

B) The tilt of the Earth's axis in relation to the Sun

C) The distance between the Earth and the Sun

D) Changes in the amount of energy coming from the Sun

E) Not sure

When large areas of forest are removed so land can be converted for other uses, such as farming, which of the following occurs?

A) Increased erosion

B) Colder temperature

C) Decreased carbon dioxide

D) Greater oxygen production

E) Not sure

An antacid relieves an overly acidic stomach because the main components of antacids are...
A) Neutral
B) Acids
C) Bases
D) Isotopes
E) Not sure

\section{0) Demographic questions}

-page break-

- What is your age?

- What is your gender?

Answer options: male, female, other

- What is the highest level of education you have completed? If currently enrolled, choose the highest level you have previously completed.

Answer options: Less than high school degree, High school degree or equivalent, Bachelor's degree, Master's degree, Doctoral degree (PhD, JD, MD, etc.)

- What is your political orientation?

Answer options: Extremely Conservative, Moderately Conservative, Moderately Liberal, Extremely Liberal, Libertarian, Independent

- $\quad$ Do you have any personal relations to the fossil fuel industry? For example, do you have family members who are employees of a fossil fuel company? If so, please list below: (open-ended response recorded) 


\section{1) General comments}

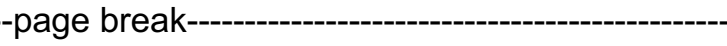

We would like to hear your honest opinion on the activities you have completed. If you have any comments, thoughts, or complaints about the survey as a whole, please feel free to write them here. (open-ended response recorded) 